University of South Florida

DIGITAL COMMONS

@ UNIVERSITY OF SOUTH FLORIDA
Digital Commons @ University of

South Florida

$11-1-2010$

\title{
Incorporating TDM into the Land Development Process
}

CUTR

Follow this and additional works at: https://digitalcommons.usf.edu/cutr_nctr

\section{Recommended Citation}

"Incorporating TDM into the Land Development Process," National Center for Transit Research (NCTR) Report No. CUTR-NCTR-RR-2004-06, Center for Urban Transportation Research, University of South Florida, 2010.

DOI: https://doi.org/10.5038/CUTR-NCTR-RR-2004-06

Available at: https://scholarcommons.usf.edu/cutr_nctr/182

This Technical Report is brought to you for free and open access by the National Center for Transit Research (NCTR) Archive (2000-2020) at Digital Commons @ University of South Florida. It has been accepted for inclusion in Research Reports by an authorized administrator of Digital Commons @ University of South Florida. For more information, please contact digitalcommons@usf.edu. 


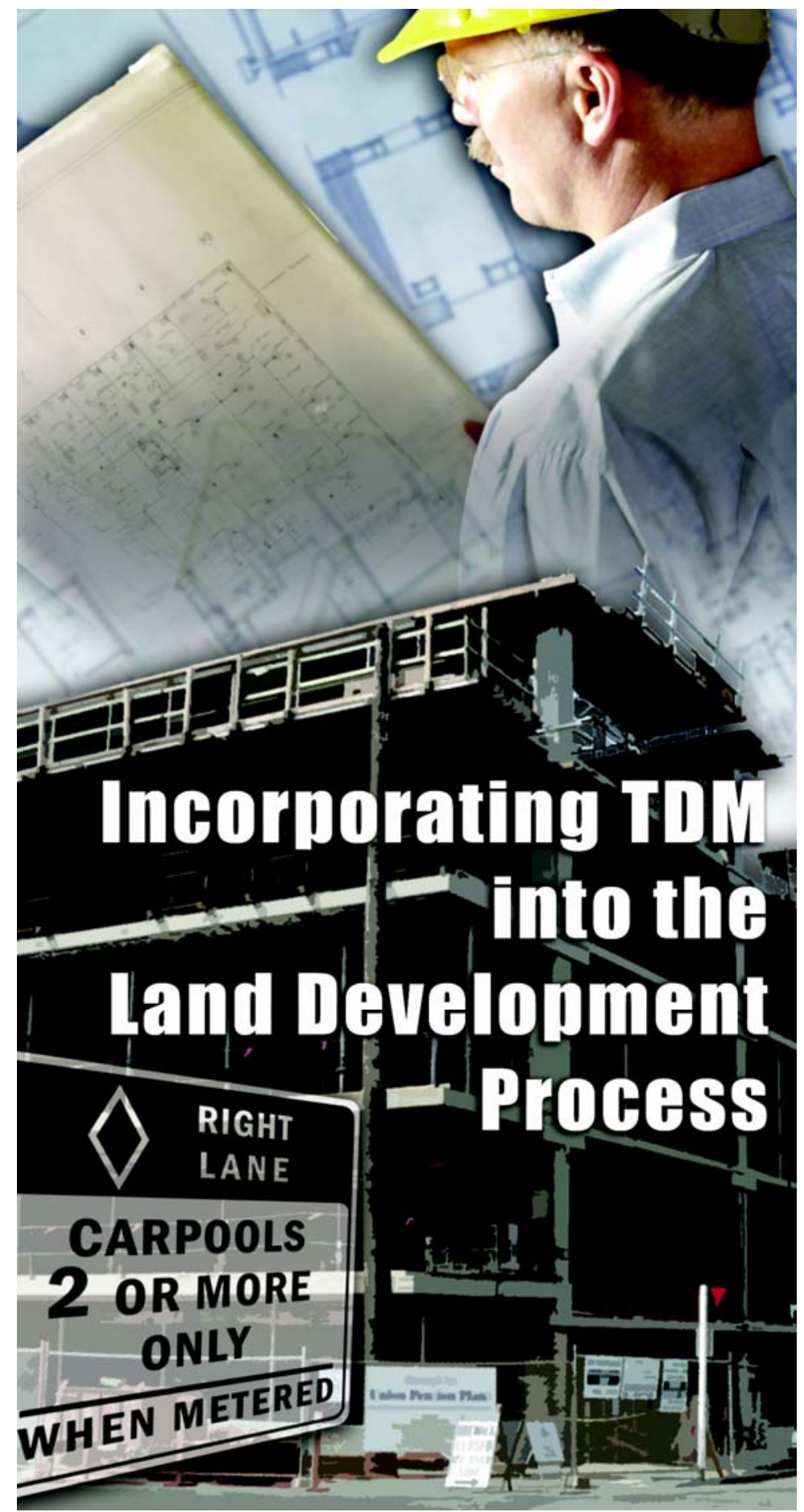

Final Report

FDOT Contract Number: BD-549-12 



\title{
Incorporating TDM Into the Land Development Process
}

\author{
Final Report \\ Prepared By \\ Karen E. Seggerman, AICP \\ Sara J. Hendricks, AICP \\ $\|_{\text {CUTR }}$

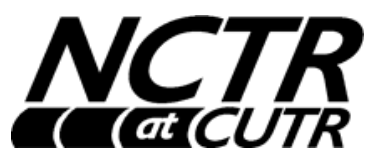 \\ USF \\ National Center for Transit Research \\ Center for Urban Transportation Research \\ University of South Florida \\ 4202 E. Fowler Avenue, CUT100 \\ Tampa, FL 33620-5375 \\ (813) 974-3120 \\ http://www.nctr.usf.edu

\section{Edward Mierzejewski, CUTR Director} \\ Joel Volinski, NCTR Director \\ Dennis Hinebaugh, Transit Program Director \\ Philip Winters, TDM Program Director, National TDM and Telework Clearinghouse
}
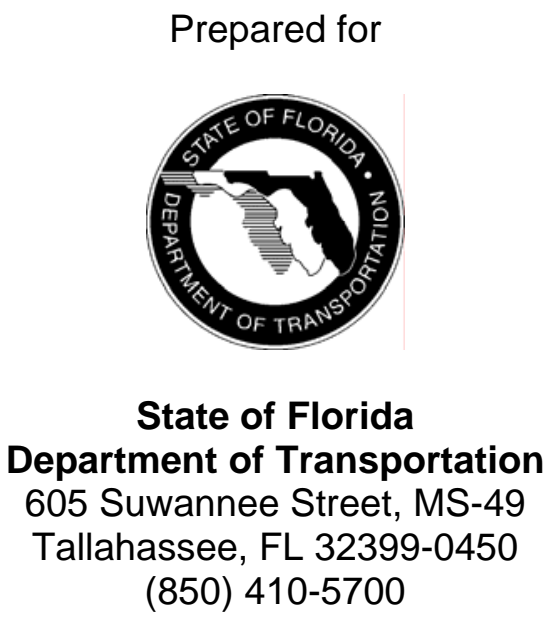

Project Manager:

Michael Wright

The opinions, findings, and conclusions expressed in this publication are those of the authors and not necessarily those of the U.S. Department of Transportation or the State of Florida Department of Transportation. 


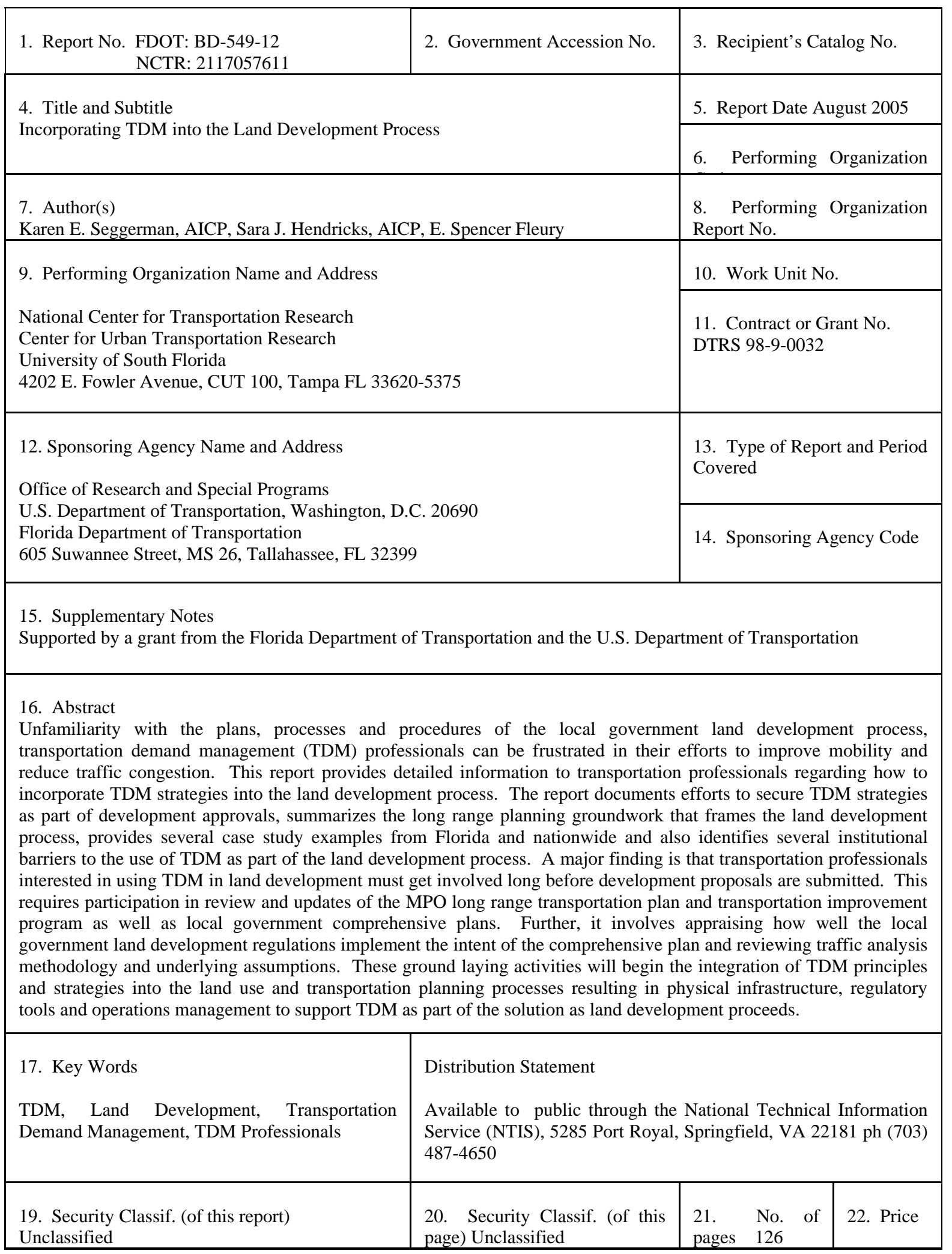

Form DOT F 1700.7 (8-69) 


\section{ACKNOWLEDGMENTS}

This report is prepared by the National Center for Transit Research at the Center for Urban Transportation Research, College of Engineering, University of South Florida, through the sponsorship of the Florida Department of Transportation and the U.S. Department of Transportation.

FDOT Project Manager

Michael Wright, Transit Office, Florida Department of Transportation

\section{CUTR Project Team}

\section{Principal Authors}

Karen E. Seggerman, AICP, Senior Research Associate, Planning \& Corridor Management

Sara J. Hendricks, AICP, Senior Research Associate, Transportation Demand Management

\section{Research Assistant}

E. Spencer Fleury, Graduate Research Assistant, Transportation Demand Management

\section{Contributors and Reviewers}

Philip L. Winters, Transportation Demand Management Program Director, CUTR/NCTR

Holly Alderman, Program Publications Coordinator, Planning \& Corridor Management

Sue LoBianco, Program Assistant, Transportation Demand Management Program 


\section{TABLE OF CONTENTS}

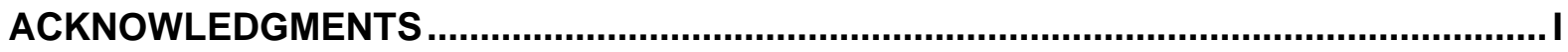

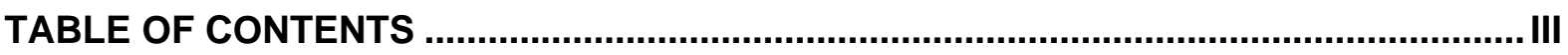

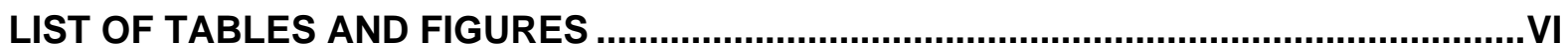

EXECUTIVE SUMMARY ........................................................................................ VII

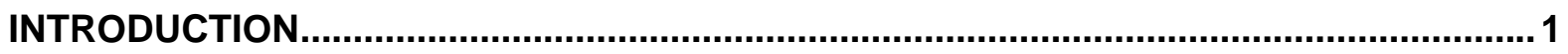

Methodology ............................................................................................................. 2

LEGAL FOUNDATION ............................................................................................... 5

Federal Law - Metropolitan Planning Organizations (MPOs) .................................. 5

Florida Law.............................................................................................................. 5

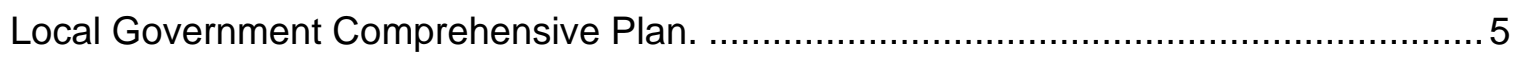

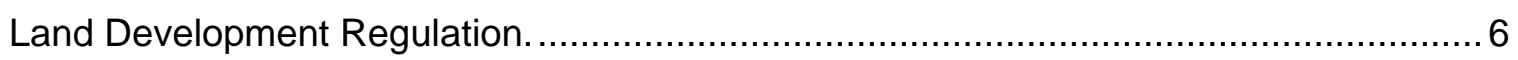

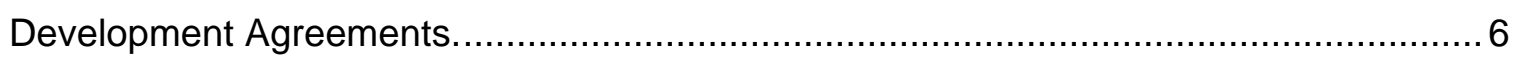

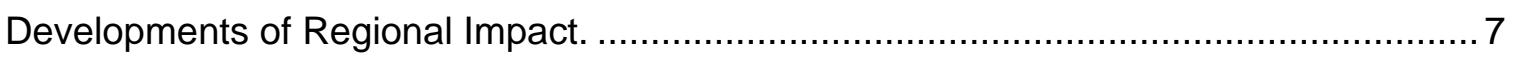

RELATING TDM TO THE LAND DEVELOPMENT PROCESS .......................................11

CHALLENGES AND OPPORTUNITIES FOR THE INCLUSION OF TDM IN THE LAND DEVELOPMENT PROCESS .................................................................................. 17

\section{CURRENT PRACTICE OF INCORPORATING TDM INTO THE LAND DEVELOPMENT} PROCESS................................................................................................................... 25

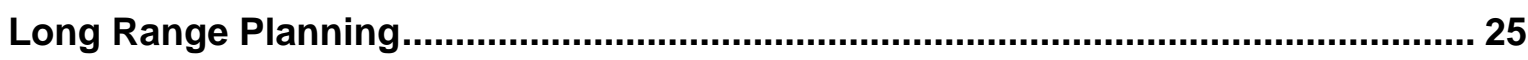

MPO Long Range Transportation Plan (LRTP) ................................................... 25

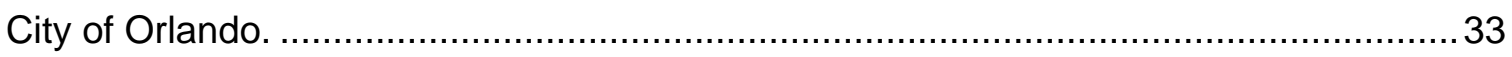

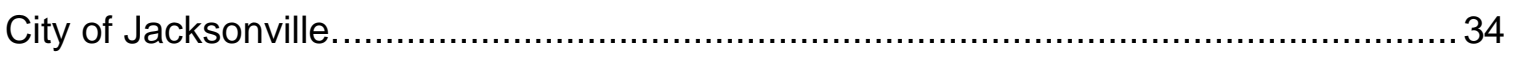

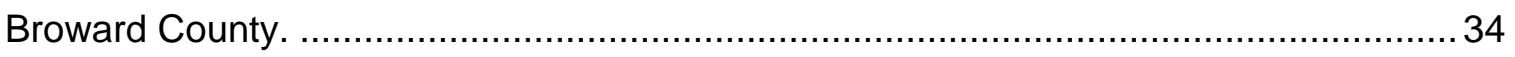

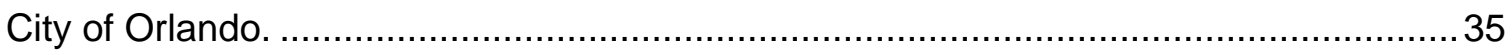

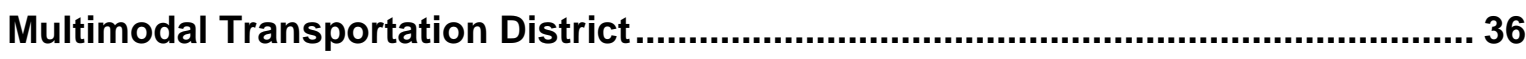

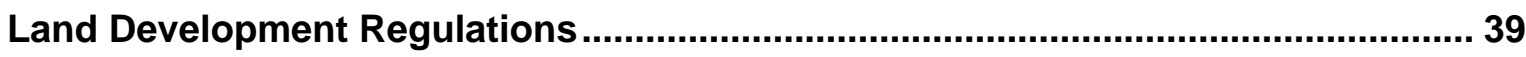

Land Developer Engagement Through TMA Participation ...................................... 47

Individual Site Plan Evaluation .......................................................................... 48

Where Municipal Plans, Policies, and Regulations Coincide with an Individual Development Proposal........................................................................................... 48

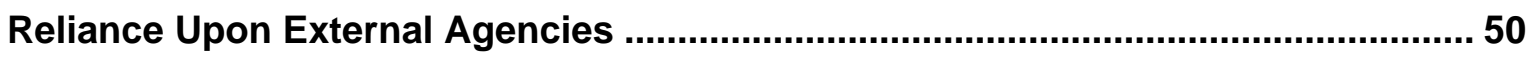

Rezoning: Where a Land Development Proposal Usually Begins ............................ 50

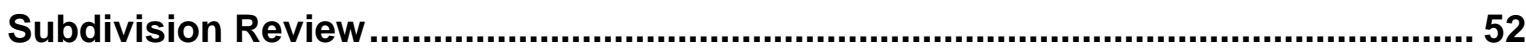

Site Plan Approval Process ................................................................................ 54 


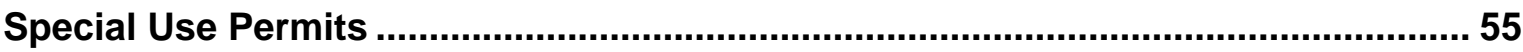

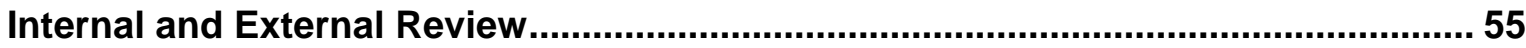

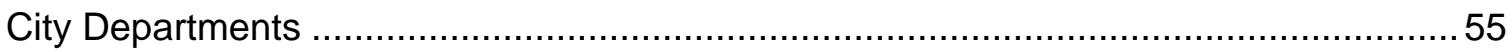

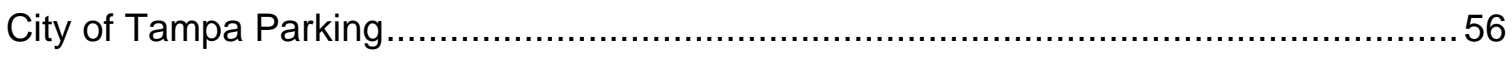

Building Plan Approval Process ....................................................................... 57

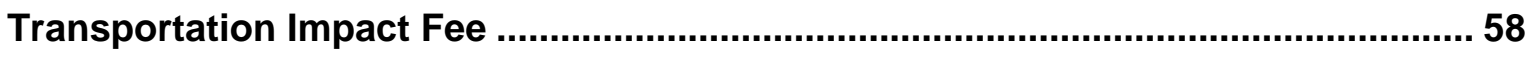

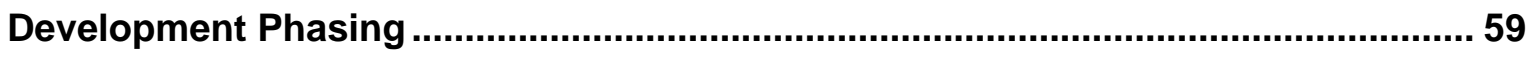

RECOMMENDATIONS FOR INCORPORATING TDM INTO THE LAND DEVELOPMENT

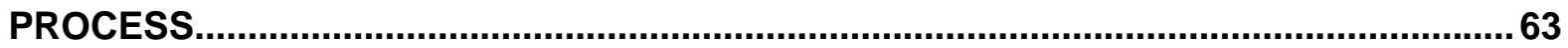

1. Immediate Actions for Specific Proposals......................................................... 63

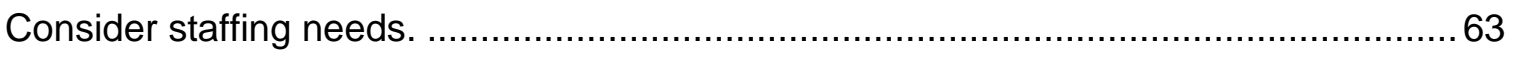

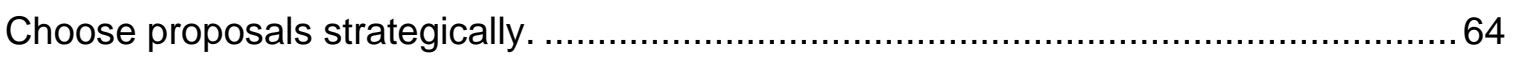

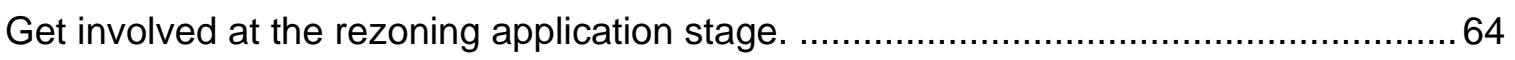

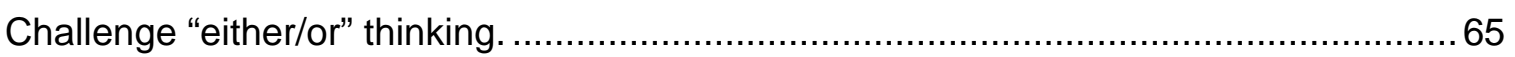

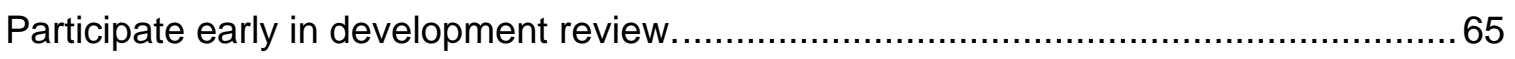

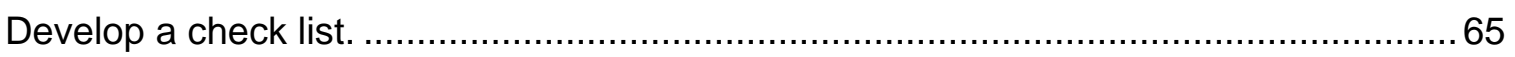

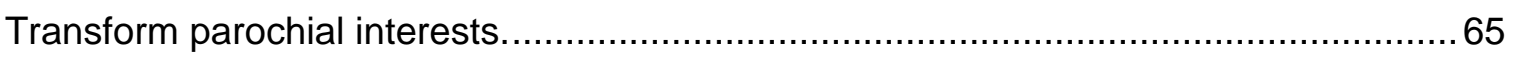

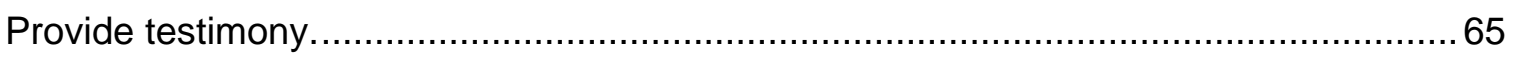

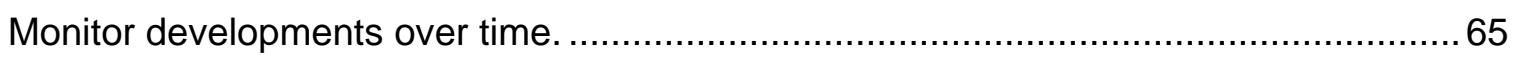

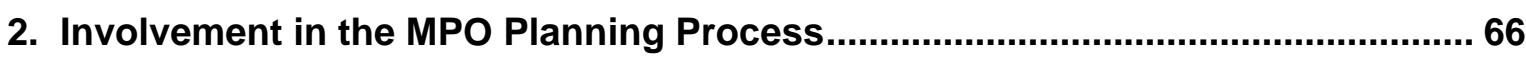

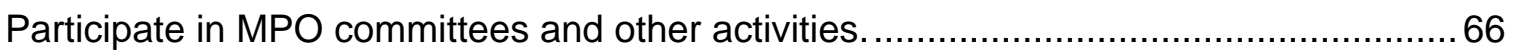

Influence MPO product content and advocate for funding of transit and TDM-related

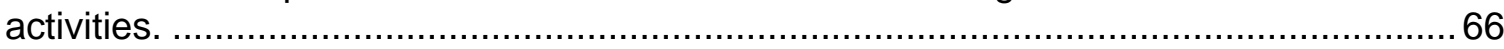

Improve relations by involving MPO Board, staff, and committee members in transit or

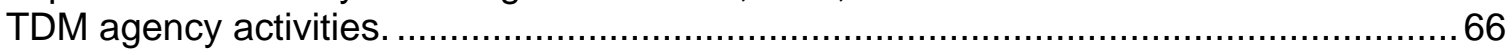

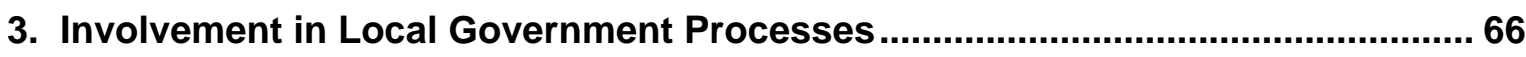

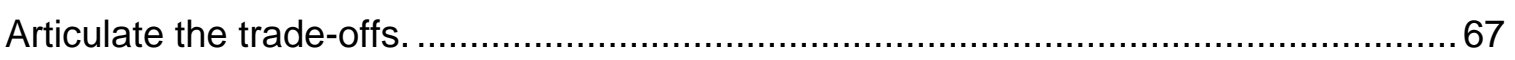

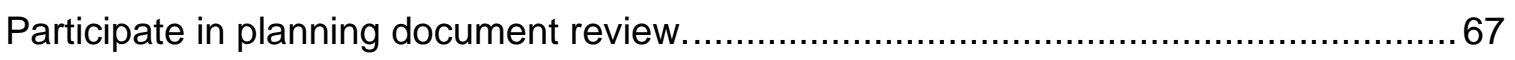

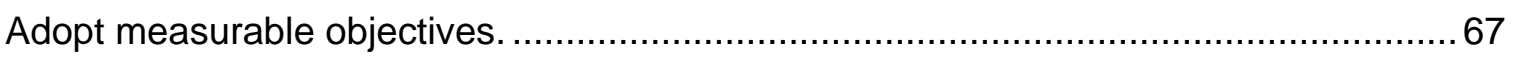

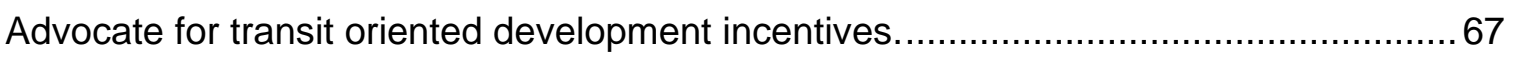

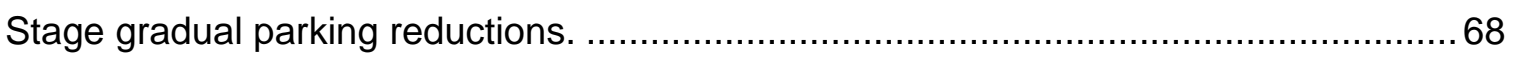

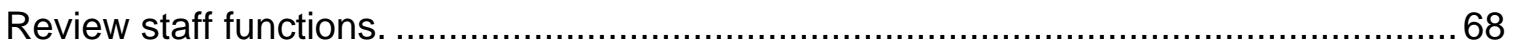

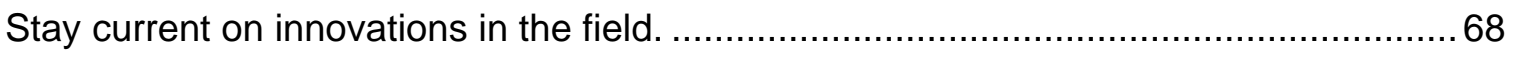

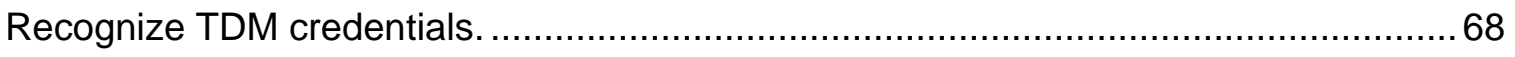


4. Involvement in State Government Processes .................................................. 68

Update the Development of Regional Impact (DRI) analysis process. ......................... 68

Consider the impact of emergency evacuation on statewide transportation planning. ...68

Funding allocations are influenced by the source of revenues.

5. Seek refinement of methodology for determining transportation impact of land

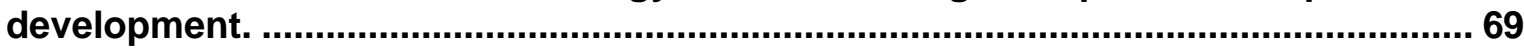

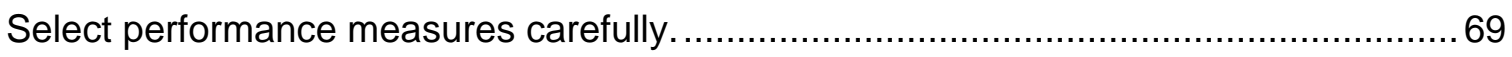

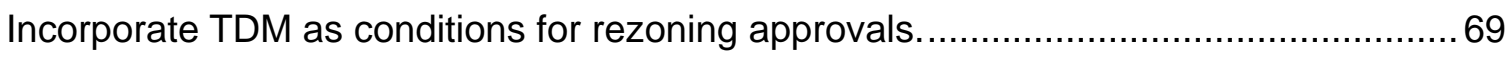

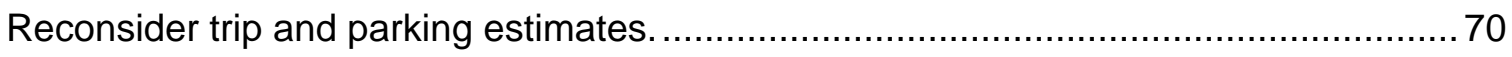

Encourage the development of LOS evaluation that enables trade-offs among modes. 70

6. Develop professional relationships.................................................................. 70

Identify key people in the local development process........................................... 70

Involvement at the neighborhood level sets the stage for TDM implementation.............70

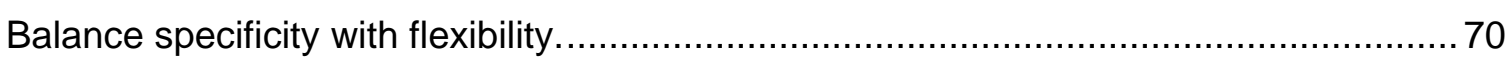

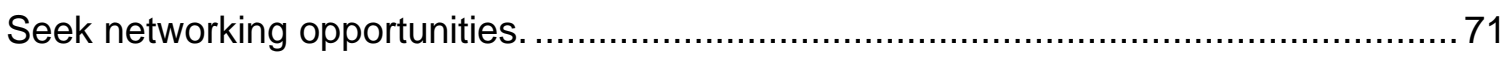

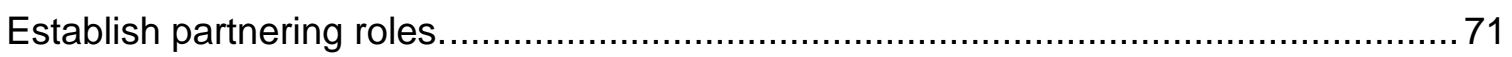

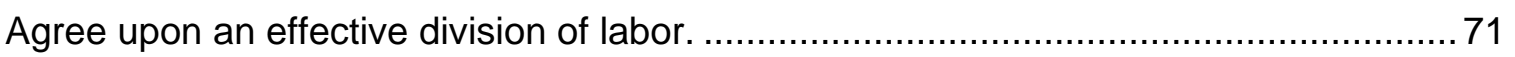

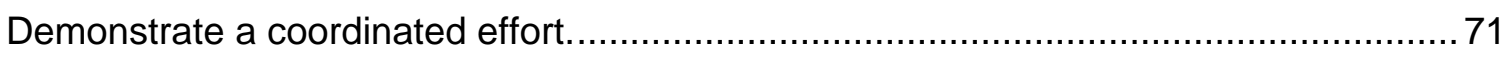

Be mindful of how one TDM strategy can impact others advocated by partners. ...........71

Reach out to economic development interests. .................................................. 72

Educate the media about the use of TDM as mobility management............................72

Publicly praise land development that supports community transportation goals..........72

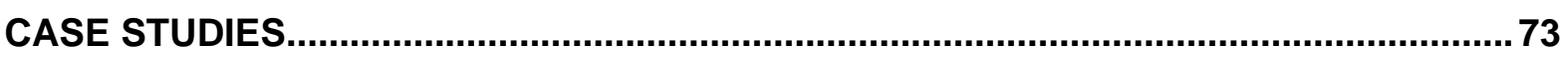

Commute Trip Reduction Program ..................................................................... 73

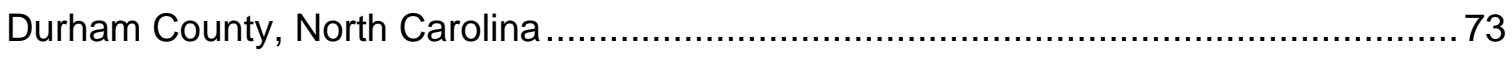

Parking and Transportation Demand Ordinance.................................................. 76

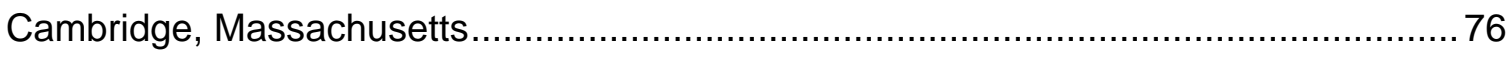

Background............................................................................................................... 76

Parking and Transportation Demand Management Ordinance (PTDM) ................... 77

Negotiations between the City and the Developer .............................................. 78

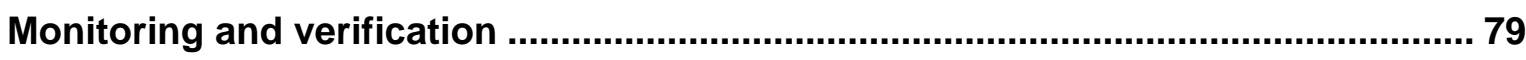

Transportation Management Association role ....................................................... 79

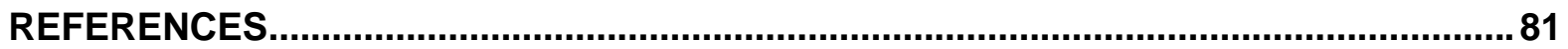

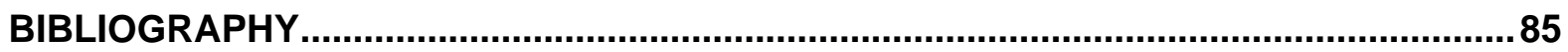

APPENDIX A: SARASOTA COUNTY DEVELOPMENT AGREEMENT ........................... 93 
APPENDIX B: DEVELOPMENTS OF REGIONAL IMPACT AND THE FDOT SITE IMPACT ANALYSIS METHODOLOGY 105

APPENDIX C: PINELLAS COUNTY LRTP TDM POLICIES .........................................113

APPENDIX D: CITY OF SARASOTA TDM POLICIES ................................................ 115

APPENDIX E: TRAFFIC IMPACT FEE REDUCTION INCENTIVES, CLARK COUNTY, WASHINGTON

\section{LIST OF TABLES AND FIGURES}

Table 1: Range of TDM Strategies Potentially Addressed in the Land Development

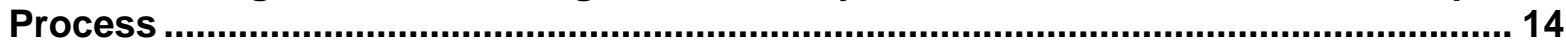

Table 2: Transportation Demand Management Projects......................................... 32

Table 3: Maximum Trip Reduction Credits ................................................................ 42

Table 4: Proposed Traffic Impact Fee (TIF) Credits for Mixed Use Zone ...................... 43

Table 5: Minimum Number of Required Off-Street Parking Spaces Per Land Use Category* 57

Figure 1: TDM is a Key Strategy for Achieving Transportation Goals .......................... 1

Figure 2: TDM Tactics Apply to a Range of Land Development Types ........................ 3

Figure 3: TDM Tactics Can Apply to All Stages of the Land Development Process ... 11

Figure 4. City of Tampa's Development Review Process for Planned Developments 53 


\section{EXECUTIVE SUMMARY}

\section{Problem statement}

Transportation planning and system development in Florida, including the use of transportation demand management strategies, begins with both federal and state law. These laws, combined with escalating right-of-way and construction costs and shrinking revenue sources, have influenced transportation decision makers to place more attention on maximizing the use of the existing transportation system through the approach of transportation demand management (TDM). However, numerous barriers and obstacles exist for the incorporation of TDM into the land development process. Consistent prioritization of funding for private automobile and truck transportation service over the years reinforces existing travel behavior and public expectations at the local level. Historically, urban transportation planning carried out by both state and municipal governments nationwide has accommodated the demand for travel and safeguarded this accommodation from land development. TDM is concerned with managing (reducing in many cases) the demand for travel by seeking to create conditions that meet travelers' needs and at the same time alter their behavior to reduce adverse impacts and to generate greater efficiencies. The land development process is where these two philosophies to transportation system development and management (managing vs. accommodating) come into conflict and can potentially be resolved.

\section{Study purpose and objectives}

While TDM usually has been applied as an effort to convince employees to use alternative transportation, there are diverse settings and contexts for using TDM, both on-site and off-site, and providing for physical facilities as well as management and operations. In addition to alternative mode use, TDM strategies influence travel behavior by time of day or day of the week, trip frequency, trip length, regulation, route and cost. For example, single-occupant vehicle commuters can still participate in TDM by relocating to a work site branch office closer to home (proximate commuting), telecommuting one or more days of the week or staggering work hours.

One of the challenges in the use of impact fees, impact fee offsets, concurrency assessments and trip reduction ordinances is determining a reasonable and effective dollar amount required that covers the costs of needed facilities and can be demonstrated to represent the impact from the development. In the case of a concurrency management system, if trip credits are awarded in exchange for the conduct of a TDM program, the challenge is to refine a method for calibrating the credit amounts of developments of different sizes so that it encourages an effective TDM program and provides a worthwhile financial savings to the developers.

The goal and objectives of this study were based on the premise that a systemwide integrated approach to achieving transportation goals should be used and that transportation demand management is a critical component in conjunction with land use planning, transportation system construction and transportation systems management for the development of a cost-effective and functional intermodal and multimodal transportation system. The report provides information for municipal planners, traffic engineers, land development proposal reviewers and TDM professionals working for commuter assistance programs, transportation management associations and in other capacities. This study was sponsored by the Florida Department of Transportation and funded through the National Center for Transit Research.

The geographic focus of this study was the state of Florida; however, the findings and recommendations will have application to municipalities nationwide. The purpose of this study was to determine ways that TDM could be more effectively incorporated into the land development 
process, so that the necessary foundation for later TDM program implementation is laid. This goal was achieved through the study objectives of:

$\checkmark$ Reviewing the federal and state legal framework;

$\checkmark$ Exploring the many means of influencing travel behavior, with examples of TDM strategies, how these may fit into the land development process and what parties may be potential implementing partners;

$\checkmark$ Identifying challenges preventing the inclusion of TDM in the land development process;

$\checkmark$ Summarizing current practice at the local level;

$\checkmark$ Providing case study examples both nationwide and from Florida; and

$\checkmark$ Providing recommendations for incorporating TDM into the land development process.

Report appendices include excerpts from development agreements, analysis of site impact methodology, example of long range transportation plan TDM policies, and traffic impact fee reduction incentives.

\section{Findings and Conclusions}

A total of 38 recommendations are provided in this report, which fall under six general categories, including:

- Immediate actions for specific proposals

- Involvement in the MPO planning process

- Involvement in State government processes

- Seeking refinement in methodologies

- Developing professional relationships

A few of the findings and recommendations are highlighted below.

The mission of the Florida Department of Transportation is to advance transportation for statewide purposes, which is in some ways fundamentally different from the transportation interests of local urban areas. The state roadway system primarily serves through movements for regional mobility purposes while municipal roadways of varying functional classifications attempt to juggle access provision while meeting level of service standards. The presence of state roads, built to specifications for moving through traffic, affects the pattern of local land development in that there is an attraction to build near available capacity. Resulting dispersed land development is difficult to serve with transportation alternatives.

Vital to the administration of the land development process is maintaining the confidence of land developers that each one is treated fairly and in the same manner as all other developers. This places a responsibility on any such method to determine the magnitude and quality of future impacts of development, to attribute the impacts accurately to the responsible party, and to identify mitigating measures that will both directly address those impacts as well as serve the development of the contributing party. The rational decision making process and range of answers generated for the development of the transportation system is linked to the kinds of data collected, the degree of detail and scope of the collected data and the analysis techniques used. The analysis techniques used incorporate assumptions about desired outcomes as well as drive particular analysis outcomes.

One finding from the literature review that has strong relevance to the application of TDM in the land development process is the analysis conducted by Donald Shoup of UCLA regarding the use of 
Institute of Transportation Engineers (ITE) trip generation and parking rates. Shoup found that local governments tend to overly rely upon the accuracy of these rates despite cautions provided by ITE for their appropriate application. In Florida, local governments primarily use ITE rates for determining concurrency, the extent and type of needed transportation improvements as part of land development and in the application of transportation impact fees. However, the ITE trip rates primarily represent land development patterns that provide no other choice besides private automobile driving and therefore demonstrate little use of alternative transportation. The lack of use of transportation alternatives is misinterpreted as a lack of need for transportation alternatives. Reinforcing this outcome is also the misapplication of ITE parking generation rates that are likewise generated from locations that offer no transit service and which result in overestimates of needed parking. Use of ITE traffic and parking generation rates should be supplemented with traffic counts when possible. Additional analysis should be conducted with the intent to estimate the nature and magnitude of transportation demand under conditions where transit service reaches a level of quality described in long range planning documents and after a program of parking management, where transit oriented development phasing has reached completion, and where there is a high quality pedestrian environment and TDM programs in place.

TDM professionals should get involved in the land development process as early as the rezoning application stage. TDM professionals should request a copy of the application. A first question for TDM professionals to consider, in an evaluation of a project, is whether a rezoning request preserves the intent of the Comprehensive Plan, especially with respect to urban infill, revitalization, and urban redevelopment within a TCEA. TDM professionals should check to see if its location lies within a TCEA or some other district requiring special considerations. TDM professionals have an opportunity to use the TCEAs or other special district designation as a means to promote TDM strategies for consideration as congestion mitigation and mobility enhancement.

As a committee member and regular participant in metropolitan planning organization (MPO) activities, the TDM professional has the opportunity to influence MPO guiding policies which directly impact the content of the Long Range Transportation Plan as well as the Transportation Improvement Program (TIP) and subsequent project funding. The commuter assistance program (CAP) executive director should not only educate the MPO Board and committee members regarding the benefits of TDM strategies, but also offer specific ways for including them in the various MPO products. This report has included a number of useful policies for use in long range transportation plans. The CAP representative also should assist in developing alternative revenue sources and seek earmarks for TDM strategies.

The focus of TDM program budgeting often has been based upon short term time frames. For example, CAPs may be evaluated based upon annual work plans supported by annual budgets; therefore, some of the most important work with far reaching and lasting impact (TDM strategies corresponding to land development) takes a back seat if performance results must be demonstrated within the year. The CAP representative should work with MPO staff to consider more realistic time frames not only for implementation of TDM strategies but also for tracking and measuring program results. Match these with work programs and budgets that coordinate with those time frames.

Of all features in the site plan and building plan, the availability and amount of parking is the cornerstone of shifting a balance toward the use of other modes, as well as other means to reduce the need to travel. Limiting the availability of parking has a strong impact on the use of the transportation system but efforts can backfire if satisfactory alternative transportation is not concurrently in place. TDM professionals should advocate for a more complete multimodal system. As the level and quality of multimodal transportation service increases, parking limitations can gradually be established. TDM professionals should stimulate discussion through arranging forums 
among bankers, developers and local governments about the marketability of development with reduced parking. TDM professionals should suggest a plan for staging the gradual reduction of parking availability in coordination with redevelopment, which includes triggers or thresholds that precipitate the institution of parking reductions.

In the future, renewed consideration and research should be focused upon refining the Development of Regional Impact (DRI) traffic impact methodology and the 9J-2.045 F.A.C. Transportation Uniform Standard Rules to recognize that transportation demand calls for a wider offering of mobility services and authorize their use. Such methodology and authorized mobility measures would recognize that the demand for transportation alternatives will not be obvious or easily measurable while the basic system providing for alternative mobility service is not fully in place.

TDM professionals should encourage planners and engineers to weigh the limitations of using various TDM performance measures against the particular goals to be achieved. Examples include reducing single occupant vehicles (SOV), average vehicle occupancy (AVO), and average vehicle ridership (AVR), understanding that their use will limit the actions taken. Reducing SOV limits TDM strategies to mode shifting and does not recognize that SOV drivers can also participate in TDM. AVO does not incorporate the effects of bicycling, walking or telecommuting. AVR is a measure associated with work sites, limiting TDM application to commute travel. AVR also does not incorporate the effects of bicycling, walking and telecommuting. These are all useful measures but they should be applied only with the understanding of what they do not consider and should perhaps be used with other measures such as a vehicle employee ratio (VER), also known as vehicle trips reduced (VTR), which is the number of vehicles per 100 employees. Other measures might include reducing vehicle trips (VT) or reducing vehicle miles traveled (VMT).

Available transportation planning methods fall short of enabling an evaluation of a trade-off among modes. Research should continue to focus on this missing piece, starting with the Strategic Intermodal System geodatabase. TDM professionals should become more active in the discussion about the application of multimodal LOS standards as part of the transportation approval process. Ideally, TDM professionals should generate support for the future development and application of a method to make tradeoffs across modes. Preserving roadway level of service standards for private motor vehicles as specified in the local Comprehensive Plan appears to drive the process thereafter. In the long range transportation planning process, TDM professionals should suggest exploring the use of alternative standards for combined people-moving capacity across modes along corridors carrying heavy directional traffic

\section{Benefits}

These study results provide practical insight and specific recommendations, not only to TDM professionals, but also to municipal traffic engineers and planners and land development proposal reviewers. The recommendations include immediate actions and longer range activities in several arenas. They also identify a broader range of stakeholders. Implementation of these recommendations will accelerate a transition toward a more integrated transportation system that provides better, more cost-effective service and mobility choices. 


\section{INTRODUCTION}

While the use of transportation demand management (TDM) offers the possibility of relief from today's congested roadways, a key to the successful use of these strategies is incorporating them into the land development process. Local governments are responsible for the regulation of land development activities, from developing generalized long range plans that guide future growth to negotiating development orders that will shape travel characteristics at the site-specific level. While federal and state governments encourage alternative transportation, local governments still face a number of barriers to strengthening transportation options through the land development process. The challenge is to incorporate TDM into all stages of the land development process thus making it integral to the process rather than an afterthought. This study examines how TDM is incorporated into long range transportation plans, local government comprehensive plans, land development regulations, and site development. It also discusses the various challenges of incorporating transportation demand management into the land development process and identifies opportunities for TDM professionals to champion TDM strategies throughout the process.

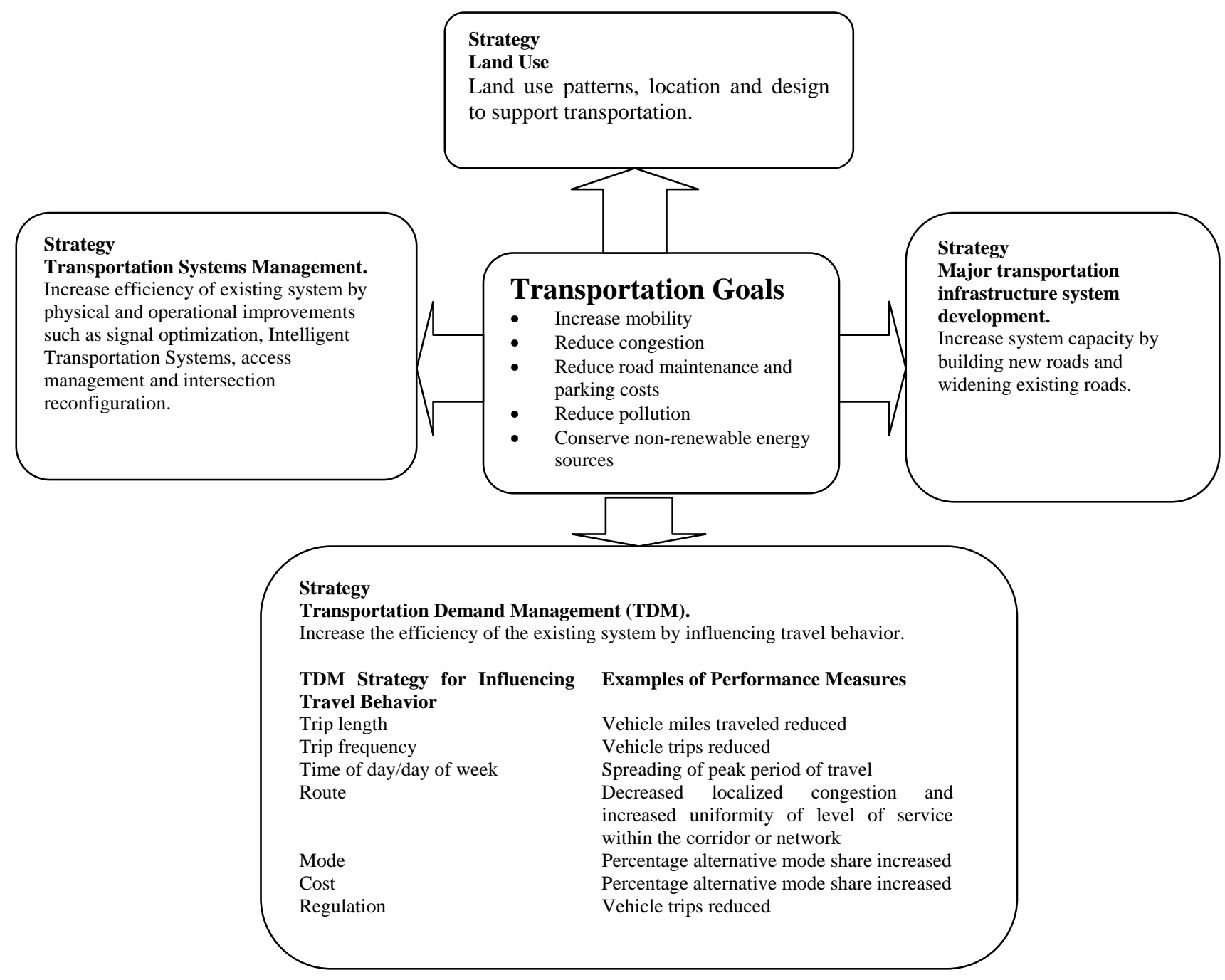

Figure 1: TDM is a Key Strategy for Achieving Transportation Goals 
A common past approach to achieve transportation goals was to emphasize one particular strategy alone, such as either expanding the physical capacity of the system or applying TDM strategies, with the expectation that each should function as stand alone strategies. As illustrated in Figure 1 above, this report is based on the premise that a systemwide integrated approach to achieving transportation goals should be used. This is achieved by expanding the physical capacity of the transportation system combined with land use controls, TDM and transportation systems management. What this means for TDM is to incorporate TDM strategies into the land development process from the very beginning long range transportation and land use planning stages, through land use regulatory regimes, and continuing through site development negotiations and property management stages.

TDM encourages better management of existing transportation infrastructure, services and resources. Examples of TDM tactics include public transit services, ridesharing, compressed work week, telecommuting, limiting parking, and provision of bike and locker facilities by employers. Interest regarding methods of including TDM strategies in land development processes is growing among planning professionals. The purpose of this report is to identify where the integration of TDM strategies occurs within various stages of the land development process and how TDM professionals can influence this process. The report provides information for municipal planners, traffic engineers, land development proposal reviewers and TDM professionals working for commuter assistance programs, transportation management associations and in other capacities.

According to the Victoria Transport Policy Institute (VTPI), "Transportation Demand Management or TDM (also called Mobility Management) refers to various strategies that change travel behavior (how, when, and where people travel) in order to increase transport system efficiency and achieve specific objectives such as reduced traffic congestion, road and parking cost savings, increased safety, improved mobility for non-drivers, energy conservation and pollution emission reductions.” There are many different TDM strategies with a variety of impacts. Some improve the transportation options available to consumers, while others provide an incentive to change travel mode, time or destination. Some reduce the need for physical travel through mobility substitutes or more efficient land use (1).

Transportation Demand Man-
agement or TDM refers to
various strategies that
change travel behavior in
order to increase transport
system efficiency and
achieve specific objectives,
such as reduced traffic
congestion, road and parking
cost savings, increased
safety, improved mobility for
non-drivers, energy con-
servation and pollution
emission reductions.

While TDM usually has been applied as an effort to convince employees to use alternative transportation, it is much more than that. As illustrated in Figure 2 below, there are diverse settings and contexts for using TDM, both on-site and off-site, and providing for physical facilities as well as management and operations. In addition to employees, TDM can be applied to residents, visitors, patients and many other groups defined by specific travel patterns and needs. In addition to alternative mode use, TDM strategies influence travel behavior by time of day or day of the week, trip frequency, trip length, regulation, route and cost. For example, single-occupant vehicle commuters can still participate in TDM by relocating to a work site branch office closer to home (proximate commuting), telecommuting one or more days of the week or staggering work hours.

\section{Methodology}

The project involved the following research approach:

- Review the literature and current policies in Florida and other states, if applicable, as they relate to MPO long range transportation plans, local comprehensive plans, and various land development regulations, including trip reduction ordinances. 
- Investigation of 16 selected Florida municipalities. Identification and documentation of specific case studies illustrating the process of development review between local governments and land developers.

- Summarization of general findings and conclusions regarding the incorporation of TDM in the land development process.

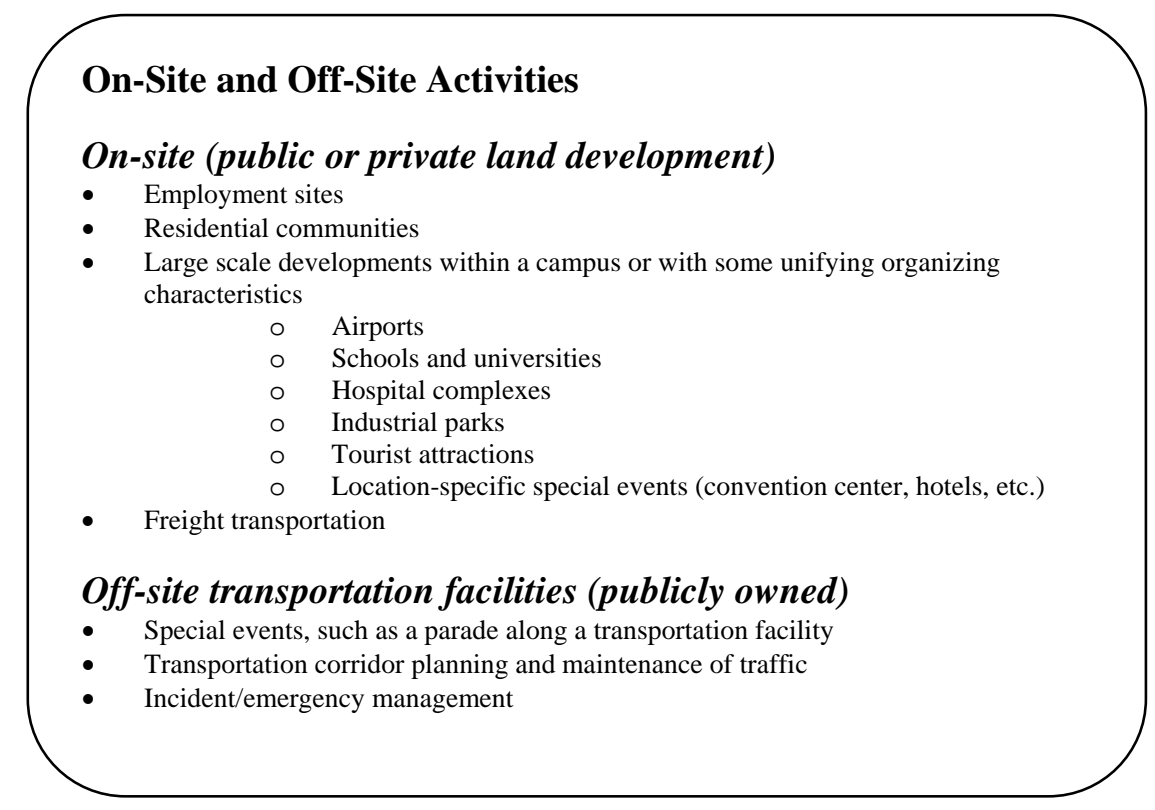

Figure 2: TDM Tactics Apply to a Range of Land Development Types

This report begins with a review of the federal and state legal foundation that provides requirements and limitations as well as opportunities for land development and the use of TDM to support it. Secondly, a discussion is presented about the many means of influencing travel behavior, with examples of TDM strategies, how these may fit into the land development process and what parties may be potential implementing partners. Thirdly, barriers and challenges to the inclusion of TDM in the land development process have been identified. The report next summarizes current practice at the local level for incorporating TDM into the land development process, providing case study examples both nationwide and from Florida of long range planning by the metropolitan planning organizations, local government comprehensive plans, land development regulations and the site development approval process. Recommendations for incorporating TDM into the land development process are provided. Appendices include excerpts from the Sarasota County Development Agreement, a discussion of Florida Developments of Regional Impact and the methodology used for assessing site impacts, an example of Long Range Transportation Plan TDM policies from Pinellas County and the City of Sarasota, traffic impact fee reduction incentives from Clark County, Washington and the comprehensive transportation review methodology from the City of Rockville, Maryland. 


\section{LEGAL FOUNDATION}

Transportation planning and system development in the state, including the use of transportation demand management strategies, begins with both federal and state law. These laws, combined with escalating right-of-way and construction costs and shrinking revenue sources, have influenced transportation decision-makers to place more attention on maximizing the use of the existing transportation system through the approach of transportation demand management (TDM).

\section{Federal Law - Metropolitan Planning Organizations (MPOs)}

A long range transportation planning process is undertaken by metropolitan planning organizations (MPOs) across the nation (in urbanized areas where the population is greater than 50,000). The metropolitan planning process is a continuing, cooperative and comprehensive process involving local government officials and other transportation stakeholders. The MPO planning process has been guided by the Transportation Equity Act for the $21^{\text {st }}$ Century (TEA-21) and its predecessor, the Intermodal Surface Transportation Act (ISTEA) that “...shifted the focus of transportation planning away from narrowly addressing traffic congestion through new highway construction to holistically resolving identified transportation needs through enhanced multimodal transportation alternatives and improved long range transportation decision-making” (2). Now the MPO planning process is given new direction through the federal Safe, Accountable, Flexible, Efficient Transportation Equity Act: A Legacy for Users (SAFETEA-LU). In August 2005, SAFETEA-LU was signed into law by the President, which authorizes federal surface transportation programs for highways, highway safety and transit for the five-year period, 2005-2009. The full implications of the new law on TDM as it relates to land development are not fully known as passage of the new law coincided with the end of this research study period.

TEA-21 established that the MPO transportation planning process must address seven emphasis areas, among them to "increase the accessibility and mobility options available to people and for freight...”(3). It also established the legal framework for MPO organizational structures and responsibilities. Although the MPO planning process primarily addresses transportation, land use is ultimately affected. According to the Federal Highway Administration, "Not only does the transportation system provide for the mobility of people and goods, it also influences patterns of growth and economic activity through accessibility to land” (4). The Unified Planning Work Program (UPWP), the Long Range Transportation Plan (LRTP), and the Transportation Improvement Program (TIP) are the key documents produced by the MPO planning process.

\section{Florida Law}

Local Government Comprehensive Plan. In Florida, the Local Government Comprehensive Planning and Land Development Regulation Act, Chap. 163.3161 F.S, both authorizes and requires local governments to control future land development to ensure stable and orderly growth that includes an intermodal transportation system. This is accomplished through local government comprehensive plans (LGCP) that, among other things, "facilitate the adequate and efficient provision of transportation...”(5). The Act also provides that no public or private development can be permitted except in conformity with the LGCP. At the same time, all ordinances and programs adopted under the authority of the Act must be developed and applied with sensitivity to private property rights.

Municipalities having populations greater than 50,000 and counties having populations greater than 75,000, or local governments within the boundaries of a metropolitan planning organization, must include a transportation element within their LGCP that specifically includes mass transit, ports, 
aviation, recreational traffic, and parking (6). The intent of the transportation element is to ensure a comprehensive, multimodal transportation system.

LGCPs must also include a five-year, financially-feasible, capital improvements element (CIE). The CIE must include principles guiding the expansion or increase in public facilities, principles to correct existing deficiencies in public facilities, an estimate of public facility costs, and provisions for "standards to ensure the availability of public facilities and the adequacy of those facilities," a concept commonly known as concurrency or adequate public facilities (7). Chapter 163.3180 F.S. states that public facilities, including transportation facilities, must be available to provide adequate service concurrent with the impacts from new development. This state law is implemented through local government concurrency management plans as guided by Florida Administrative Code 9J-5. Concurrency management planning directly affects local capital improvement programming as well as the land development process.

In 1999, the Florida Legislature amended Chapter 163 authorizing local governments to establish multimodal transportation districts (MMTD) (8). The purpose of the legislation was to provide a planning tool that Florida communities could use to systematically reinforce design elements that support walking, bicycling and transit use. It also enabled Florida communities to advance transportation concurrency through development of a high quality multimodal environment, rather than the typical approach involving road widening for automobile capacity. A multimodal transportation district is an area where primary priority is placed on "assuring a safe, comfortable, and attractive pedestrian environment, with convenient interconnection to transit” (9).

Land Development Regulation. While the local government comprehensive plan sets the policy framework guiding new development, land development regulations (LDR) adopted by a local government implement the comprehensive plan by specifying minimum standards for development. Chapter 163 F.S. requires each local government to unify its set of land development regulations into one Land Development Code. State law explicitly encourages local governments to use such land development regulations as subdivision regulations, incentive zoning, planned unit development, and impact fees. It is within the land development code that local governments can specify criteria for inclusion of TDM strategies in land development.

Development Agreements. A development agreement is a formal, consensual, binding contract between a local government, the land developer/owner, and if appropriate, other parties (i.e. the Florida Department of Transportation or adjacent land owners). In Bargaining for Development, David Callies et al. state, “The landowner generally wishes to guarantee that the local government's land use regulations, conditions, and exactions remain fixed during the life of a prospective land development on the subject parcel. The local government, on the other hand, seeks as many concessions and land development conditions as possible beyond what it could reasonably require through subdivision exactions, impact fees, and other conditions under the normal exercise of its regulatory authority or police power” (10). In short, the agreement ties land development rights to the provision of public facilities.

Chapter 163.3220-163.3245 authorizes local governments, by ordinance, to enter into development agreements with "any person having a legal or equitable interest in real property located within its jurisdiction” (163.3223 F.S.) and sets the parameters. Among other things, development agreements must include a legal description of the land, its owners, a timeframe for the agreement not to exceed 10 years, permitted uses, and information regarding the roles and responsibilities of the parties in terms of the provision of public facilities, confirmation of consistency with the local government's comprehensive plan and LDRs. Land development regulations in place at the time the development 
agreement is executed govern the development throughout the timeframe established in the agreement.

The flexibility of the development agreement makes it a useful tool for local governments by allowing them to address a variety of issues. For example, Sarasota County adopted a Development Agreement Ordinance (Ord. No. 2004-086 now Article VIII. Sec. 94-261 through Sec. 94-268 of the Sarasota County Code.) in late 2004 with the stated intent, "to promote and facilitate orderly and planned growth and development by providing a degree of certainty in the development approval process" (11). The Ordinance includes sections on findings, regulations, applicability, effect on other ordinances and regulations, local laws and policies governing development agreements, forms, enforcement, legislative act, severability, codification, filing and an effective date. During the adoption hearing, county staff promoted the benefits of the ordinance by indicating that it would allow the County to enter into public-private partnerships and encourage developers to participate in public improvement projects in which they might not otherwise participate (12). Appendix A contains the Sarasota County Development Agreement Ordinance. Development agreements are used principally for developments of regional impact.

Developments of Regional Impact. Developments of regional impact (DRI) are designated as such by their size and have greater impact on land development patterns than the transportation system. Most local governments in Florida use development agreements exclusively for Developments of Regional Impact (DRIs). Pursuant to Chapter 380 F.S., developments meeting specific criteria that have the potential to impact more than one county must undergo the DRI review process, including the documentation of impacts on the regional transportation system, as part of an Application for Development Approval (ADA), which must be approved by the State Department of Community Affairs. All impacted local government jurisdictions and any agencies with jurisdiction, such as the Florida Department of Transportation, participate in the DRI review process which is overseen by a regional planning council.

Under the current DRI review process, level of transportation service is measured in terms of roadway capacity leading to developer-funded improvements to maintain automobile/truck level of service (LOS). The estimated traffic impact is the basis for determining the developer's fair share cost in contributing to roadway improvements that are necessary to maintaining automobile/truck LOS.

The DRI transportation impact analysis focuses primarily on the impacts of the private automobile, with little attention devoted to a large array of potential considerations. Any multimodal strategies are addressed in one question on the DRI application, "What provisions, including but not limited to sidewalks, bicycle paths, internal shuttles, ridesharing, and public transit, will be made for the movement of people by means other than private automobile? Refer to internal design, site planning, parking provisions, location, etc.” Rule 9J-2.045(6)5 F.A.C. authorizes provision of “...programs that provide alternatives to single occupancy vehicle travel...” as long as such programs "...assure that public transportation facilities shall be constructed and made available when needed to accommodate the impacts of the proposed development...”. This guidance does not define or specify TDM but rather public transportation capital improvements. Earlier language that was removed during an amendment process allowed explicitly for buses and vehicles for vanpools. Appendix B contains a detailed discussion of the relationship between DRIs, FDOT Site Impact Methodology, and bus transit. Other factors intrinsic to the traffic impact methodology such as guidelines for acquiring and applying mode split (trade-off between private auto trips and transit trips) further impede the inclusion of multimodal strategies. Because the traffic impact analysis is focused on private automobiles/trucks, developer contributions to pay for traffic mitigation go to roadway 
improvements. Transportation improvements, as provided by developers, also must meet certain tests as provided by state law, summarized below (13):

- The transportation need that must be mitigated must be attributable to the proposed development paying for the mitigation.

- The amount of the contribution must correspond to the amount needed to mitigate the impacts from the development.

- The funds must go toward improvements to serve that development.

- Developers of DRIs cannot be required to contribute funds for mitigation unless the host local government has an ordinance in place requiring non-DRIs to mitigate their impacts.

- Developers of DRIs cannot be charged twice to mitigate for the same impacts, as in the case that a local host government charges impact fees.

These requirements pose special difficulties for developers to provide TDM improvements as mitigation for roadway impacts of a DRI. For example, if a high quality bus service, commensurate with highway level of service, is not in place, then it is not possible to reasonably estimate the need for transit service by a new development unless there is a way to measure latent demand for transit service. As a result, a very low number of bus trips is estimated. Consequently, a small amount of money or capital facilities is estimated to pay for bus mode share. Funds must be demonstrated to benefit the development. If there is an impact fee ordinance in place, then funds cannot go toward operations. This leaves capital facilities only, such as buses, bus shelters, and vans.

To encourage the desired results of engaging land developers to select TDM options as part of the DRI process, local governments should make full use of the planning and regulatory processes available to them to guide development toward locations where it is effective to provide identified TDM services. These include:

- the long range transportation planning process and the transportation improvement plan of the MPO,

- the local government comprehensive planning process, especially alternative concurrency provisions provided in 9J-2.045(6)2, F.A.C., pursuant to supporting Transportation Concurrency Exception Areas (TCEA) and Transportation Concurrency Management Areas (TCMA), where such mobility measures are specifically adopted in a local government comprehensive plan that has been deemed in compliance per F.S. 163.3180(5) and (7).

- urban development boundaries, and

- zoning and other tools within the land development code.

The Florida Department of Community Affairs (DCA) Interagency Implementation Team for transportation has plans to update F.A.C. 9J-2 to reflect changes from the recently passed Senate Bill 360. It is not known at the time of this report if F.A.C. 9J-2.045(6)2 and 5 will be revised.

Additionally, local governments could provide disincentives for a development that is located outside the existing or planned service area of transit, while offering incentives that make it more desirable to build in areas within the existing and planned bus service area.

The passage of Senate Bill 360 (“The Pay as You Grow Plan for Florida's Future”) may herald some changes and opportunities for incorporating TDM into the land development process. These include the following:

- Local governments will have an opportunity to improve their development review processes. 
- Local governments may adopt a 10-year long-term (15-year if approved by DCA) concurrency management system. The longer time frame is more conducive to demonstrating TDM impacts.

- Funding for infrastructure and technical assistance will be provided.

- Local governments must consult with FDOT and cooperatively develop a plan to mitigate impacts on the Strategic Intermodal System in TCEAs and TCMAs.

- New standards are required for TCEAs on mobility, design, urban infill, etc. TCEAs will be required to demonstrate multimodal strategies, connectivity, and urban design standards through the land development code. Existing TCEAs must be upgraded to the new standards.

- Regulatory incentives will be provided for having designated urban service boundaries and Urban Infill and Redevelopment Areas.

- The development of model TCEA strategies and evaluation criteria will be applied to three pilot communities.

However, one of the options given to developers is to pay for a project that is in the 5-year capital improvements element. This emphasis on capital improvements makes it more difficult to consider programmatic TDM strategies.

In the future, renewed consideration and research should be focused upon refining the DRI traffic impact methodology and the 9J-2.045 F.A.C. Transportation Uniform Standard Rules to recognize that transportation demand calls for a wider offering of mobility services and authorize their use. Such methodology and authorized mobility measures should recognize that this demand for transportation alternatives will not be obvious or easily measurable while the basic system providing for alternative mobility service is not fully in place. 


\section{RELATING TDM TO THE LAND DEVELOPMENT PROCESS}

As part of this study, it is helpful to identify the relationship between TDM and the land development process including the range of specific actions that can be considered and their timing in the process. Figure 3 below illustrates how TDM tactics can apply to all stages of the land development process. There are TDM tactics that represent physical facilities as well as operations and management tactics. In addition, TDM can apply to facilities, operations and management that are on-site and off-site.

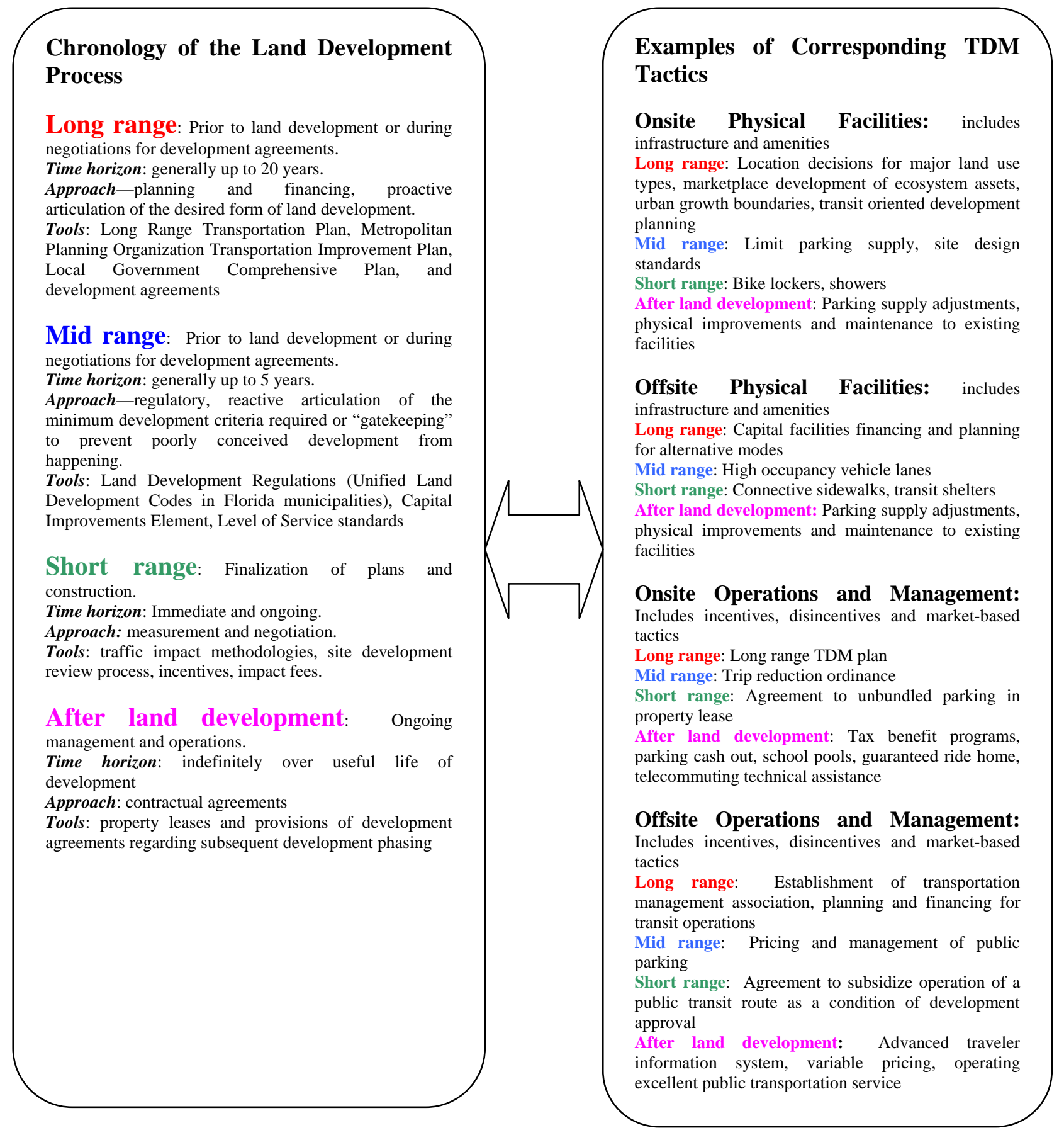

Figure 3: TDM Tactics Can Apply to All Stages of the Land Development Process 
Table 1 below illustrates TDM in a different way, according to its comprehensive applicability. TDM strategies are organized by their means of influencing travel behavior. First are those that have greater potential to affect travelers' longer term decisions about work and residential location including trip length, mode, and route. For example, in the first row, trip length may be affected by realtors who often play a role in influencing travelers' residential choices. Likewise, economic development organizations, both public and private, play a role in influencing business and employment locations. Regulation is listed next, which affects both longer term travel decision making as well as day-by-day decisions. Finally, cost, frequency, and time of day/day of week primarily influence traveler's day-to-day decisions.

As apparent in Table 1, implementation of many TDM strategies through the land development process does not necessarily rest on the shoulders of just one entity, but requires a coordinated effort. Table 1 also shows how, by all means of influencing travel behavior through TDM strategies, land developers and TDM professionals can play a role. 
Table 1: Range of TDM Strategies Potentially Addressed in the Land Development Process

MEANS OF

INFLUENCING TRAVEL BEHAVIOR Trip length.

Reduce quantity of vehicle miles.

Mode.

Increase efficiency of system to carry more people in the same number of vehicles.

\section{TDM STRATEGY} (EXAMPLES)

- Transit oriented development

- $\quad$ Proximate commuting by allowing employees to relocate job to the

- $\quad$ Access management

- Developing land in support of alternative modes, such as transit oriented development

- $\quad$ Limiting parking supply transit, vanpooling, carpooling bicycling, walking

- Carsharing branch office nearest their homes

- Offering alternative modes, such as
SUPPORTING ACTION (LAND DEVELOPMENT PROCESS)

- Clustering related land uses and providing more direct access (comprehensive plans and land development regulations)

- $\quad$ Providing incentives to employers

- $\quad$ Locating land development to take advantage of existing underutilized transportation services such as transit routes

- $\quad$ Providing on-site amenities, such as lockers, showers, bicycle parking and preferential carpool parking (land development regulations) as marketing, ridematching and guaranteed ride home

- Providing transportation services and physical transportation facilities off-site

- $\quad$ Shared parking

- $\quad$ Providing a grid system, street connectivity, and destinations within easy walking distance comprehensive plans and land development regulations

- Implementing Advanced Traveler Information Systems
- $\quad$ Providing support services such

POTENTIAL IMPLEMENTING PARTICIPANTS

- Land developer

- Municipal land development regulator

- Economic development organization

- Realtors

- Employer

- Commuter assistance program

- Transportation management association

- Land developer

- Property manager

- Municipal land development regulator

- Realtors

- Economic development organizations

- Transit agency

- $\quad$ State DOT

- Municipal public works department

- Municipal parks and recreation department

- Employer

- Commuter assistance program

- Transportation management association

- Private enterprise

- Land developer

- Municipal land development regulator

- Providing route alternatives

- High occupancy vehicle lanes
Bypass congestion.

\section{- Realtor}

- Economic development organization

- $\quad$ State DOT

- Municipal public works department 


\section{Regulation.}

Mandate specific traffic management actions or outcomes by local ordinance.

\section{Cost.}

Establish incentives and disincentives.

\section{Frequency.}

Reduce number of trips over given time period.

\section{Time of daylday of week.}

Move trips to less congested periods or avoid vehicle trip completely.
- $\quad$ State growth management provisions

- Concurrency

- Trip reduction ordinances

- Zoning ordinances

- Subdivision ordinances

- Parking ordinances

- High occupancy vehicle lanes

- $\quad$ Parking pricing

- Transit subsidies

- Parking cash-out

- High occupancy toll lanes

- Commuter tax benefits

- Providing on-site amenities

- Compressed work week

- Telework

- Compressed work week

- $\quad$ Staggered work hours

- Telework

- Flex time
- Carried out primarily by land developers, property

managers, employers, neighborhood associations

- Tax benefit program assistance

Providing physical facilities, such as employee cafeteria, fitness center, bank

- Providing technical support to employers

- Unbundling parking from employment site leases

- $\quad$ Providing technical support to employers
- Highway patrol

- State land planning agency

- $\quad$ State DOT

- Municipal land development regulator

- Municipal public works department

- Municipal parking department

- Highway patrol

- Property manager

- Municipal parking department

- State DOT

- Employers

- Commuter assistance programs

- $\quad$ Transportation management associations

- Land developer

- Property manager

- Employer

- Commuter assistance program

- Transportation management association

- Property manager

- Commuter assistance program

- Transportation management association

- Employer 


\section{CHALLENGES AND OPPORTUNITIES FOR THE INCLUSION OF TDM IN THE LAND DEVELOPMENT PROCESS}

While carefully selected and properly executed TDM strategies can improve overall mobility, there exist various challenges of incorporating transportation demand management (TDM) into the land development process.

\section{Data Availability, Analysis Methods and Transportation Concurrency}

FDOT maintains a traffic and roadway database called Traffic and Roadway Information Systems (TRIS). It contains information about traffic count statistics and roadway features for the purpose of state transportation planning and development for the State Highway System (SHS). The SHS includes roads under the jurisdiction of the State of Florida and maintained by FDOT, including roads with Interstate, U.S. and S.R. numbers. Florida is in the process of changing the way it plans the transportation system of the state. The change is from thinking of each mode separately toward an approach that manages the seamless movement of people and goods in a multimodal system. This is referred to as the Strategic Intermodal System (SIS), created in 2003. Part of this process is the development of a unified geodatabase that collects data for other modes to the same depth as has been the case for highway travel (14). This planning activity recognizes that while the older database is adequate for determining which projects within each mode are the most important, more in-depth data are needed to determine if limited funding should go toward either improving a port or instead building a new interchange on an interstate or some other intermodal trade-off. In order to make these kinds of intermodal trade-off decisions, an understanding of how the facility is used, and how it interrelates with other transportation modes is necessary. This newer planning strategy will reap advantageous benefits for the state and municipalities and it is a giant leap in the right direction toward intermodalism. It also is important to remember that the FDOT's charge as a state agency is to advance transportation for statewide purposes, which is in some ways fundamentally different from the transportation interests of local urban areas.

As this relates to the site development for a new shopping center or office building in a municipality, the transportation impacts of that new development may adversely affect the through-moving capability of a state highway. From the standpoint of serving the new development, which hopes to attract tenants, employees and customers, the more important transportation objective is providing easy access to and from the development from local and regional trip origins. The transportation improvement options for these two objectives may differ. TDM seeks to provide mobility options. To this end, intermodalism is not only important to providing options, but multimodalism is also important, in the sense that someone can choose to successfully travel entirely by walking, bicycling, riding transit or avoiding travel altogether by telecommunications. Research by Liu et al. (15) demonstrates that intermodal transfers are time consuming and are avoided by travelers whenever possible; therefore, the success and functionality of multimodal options requires developing them as complete systems that connect intermodally.

Developing complete and parallel multimodal systems that interconnect is expensive and may be criticized as redundant. However, continued dependence on one mode, highway travel by private vehicle, is also expensive and has been demonstrated that it will not continue to meet growing demand. Putting “all the eggs in one basket” exacerbates vulnerabilities to incidents, natural disasters and national security threats.

FDOT has one of the most extensive and well organized transportation data collection systems and toolbox of analysis methods of all transportation agencies in the state. The smaller the local municipality, the greater the reliance upon technical assistance from FDOT and the more likely that FDOT analysis methods and data are used for local transportation planning purposes. 
In most instances, transportation concurrency as it is written in F.S. 163.3180 more specifically addresses roadway private motor vehicle traffic. While professionally accepted methods of measuring multimodal quality/level of service have been adopted by FDOT for separate transportation modes (auto/truck, transit, bicycle, pedestrian) these methods are not meant to be used for considering trade-offs among modes (16). Instead, a level of service is computed for each mode rather than the development of a composite overall transportation level of service measure. In other words, available methodologies fall short of enabling an evaluation of a trade-off among modes in a seamless transportation system. As a result, there is currently no tool to evaluate the trade-off between allotting financial and land resources to improve bicycle LOS through the creation of bicycle lanes, which means less money and right-of-way to improve roadway LOS for motorized vehicles. Likewise, signal timing to favor pedestrians at intersection crossings increases delay and degrades LOS for motor vehicles. However, through TDM strategies, local governments are being asked to change the balance of their trade-offs toward alternative modes. Vital to the administration of the land development process is maintaining the confidence of land developers that each one is treated fairly and in the same manner as all other developers. This places a responsibility on any such method to determine the magnitude and quality of future impacts of development, to attribute the impacts accurately to the responsible party, and to identify mitigating measures that will both directly address those impacts as well as serve the development of the contributing party.

The rational decision making process and range of answers generated for the development of the transportation system is linked to the kinds of data collected, the degree of detail and scope of the collected data and the analysis techniques used. The analysis techniques used incorporate assumptions about desired outcomes as well as drive particular analysis outcomes. A summary below of the FDOT Site Impact Analysis methodology used in the traffic analysis of DRI impacts is an example of this. A detailed look at the DRI process and Site Impact Analysis methodology is provided in Appendix B, excerpted from Hendricks (17).

\section{Continuing Land Development Fuels Need for Alternative Emergency Response}

An extreme manifestation of accommodating private motor vehicle demand is hurricane evacuation. FDOT justifiably prioritizes safety first. The primary response to this need has been preserving the functioning of the FIHS to serve high speed high volume traffic, especially as emergency evacuation routes. Highways that are designated as regional evacuation routes must also maintain a high level of service. The need to maintain a high level of capacity that will be used only in emergencies creates conditions of plentiful capacity during all other times of the year. This fuels land development growth where capacity exists, which in turn creates the need to build more capacity to maintain a high level of service to be used in times of evacuation. A certain leveling of the playing field must occur with respect to transportation quality of service across modes before people will consider other modes of travel for daily purposes. That requires some degree of greater traffic congestion combined with satisfactory service offered by other modes. With the lion's share of transportation resources going toward maintaining private motor vehicle level of service, the balance needed is always out of reach.

A prescient report prepared by Wolshon et al. (2001) of the LSU Hurricane Center prior to the events of Hurricane Katrina included a nationwide survey of hurricane transportation evacuation planning policies. It cited generally limited planning at the state level for the evacuation of low-mobility groups (18). Potential low-mobility evacuees include low-income persons without cars, the elderly, the homebound infirm, school and hospital populations and tourists. To address this issue, the Florida Commission for the Transportation Disadvantaged (TD) has been operating for the past 25 years and oversees 49 Community Transportation Coordinators (CTC) in all 67 counties. 
Considering the four hurricanes that struck Florida in the summer of 2004, the performance of the CTCs was outstanding, especially under conditions of closed bridges, flooded roads, electrical outages, limited fuel and destroyed communications and computer systems. This Commission is recognized as one of the best in the nation in providing and coordinating transportation for elderly, disabled and low income citizens. However, what would an urban area do if it faced the need to evacuate a large number of low-income persons without cars? The Florida CTCs last year concentrated on the most vulnerable people-the elderly, frail and those having special medical needs. But if a large population of low-income people without cars needed to evacuate, this may overwhelm the CTCs. Local emergency plans include the deployment of municipal buses and school buses to evacuate people but does this constitute sufficient capacity? Neighboring bus systems stand ready to help evacuate. But again, is this enough and would not that burden the municipality lending its bus service?

Florida has a large low-mobility population. The demographics of Florida communities in particular show not only high numbers of tourists, even in the "slow" summer season, but also senior citizens and low-income persons. The American Community Survey (19) reported that nationwide, the number of persons with disabilities that prevent them from going outside their home was over 10.7 million persons. This is approximately 4 percent of the total population nationally. A survey conducted between October 1994 and January 1995 indicated that approximately 26 million Americans (1 in 10) described their disability as severe. A person who has a severe disability is one who is completely unable to perform a daily living activity or socially defined task or who needs personal assistance (20). Figures for those who cannot "go outside home" classification of disability at the state level were unavailable; however, there were Census 2000 estimates of the total number of persons with disabilities statewide. These included over 1.9 million or 21.9 percent of the Florida population age 21-64 and over 1.0 million or 39.5 percent of the Florida population age 65 and over. Over 17 percent of Florida's population is age 65 and over. Approximately 12.7 percent of Florida's population is low-income (21). If Florida's low income population reflects that nationwide, then approximately 25 percent of low income households in Florida do not own cars. Recent estimates for the Tampa Bay region show approximately 14,000 households in Hillsborough County and 22,000 households in Pinellas County within a Category 5 hurricane evacuation zone that do not own vehicles (22).

Transportation infrastructure in the U.S. has been developed to serve motor vehicle traffic and more recent attention upon maximizing the use of existing infrastructure in times of evacuation has focused upon highway contraflow strategies. An untested Florida DOT plan exists for the conversion of Interstate 4 in Florida between Ybor City and Orlando into a one-way eastbound evacuation route. However, in September 2005, when 200 miles of Interstate 45 north of Houston were turned into northbound only lanes, gridlock resulted for Hurricane Rita evacuees. The LSU study points out that while buses are the most common mode of transportation to evacuate low-mobility groups, many heavily populated cities do not have an adequate supply of buses to move all low-mobility evacuees that need assistance. If the priority justification behind the allocation of resources to maintain high capacity roadway service is hurricane evacuation, then the same justification should apply to maintaining bolstered public transit fleets circulating on routes with greater frequency. The resulting increase in transit quality of service due to larger in-service fleets (and the resources to operate them) would contribute toward providing satisfactory modal alternatives on a daily basis. The effects of such improved service availability would trickle down to land development location decisions and site design. But Hurricanes Katrina and Rita demonstrated that the emergency evacuation solution is somewhere beyond better transit service and more buses. It depends upon better land development that supports and is supported by the transportation system. This system must be capable of fully using strategies to manage transportation demand during times of crisis and after the crisis has passed when populations are dislocated and transportation systems are damaged. So while resources are 
poured into a regional roadway system to handle motor vehicle demand during times of hurricane evacuation, the more comprehensive solution offered by land development that enables transportation demand to be managed is overlooked.

\section{Transportation System Financing}

The regional and statewide transportation emphasis on highway system service for freight and private automobile travel reinforces a predominantly highway oriented system at the local level, as state highways traverse urban areas. This sets the development of other modal options at a disadvantage, as highway travel receives the bulk of state transportation funding and scarce resources require allocation trade-offs. The State Transportation Trust Fund is replenished by state motor fuel tax revenues, vehicle licensing fees, auto registration fees and rental car surcharges. This reflects the principle that the road system should be paid for by its users. The downside to such revenue sources is no institutional incentive to decrease auto ownership and decrease traffic as more traffic is associated with increased revenues and enhanced economic activity.

Consistent prioritization of state highway funding over the years reinforces existing travel behavior and public expectations at the local level. Section 206.46, F.S. requires that a minimum of 15 percent of revenues distributed by the State Transportation Trust Fund is devoted to local public transit systems and capital rail projects. For all practical purposes, the State Highway System for private automobile and freight traffic is the backbone of regional and intrastate travel in Florida. While FDOT has a Public Transit Office, the state does not have a statewide passenger transit system, which is commonly provided in many European nations. Instead, the Transit Office administers grants, monitors compliance with transit regulations and provides technical assistance to locally operated transit agencies. The provision of high quality transit service is potentially the most far reaching of TDM strategies to meet local travel needs efficiently. Ensuring high quality transit success depends on a pedestrian friendly environment, most often seen in the form of transit oriented development. However, once the decision is made to fund and build an additional highway, there is the added permanent commitment to maintain and resurface it on a regular schedule. Additional highway investment for private motor vehicle travel begets the need for more highway investment. In Florida, there are over 40,000 lane miles and 6,200 highway bridges on the State Highway System, all requiring regular inspection, repair and maintenance (23). The Public Transit Office's mission is to maximize the passenger carrying capacity of these surface transportation facilities. The goal is to promote use of transit for local trips so that state highways are free to serve regional travel purposes. However, regional and local travel modes are intertwined and reinforcing. A local transit system works better within the context of a strong regional transit system and vice versa. Transit 2020, the transit element of the Florida Transportation Plan, cites three key issues that impede achievement of transit goals.

- The level of transit service for most Floridians is inadequate and will worsen given current trends.

- Current transit funding levels are inadequate to fund existing as well as expanded capital, maintenance and operating programs; several funding sources lack stability and flexibility.

- Existing policies and institutional arrangements and practices sometimes hinder or fail to promote the achievement of transit objectives.

\section{Market-based Land Use Decisions}

The State specifically wants to attract high-wage jobs and private sector investment to achieve statewide economic development goals. A company's location or expansion can be adversely affected by transportation-related problems. The Economic Development Transportation Fund, 
commonly referred to as the "Road Fund," is an incentive tool designed to alleviate transportation problems that adversely impact a specific company's location or expansion decision. These grants are worth up to $\$ 2$ million and are awarded by the State of Florida to the local government for transportation facility improvements as part of the land development process. Funding pays for such eligible improvements as design and engineering, signalization, construction costs of access roads or road widening, and other work. However, the potential opportunity is recognizing that private enterprises have varying transportation needs. For example, some industries have time-sensitive freight transport requirements for expressway access at high operational level of service. These include products whose transport time should be minimized, such as refrigerated pharmaceuticals and blood products. Not all private enterprises require this kind of transportation service and access but could thrive in a transit-oriented development. For example, a medical research and manufacturing operation employing 170 people, most of them high wage, is located in downtown Seattle. Through offering employer transit subsidies coupled with a parking management program, the firm reduced the number of vehicles per 100 employees driving to the site by 10 percent between 1999 and 2001 . Later, the company moved even closer into the core of the downtown because a favorable loan arrangement and better suited physical facilities saved the company money. Incidently, the move positioned the company even closer to a transit hub, making it easier for employees to use transit. This example demonstrates that some companies are better suited to downtown locations, even some manufacturing operations, like this high technology example. (24).

Use of public transit is typically not associated with high-wage workers primarily because public transit has not been developed to provide premium service. As higher income households in both the United States and in Florida make more trips than low and middle income households (25), it is even more imperative that success in attracting high wage jobs is also combined with strategies to most efficiently use the transportation system. Application of TDM principles could demonstrate that better business placement would match its particular transportation needs to the transportation service type while preserving highway access for additional enterprises that truly need it.

\section{Balancing Competing Interests with Scarce Resources}

A quote in John Mason's white paper for FHWA entitled "Understanding the Communications and Information Needs of Elected Officials for Transportation Planning and Operations” states it best: Government leaders must balance available funding with the desires of their constituents. In addition, they must address not only transportation, but a myriad of additional community concerns, making it difficult for them to have an in-depth knowledge of any subject. Systematic inclusion of TDM in the land development process will involve an understanding of the trade-offs between private automobile use and increased mobility

"Local elected officials must manage public expectations about transportation. We walk a fine line between almost unlimited public demand for unfettered mobility on the one hand, and very limited public support for increased tax revenue with which to finance these improvements on the other" (Gerry Connelly, Chairman, Board of Supervisors, Fairfax Countv. VA) (26). through transportation demand management. It means that transportation investments are made now, incurring some present hardship, which result in benefits that are enjoyed later. An additional challenge is that changes brought on by TDM happen gradually; in the midst of explosive population growth, the positive effects of a shift in planning approaches from accommodating traffic to managing traffic can at first be obscure. 


\section{Roadway Functional Classification}

Roadway functional classification affects land development decision-making. The functional classification of a roadway sets expectations as to how the road will perform and guides decision making and priority setting with respect to how it will be improved and maintained. FDOT's functional classification of roadways describes how they are designed to serve a specific function for moving traffic. Local governments may have their own functional classification system but have found it advantageous to be consistent with the State and Federal functional classification systems. The definitions below demarcate the trade-off between unimpeded movement of through traffic and accessibility to destinations. For brevity, the list below omits freeways, expressways, the distinction between major and minor collectors, and the distinction between these classifications as rural and urban.

a. Principal Arterial - A highway which serves moderate to high volumes of traffic moving over long distances. These include interstates, freeways and expressways. They are characterized by high volumes, high capacity and continuous alignment. These facilities usually connect major population centers. Although they provide access to abutting property, such access is usually controlled through frontage roads and limitations on the number of driveway cuts. Major intersections are channelized, signalized, and spaced at intervals of at least 1/4 mile. Minor intersecting streets usually function under stop sign control.

b. Minor Arterial - Similar in function to a principal arterial but operating under lower traffic volumes and over shorter distances. Minor arterials generally have less restrictive access controls and more widely spaced intersections in rural areas.

c. Collector - Thoroughfares that provide for traffic movement between arterials and local streets. Collectors usually carry moderate traffic for moderate distances. Traffic volumes can vary depending on the density of the surrounding area. Vehicular speeds are moderate.

d. Local Street - A street intended only to provide access to residences, businesses, or other abutting properties.

Local decision makers have priorities that are partly based on the necessity to comply with state requirements as well as to secure funding. While some small proportion of state roads are functionally classified as local, most state roads are built for regional mobility purposes, which is different from the main purpose of most municipal roads. State roads run through and are connected to the local road systems of urban areas. As a result, the functioning of a local road affects the level of service of a state road. Conversely, the presence of state roads, built to specifications for moving through traffic, affects the pattern of local land development in that there is an attraction to build near available capacity. The functional classification of state roadways tends to favor serving through movements for regional mobility purposes while municipal roadways of varying functional classifications attempt to juggle access provision while complying with level of service standards to meet concurrency. This is a difficult balancing act with ramifications for land development. For example, In 1997, the City of Tampa evaluated the feasibility of a "neighborhood collector" classification to protect residential neighborhoods from the adverse impacts of through traffic. The downside to completely protecting neighborhoods from through traffic is that it reinforces the hierarchical system of roadways that requires major arterials to be multilane. In a hierarchical street system, arterials become the only routes available for areawide travel. This spurs the separation of land uses, which further impedes transit-oriented development. 
State roads, mainly arterials, are built for regional mobility purposes both running through and connecting to the local road systems that provide for local traffic movement and access to land uses. One of the main complaints regarding these arterials is the negative impact they have on the nonautomobile community. Congested arterials impede the rapid movement of buses and are often unfriendly to bicyclists and pedestrians. Planners experience resistance from developers regarding the implementation of TDM strategies. Developers have specific "formulas" for creating developments based on marketing knowledge received from their buyers. They believe, not without merit, that because their buyers are not seeking specific TDM strategies, such investments are not desired by the public and, therefore, not justified. Notably, recent interest by planners in New Urbanism and traditional neighborhood development is fostering a change in development "formulas" throughout the state. This trend shows a growing understanding on the part of the general public that lifestyle alternatives are possible. The surge of New Urbanism has brought increased interest in taming these arterials, resulting in a collaboration between the Congress of New Urbanism (CNU) and the Institute of Transportation Engineers (ITE). At the time of this writing, the CNU and ITE are working on, “...the creation of an industry-approved design guide that gives transportation engineers and thoroughfare designers design criteria that incorporate techniques and principles of new urbanism and smart growth for context-sensitive major thoroughfares for urban settings" (27).

\section{Programming and Evaluation Time Frames Do Not Correspond}

The focus of TDM program budgeting often has been based upon short term time frames. For example, commuter assistance programs (CAP) may be evaluated based upon annual work plans supported by annual budgets; therefore, some of the most important work with far reaching and lasting impact (TDM strategies corresponding to land development) takes a back seat if performance results must be demonstrated within the year. TDM programs often require longer time frames for implementation and for demonstrating changes in travel behavior. Because the land development process often takes longer than a year and straddles work plans of multiple years, it does not fit the evaluation time frame.

\section{Lack of Knowledge and Lack of Resources}

Most local government staff members are unlikely to have the full knowledge and understanding of the TDM strategies available to them. It is likely that, without specific examples of how TDM strategies can be included in the land development process from long range plans through development agreements, TDM strategies will be either weak or non-existent. Also, many TDM strategies are not capital intensive and therefore may require more effort to devise programs that establish who is responsible for implementation and how to gauge results. TDM professionals are not included among those who regularly review land development proposals or traffic analyses. Public transit and TDM agencies rarely have the staff resources to stay on top of the myriad development proposals under review at any one time, leaving it up to the local host government to advocate on their behalf. Even in the case of developments of regional impact, in which transit agencies are usually involved, it is often the case that the review process occurs over an extended period of time during which the development concept may change repeatedly in response to market conditions. Changing conditions may necessitate follow-up reviews for which transit agencies may not have the staff resources.

\section{TDM is Considered a Mitigative Measure Only}

TDM has traditionally been viewed and applied as a mitigative response to an already congested roadway system that primarily serves private motor vehicles. This practice of waiting until there is a congestion problem before implementing TDM strategies places increased pressure for results that 
take years to achieve. If applied systematically throughout the land development process, TDM would be regarded not so much a mitigative measure as it would a means to enhance mobility. Systematic incorporation of TDM in the land development process would incorporate travel demand management, in all its definitional aspects, right from the very beginning of the long range land use/transportation planning process through to the day-to-day travel options people consider.

\section{Relationship Between Local Government and Developer}

The developer often is uninformed regarding the integration of TDM into land development projects. While there are many TDM-related services and facilities that could be made possible through land developer participation, the host local government balances conditions and requests against enticements to maintain a positive business relationship with the developer. Certain considerations by the host local government can make a difference in whether the business of land development remains worthwhile and profitable. These include the following:

- Certainty of the process;

- Fair treatment in relation to business competitors as well as in relation to the negotiated responsibilities of the developer and the host local government;

- Flexibility in solution seeking; and

- Respect for time constraints of the land development process.

\section{Monitoring Development Agreements}

Despite a local government's focus on creating development agreements, challenges remain in monitoring them. Most often, monitoring occurs at points in time when developers must apply for site plan or building permit approvals or submit annual reports. Occasionally, complaints from the general public trigger a review of the development agreement and the developer's compliance with that agreement. Often, staffing constraints make it difficult for local governments to be vigilant regarding implementation of programmatic transportation improvements and services. As a result, TDM strategies that require non-physical improvements in a development agreement may have little compliance. This challenge is evident in the case studies compiled for this report. 


\section{CURRENT PRACTICE OF INCORPORATING TDM INTO THE LAND DEVELOPMENT PROCESS}

For the purposes of this report, the land development process in Florida includes long range planning, land development regulations (addressing zoning, subdivision, parking, etc.), other ordinances (such as concurrency and trip reduction), as well as various permitting processes. Managing transportation demand involves each stage of the development process. Often, the land development process is weighted toward accommodating the demand for private motor vehicles at the expense of managing transportation demand. Challenges of incorporating TDM strategies into the land development process exist in each stage of the process and affect the outcome. This discussion of the land development process from long range planning through site development identifies how TDM is currently being incorporated into each stage as well as some of the factors that may work against transportation demand management.

\section{Long Range Planning}

Local governments are responsible for land development policy setting through development of generalized long range plans guiding future growth, as well as regulating development at the sitespecific level. Long range planning includes both transportation planning as carried out by metropolitan planning organizations and comprehensive land use planning as carried out by local governments. Although local government comprehensive plans provide guidance for the entire jurisdiction, local governments are increasingly developing sub-area, small area, sector, or selected area plans to respond to individual land use, transportation, and economic needs as well as to resident desires in specific areas.

MPO Long Range Transportation Plan (LRTP) In a 2002 review, Kramer and Mierzejewski found that "almost all MPOs incorporated the concepts of intermodalism and multi-modalism into their long range transportation plans" (28). For the first time, the majority of Florida MPOs considered alternative modes of transportation in addition to the automobile, including bike paths, sidewalks, multi-use trails, rail lines, bus rapid transit, express bus routes, and HOV lanes. Although most MPOs allotted some funding for alternative modes of transportation, the majority of funding went to auto-related improvements.

A few MPOs, including the Tallahassee/Leon County MPO (now the Capital Region Transportation Planning Agency, CRTPA), the Broward County MPO, and the Gainesville MTPO, established unique approaches to promoting multi-modal transportation systems in their 2020 LRTPs. The CRTPA “...conducted a two-tiered walkability/bikability analysis to target bicycle and pedestrian enhancements to areas that have a high potential for bicycle and pedestrian activity.” The Broward County MPO Board included a significant number of transit-related improvements through complex alternatives testing which included both highway and transit alternatives. Finally, the Gainesville MTPO adopted a variety of multimodal projects including road connectivity projects, lane reductions to enhance pedestrian and bicycle facilities, as well as express bus service.

Most Florida MPOs are currently preparing updates to their long range transportation plans; to date, seven of them have completed the process and adopted the updated plans. Although many of the LRTP updates are not complete as of this writing, most MPOs have adopted their guiding goals, objectives, and policies (GOPs). A review of these GOPs reveal greater policy emphasis on managing transportation demand, including the following generalized objectives.

MPOs seek to change user behavior to accomplish reductions in SOV (single-occupant vehicle) dependency through increased vehicle occupancy, reduced peak period travel, and increased 
availability and use of alternative modes of travel (29). The concept of changing user behavior to maximize the capacity and efficiency of the transportation system appears as a policy in MPO LRTPs. While recognition of managing transportation demand in plan updates is a positive sign, the key concept that is missed by the general objective above is that TDM comprises many other ways to manage demand besides modal options. While the emphasis in the objective is upon reducing singleoccupant vehicle travel as the means to decrease traffic congestion, examples of other strategies, including congestion pricing and compressed work week, do not necessarily reduce SOV use but can decrease congestion. This illustrates the need for planners and policy makers to better understand that TDM includes influencing travel behavior by mode, time of day, trip frequency, trip length, route, cost and regulation, and that the selection of one or more objectives to accomplish the goal may or may not include SOV reduction. This recognition is especially important in Florida urban areas where parking is plentiful and small effort is being made to limit parking.

A handful of policy statements attempt to make more specific recommendations, including reducing peak period travel using TDM strategies and providing a telecommunication network that would enhance people's ability to avoid trips entirely. Examples of goals, objectives, and other policy statements expressing these planning concerns include:

- Okaloosa-Walton TPO: Reduce energy consumption by promoting actions to increase the occupancy in vehicles (e.g. ridesharing, mass transit, HOV lanes).

- Collier County MPO: Encourage employers to use incentives for transit use, such as bus passes, van pooling, and coordination of ridesharing activities.

- Lee County MPO: Reduce peak period travel through the use of Transportation Demand Management measures (e.g. carpooling, vanpooling, telecommuting, flexible work hours, etc.).

- Pinellas County MPO: Encourage the development of a telecommunication infrastructure to provide universal service access to all citizens for expanding educational opportunities via distance learning, obtaining medical information via telemedicine, increasing commerce via the purchase of goods by online shopping, and creating job opportunities via telework. These elements will foster economic development by helping citizens and businesses move intellectual property, data and information electronically. This policy is intended to reduce or even eliminate the need to travel for these purposes.

Another observation is the frequent use of "soft" verbs-actions that sound good but for which progress is difficult to measure. These actions include "coordinate with", "promote", "encourage", "consider" and "continue to support". Another common phrase is "implementing where feasible" which suggests the intent to use TDM but provides a way to justify avoiding TDM based upon professional judgment. Related to this are ambiguities in the use of wording that expressly requires an action versus that which implies it is optional (i.e., "shall” versus "will”, where standard rules for these words often do not reflect actual usage). Policy language must be clear about what is mandatory. Word selection in policies also should clearly describe the intended application of TDM. For example, the difference between the use of "transportation alternatives" and "transportation choices" may be interpreted differently by some. Critical to the initial acceptance of TDM, particularly as citizens are being asked to change their travel behavior, is the concept that TDM provides everyone with choices and the selection of one mode or action does not have to be used every time. TDM enables travelers to have the option to choose transit one day and drive to work 
alone another day when needed. TDM is intended to maximize travel flexibility while encouraging the selection of the best and most efficient travel choice for each trip.

Under the sponsorship of Bay Area Commuter Services, the regional commuter assistance program in the Tampa Bay area, long range TDM planning for municipalities was advanced through the preparation of Long Range TDM Plans for Hillsborough and Pinellas Counties by the USF Center for Urban Transportation Research. These were developed with the active participation of advisory committees comprised of their respective MPOs, city and county staff, transit agencies, FDOT and other key stakeholders. Baseline performance was measured for 2000 and peer communities were selected in regard to demographic, transit, vanpool program and congestion index characteristics. Forecasts for 2025 were developed using the Environmental Protection Agency's (EPA) COMMUTER Model. The model estimated the impact of TDM strategies based upon several scenarios developed by the advisory committees. The plans demonstrated that success of TDM depends upon the packaging of various actions that complement and reinforce each other to achieve a desired objective. The plans also contain estimated costs of implementation and demonstrate that the impact of TDM strategies corresponds to the degree of financial support and commitment assigned to their implementation (30a and $b$ ).

The Pinellas County MPO example cited above regarding encouraging the development of telecommunications infrastructure points to a different challenge entirely. While many transportation entities at the federal, state and local levels provide programs to promote telework, they do not control telecommunications infrastructure. While the FDOT has pursued the development of a fiber optic network, it has been for Intelligent Transportation Systems (ITS) applications for optimizing highway traffic flow rather than reducing the need to travel through electronic access. Telecommunications within the transportation arena is an underdeveloped area well worth pursuing (31).

MPOs seek to make modal alternatives more viable through increased availability, improved service, and additional funding (29). Increased multi-modalism is one of the key priorities of the Intermodal Surface Transportation Efficiency Act of 1991 (ISTEA) and remains a corner-stone of transportation policy at both the federal and state levels. Individual MPO priority statements touch on a variety of issues and subjects, each of which can be categorized generally under a desire by MPOs to create a multi-modal transportation system. Again, the majority of objectives and policies address alternative modes of transportation including bike paths, sidewalks, multi-use trails, rail lines, bus rapid transit, express bus routes, and HOV lanes. Many MPOs express a clear desire to make alternative modes of transportation competitive with the single occupant vehicle through improved travel time, accessibility, and aesthetics. Examples of goals, objectives and other policy statements expressing these planning concerns include:

- Ocala/Marion County TPO: Provide increased fixed route transit services by expansion of the existing transportation system into areas of high population, employment, or services, and/or by decreasing existing bus route times thereby providing more frequent service.

- Florida-Alabama TPO: Encourage developers in the local government site plan review process to include provisions for alternate forms of transportation such as a compact car, motorcycle, golf cart, designated car pool, and bus as well as for bicycle racks, High Occupancy Vehicle (HOV) lanes, and designated park and ride lots. 
- Gainesville MTPO: Improve the viability of alternatives to the single-occupant automobile (bicycle, walking, public transit, carpooling, and telecommuting) as options for all users of the transportation system through accessibility, convenience and comfort.

MPOs seek to improve the connectivity of the transportation network through the provision of alternate routes (29). Some MPOs address the need to improve connections between roadways of various functional classes (arterials, collectors, local roads, etc.) to encourage an appropriate distribution of vehicle traffic across the entire roadway system and relieve congestion on the higher order roadways. A few MPOs expand upon that concept to include improved connectivity between all components of the transportation system including sidewalks, bikeways and transit ways. Examples of goals, objectives and other policy statements expressing these planning concerns include:

- Capital Region TPA: Improve connectivity of the collector roadway network to relieve congestion on arterial and freeway facilities.

- Florida-Alabama TPO: Provide design guidelines for developers to ensure multimodal connectivity in or between new developments.

- Volusia County MPO: Support in-fill development and the concentration of new commercial and office space in activity centers that can be interconnected by transit, bikeways and sidewalks.

MPOs seek to promote livable communities through the design of a transportation system that is both sustainable and sensitive to community visions and values (29). MPOs also indicate support of community livability through the transportation planning process, stressing the need to provide a transportation system that enhances multi-modal access to key community facilities such as schools, work places, shopping districts, recreational venues, cultural facilities and medical services. A policy example addressing livable communities is below:

- METROPLAN ORLANDO: Provide a pedestrian system that connects to an inter-modal transportation system in order to support neighborhood and community livability and vitality.

MPOs seek to encourage local governments to adopt urban design strategies and corresponding land development regulations that support the integration of land use and transportation (29). While MPOs encourage local governments to develop and implement urban design strategies that integrate transportation and land use, local governments are directly in control of the land development process. Some specific design concepts recommended by MPOs include designs that encourage internal trip capture, control of access along major facilities, mixed use development, transit-oriented development, walkable communities and more intense non-residential development in transit corridors while discouraging the development of strip commercial land use and improvements that support peripheral growth and urban area sprawl.

Additionally, MPOs encourage local governments to include requirements in their land development regulations to ensure that new development is integrated into the multimodal transportation system. Suggestions include regulations that require developers to integrate design elements in their site plans that would facilitate transit use (transit stops and connections, etc.), encourage walking, biking and other modal transportation modes (bicycle racks, lighted sidewalks, benches, van pool parking 
spaces, etc.), and provide for multi-modal connections to adjacent land uses. Examples of goals, objectives and other policy statements expressing these planning concerns include:

- Ocala/Marion County TPO: New subdivisions and developments shall be required to provide multi-modal interconnections to adjacent properties to permit travel to neighboring land uses without having to use the public roadway system.

- Collier County MPO: The MPO will work with local governments to develop ordinances that require all new and redevelopment projects to consider alternative modes and "smart growth" design techniques.

- Volusia County MPO: Support in-fill development, redevelopment and the concentration of new commercial and office space in activity centers that can be inter-connected by transit, bikeways, and sidewalks.

- Capital Region TPA: Coordinate with local governments and other agencies, to discourage development of strip commercial land use, encourage the control of access along major facilities, encourage mixed-use development, and encourage transit-oriented development with more intense non-residential development in existing and planned transit corridors.

- Miami-Dade MPO: Discourage improvements that support peripheral growth and urban area sprawl.

In crafting TDM-specific objectives and policies, each MPO must remain aware of its role in establishing guiding policies for the transportation system while still being specific about what is to be accomplished and how it is to be accomplished. The following discussion includes examples from a few MPOs that specifically use the terms "transportation demand management" or "TDM" in their respective LRTPs. Note that the Collier MPO “encourages” TDM, while Pinellas County MPO establishes a more active role for itself in working with local governments regarding transportation demand management. Finally, the Hillsborough County MPO sets aside specific funding for TDM programs. Each level of inclusion serves a useful role for the population it serves.

In the first example, the adopted GOPs for the Collier MPO 2030 Long Range Transportation Plan Update specifically included TDM in the following objective and accompanying policies:

\section{OBJECTIVE 1.14 Encourage utilization of Transportation Demand Management (TDM).}

POLICY 1.14.1 The MPO will encourage local jurisdictions to develop multimodal plans, services, and programs that decrease reliance on the single occupant vehicle as the dominant means of travel.

POLICY 1.14.2 The MPO 2030 LRTP will identify methods citizens can use to commute to work and decrease overall traffic demand on the transportation system. These methods may include transit ridership, telecommuting, flexible work schedules, carpooling, vanpooling, walking, and bicycling.

It is important for TDM professionals to point out to transportation planners and policy makers that while TDM has traditionally been applied to commuter travel, commute trips only constitute 20 percent of all travel. TDM can be applied to a variety of trip purposes and land development settings. FHWA comprehensively identifies the range of application settings for implementing TDM (32). 
These are not just employment sites targeting commute trips. As illustrated in Figure 2 in the introduction of this report, these application settings include schools, special events, recreation and tourism, corridor planning and construction mitigation, freight transport, airports and incidents and emergencies.

The Collier MPO Policy 1.14.1 limits the role of the MPO to providing encouragement to local governments to make their own efforts. Although in Policy 1.14.2, the MPO takes an active role to "identify methods citizens can use," the policy provides no further guidance regarding how to share those methods with citizens. On the other hand, the Pinellas County 2025 Long Range Transportation Plan Update provides more specific actions for the MPO. One of the objectives in the Pinellas County Plan is devoted to transportation demand management stating, "Reduce traffic congestion and positively impact air quality by decreasing the use of the single occupant vehicles (SOV) at peak hours" (33). This objective is supported by fourteen policies (Appendix C) outlining the MPO's intent to perform various support roles in the implementation of TDM measures throughout the County. Below are just a few of the policies from this Plan:

1.7.1. Policy: The MPO shall work with local governments, transportation demand management (TDM) agencies and FDOT to develop vehicle trip (VT) reduction and vehicle miles of travel (VMT) reduction goals.

1.7.2. Policy: The MPO shall assist and support the efforts of Bay Area Commuter Services (BACS) to implement and achieve the goals of its Long Range Transportation Demand Management Plan and to carry out recommended actions derived from related studies.

1.7.3. Policy: The MPO shall assist and encourage the efforts of local TDM agencies by providing technical and funding support for promotion of alternatives to SOV travel, including carpool, vanpool, transit, walking, bicycling, telecommuting and variable work schedules.

1.7.4. Policy: The MPO shall continue to participate in events and other activities sponsored by local transportation-related agencies that support and facilitate the use of alternatives to driving alone by commuters and other travelers (e.g., Commuter Choices Week, B-BOPP, Tampa Bay Commuter, etc.).

In these and the remainder of the policies devoted to TDM, the Pinellas County MPO stresses action in terms of "work with, assist, encourage, participate, and provide technical and funding support." Policy 1.7.1 states that vehicle trip (VT) and vehicle miles of travel (VMT) reduction goals will be the result of collaboration between the MPO, local governments, TDM agencies and the FDOT. Further, Policy 1.7.3 specifies that the MPO will provide technical and funding support to local TDM agencies.

As evidenced in the Collier and Pinellas County MPO plans, most TDM-related policies affirm the MPOs intent to influence or encourage local governments and other agencies to implement the measures because, in reality, each MPO guides transportation funding not land development or program implementation. MPOs also have the capacity to provide technical support for transportation planning where local agencies lack the necessary expertise. The goals, objectives and policies adopted by each MPO serve as a valuable tool for local governments to build on as they develop their comprehensive plans. 
Each MPO adopts GOPs to serve as guidance in developing alternatives and, ultimately, expenditures for the adopted plan. The MPO solidifies its intent for the transportation system through its funding or investment choices. Whereas TDM is often mentioned within the goals, objectives and policies of each MPO, there is seldom any funding attached to TDM programs. An example of an MPO that has included specific TDM funding in their plan is the Hillsborough County MPO. The Adopted 2025 Long Range Transportation Plan was guided by a number of Goals, Principles, and Objectives or GPOs (rather than goals, objectives, and policies), several of which either specifically include transportation demand management or refer to it. Below are the various objectives referring to TDM along with the accompanying goals and principles:

\section{Goal I: Vitality of the Tampa Bay Region}

Principle 1.1 Relieve Traffic Congestion and Minimize Travel Time

- Foster strategies that reduce the growth in peak hour vehicle travel (i.e., carpooling, telecommuting, bicycling, etc.).

Principle 1.4 Encourage Private-Sector Transportation Investments

- Encourage private-sector participation in providing the design, right-of-way, and construction of transportation improvements.

- Consider, where feasible, incentives for private sector participation in the development of transit stations, intermodal terminals, toll roads, and transportation demand management programs.

Goal II: Promote Accessibility \& Mobility Options Available to People or Freight, and Enhance the Integration and Connectivity of the Transportation System

Principle 2.2 Decrease Reliance on Single-Occupancy Vehicles.

- Increase the percentage of persons using alternative modes, especially during peak hours.

Goal IV: Preserve Existing Facilities and Promote Efficient System Management and Operations

Principle 4.4 Emphasize the Use of Existing Transportation Systems to Avoid Unnecessary Capacity Improvements.

- Promote policies that maximize the use of the existing transportation system and explore opportunities for connectivity before building new facilities (i.e., restriping for bicycle lanes, new technologies, access management, and transportation demand management).

- Encourage local governments and private entities to implement transportation demand management techniques in order to reduce demand and provide commuter benefits.

Although the GOPs refer to transportation demand management, the Plan text uses the term travel demand management rather than transportation demand management and describes it as follows:

Travel Demand Management (TDM) comprises an array of strategies to address peak-hour congestion through reducing demand for road-space. In general, TDM strategies encourage 
travelers, especially commuters, to make their trip via some method other than driving alone (bus, carpool, vanpool, bike, walk); or not to make the trip at all (telecommute); or to shift their travel time to off-peak hours (compressed work week and flex-time programs).

The Plan lists the agencies within Hillsborough County (the MPO's jurisdiction) that implement TDM programs. Each agency works with “...employers to encourage their voluntary adoption and support of TDM programs, such as carpool incentives and telecommuting.” The Plan suggests a program that "would make employer TDM programs available to at least 50,000 workers in Hillsborough County." In order to accomplish this goal, it is envisioned that the various TDM agencies would approach those businesses employing a minimum of 500, 250, and 50 employees, respectively. Of the trip reduction facilities and incentives discussed for this program, one includes a, “... government-funded match for employer subsidies of employees' transit fares.” An example of this incentive could involve the purchase of a transit pass by an employee for 50 percent of the normal fare. The remaining 50 percent would be split by the employer and the MPO match program.

Not only does the Hillsborough County MPO include TDM in its Goals, Principles, and Objectives, as well as a discussion in the text of the document, it establishes funding for the program beginning in 2010. Using revenue from the Transportation Management Area funds (also known as federal urban allocation funds and available to MPOs with an urbanized area population over 200,000), the funding total for the TDM program's first five years is $\$ 12,966,712$ of the $\$ 126,781,006$ available; for the fifteen-year period from 2010 to 2025 it reaches a total of \$35,411,232 of the \$310,568,927 available. Details of the funding allocated in the MPO's LRTP are presented in Table 2 of this report.

The Hillsborough County MPO has chosen to support transportation demand management through appropriate funding, and to establish a program goal of making TDM programs available to 50,000 employees throughout the County. Other Goals, Principles, and Objectives in the Plan address increasing transit service and availability as well as site plan, subdivision design, and land development patterns that encourage livable communities and discourage single-occupancy vehicle travel. While this type of language is contained in each MPO's long range transportation plan, subsequent funding of programs that support the language is key to reaching specific TDM goals.

Detailed alternatives analysis, as performed by Broward County, emphasizes the trade-off between modes and enables transportation decision-makers to reach informed decisions regarding the transportation system. More up-front work is required in order to perform this type of alternatives analysis, but can result in decisions leading to a functional multimodal transportation system later. Although many MPOs include transportation demand management provisions in their GOPs, most alternatives analysis still focuses on serving private motor vehicles. While limiting, this emphasis is not necessarily incompatible with TDM if strategies of influencing travel behavior by time of day, day of week, trip frequency, route and cost are used.

Table 2. Transportation Demand Management Projects

TDM PROJECTS

Telecommuter/Compressed Work Week

Employer Outreach Program

Vanpool Program

Publicity
JURISDICTION

BACS

BACS

TMOs

BACS

BACS
INTERIM PLAN

$\$ 2,578,878$

$\$ 4,605,180$

$\$ 1,451,502$

$\$ \$ 1,831,152$
LONG RANGE

$\$ 4,298,130$

$\$ 7,675,300$

$\$ 2,419,170$

$\$ 3,051,920$
TOTAL

$\$ 6,877,008$

$\$ 12,280,480$

$\$ 3,870,672$

$\$ 4,883,072$ 


\begin{tabular}{|c|c|c|c|c|}
\hline Transit/Vanpool Fare Incentives & $\begin{array}{l}\text { BACS } \\
\text { HART }\end{array}$ & $\$ 2.500 .000$ & $\$ 5.000 .000$ & $\$ 7,500,000$ \\
\hline TOTAI & & $\$ 12966712$ & $\$ 22444520$ & $\$ 35411232$ \\
\hline
\end{tabular}

Local Government Comprehensive Plans (LGCP) Both authorized and required by the Local Government Comprehensive Planning and Land Development Regulation Act, Chapter 163.3161, F.S., local governments in Florida prepare comprehensive plans to address land use, transportation, housing and environmental resources, along with other required plan elements. Local government comprehensive plans (LGCP) establish the policy direction of a jurisdiction's land development regulations. Local governments across the state have prepared and implemented long range comprehensive plans with varying degrees of success in managing growth. Limited success in managing growth is evident through several factors, including increases in traffic congestion and decreases in accessibility and mobility.

As with the MPO long range transportation plans, most goals, objectives, and policies of local government comprehensive plans, incorporate a variety of multimodal alternatives, site plan and subdivision design guidelines, and land development patterns that encourage livable communities while discouraging single-occupancy vehicle travel. Although it is important that the LGCP strongly and clearly provide the policy foundation for incorporating TDM strategies into the land development process, most LGCPs in Florida only encourage the practice.

Due in part to traffic concerns over recent years, people across the nation have had an increased interest in sustainable communities concepts such as establishing urban growth boundaries, directing land development inward, revitalizing downtowns and creating livable communities. This interest is often reflected in the use the local government comprehensive planning process and corresponding land development code to implement these concepts. Local government comprehensive plan examples discussed here are from the City of Orlando, the City of Jacksonville, and Broward County.

City of Orlando. The City of Orlando relies on METROPLAN ORLANDO (Orlando's Metropolitan Planning Organization) and LYNX (the Central Florida Regional Transportation Authority) to organize and implement TDM programs in the city. Objective 4.2 and Policies 4.2.1 through 4.2.6 of the Orlando Growth Management Plan below address TDM by encouraging METROPLAN Orlando and LYNX to take various actions regarding transportation demand management, obligating the City only to participate.

Objective 4.2 The City shall annually coordinate with METROPLAN ORLANDO and the Central Florida Regional Transportation Authority (dba LYNX) to undertake efforts to promote Transportation Demand Management programs focusing on the region's major activity centers.

Policy 4.2.1 The City shall support and will participate in activities of Metroplan Orlando and the Central Florida Regional Transportation Authority (dba LYNX) to promote Transportation Demand Management programs in the region.

Policy 4.2.2 The City shall encourage METROPLAN ORLANDO and the Central Florida Regional Transportation Authority (dba LYNX) to undertake efforts to increase regional awareness on the importance of Transportation Demand Management programs in addressing traffic congestion, environmental protection, and energy conservation. 
Policy 4.2.3 The City shall encourage METROPLAN ORLANDO and the Central Florida Regional Transportation Authority ( $d b a$ LYNX) to develop incentives for employers to implement Transportation Demand Management (TDM) programs. The TDM programs may include, but not be limited to, ridesharing, flexible work hours, telecommuting, preferential parking, bicycle parking, and transit subsidies.

Policy 4.2.4 The City shall encourage METROPLAN ORLANDO and the Central Florida Regional Transportation Authority (dba LYNX) to develop thresholds at which various Transportation Demand Management measures could be required by local governments.

Policy 4.2.5 The City shall encourage METROPLAN ORLANDO and the Central Florida Regional Transportation Authority ( $d b a$ LYNX) to conduct transportation surveys to assess changes in alternative transportation modes use.

Policy 4.2.6 All projects that are located outside metropolitan activity centers, and that will include a concentration of more than 500 employees, shall coordinate with METROPLAN ORLANDO and the Central Florida Regional Transportation Authority.

City of Jacksonville. In an effort to increase bicycle and pedestrian travel, the City of Jacksonville's 2010 Comprehensive Plan directs the City to support the development of pedestrian accommodations and bikeways throughout planning and land development and to "actively encourage" citizens to use those facilities. The Plan also establishes a Transportation Management Area (TMA) in the area of State Road 9A at J. Turner Butler Boulevard and Baymeadows Road (Objective 1.3). Policy 1.3.11 specifically requires a TDM plan:

Any non-residential development proposed within the TMA which will employ more than one hundred (100) persons shall submit to the City, prior to the issuance of final development agreements or permits, a plan for the use of Transportation Demand Management (TDM) strategies and incentives. Such strategies may include participation in the Jacksonville Transportation Authority's (JTA) Suburban Mobility Management Program, participation in a Transportation Management Organization (TMO) and other strategies recommended in the MPO's Congestion/Mobility Management Plan for the Jacksonville Urbanized Area and the MPO's Commuter Assistance Program. Any such development shall implement its TDM plan, as submitted to the City. All non-residential development within the TMA shall participate in the MPO's Commuter Assistance Program.

According to the City's current planning staff, there is no actual process to implement this provision. When the City does ask developers to include transit or TDM in transportation for their development, many reasons are offered as to why such measures simply "won't work." The City does coordinate with the First Coast MPO who administers the Metropolitan Commuter Assistance Program (MCAP) through funding from the Florida Department of Transportation.

Broward County. Most proactive in its inclusion of TDM strategies is the Broward County Comprehensive Plan (BCCP). Its policies are measurable. When this is the case, plan policies can be evaluated regarding whether or not they have been met. The BCCP contains the following policy:

Broward County shall provide for an energy efficient roadway network through implementation of, but not limited to, the following programs, activities, or actions:

o Through participation in the MPO, increase the vehicle occupancy rate from 1.37 to 1.43 persons per vehicle through transportation demand management (TDM) strategies, such as ridesharing programs, preferred parking, and high occupancy vehicle lanes. 
o Through participation in the MPO, work to reduce the per capita vehicle miles traveled (VMT) below the year 2002 projected daily per capita VMT of 19.42 by implementing TDM strategies.

o Through its membership on the MPO, maintain and, where feasible, expand the number of ride-sharing lots in Broward County.

In its 2004 Evaluation and Appraisal Report, Broward County noted that it "has increased the vehicle occupancy rate per vehicle through transportation demand management (TDM) strategies, such as ride-sharing programs, preferred parking, and high occupancy vehicle lanes.” Broward County has begun both carpool and vanpool programs and provided funding for transit shuttles in support of these policies. The number of park and ride lots has increased from 5 lots to 23 lots. The actions taken by Broward County illustrate that stating clear, measurable goals within its Plan policies along with appropriate funding leads to successful implementation. Performance measurement enables an effective TDM program to continue to win funding and support.

It is important to select program measures with care. Performance measures will dictate what actions are taken and may de-emphasize some actions that would otherwise be highly effective in achieving the goal. For example, Broward County's goal is to provide for an energy efficient roadway network and measures this using a vehicle occupancy rate. This performance measure places program emphasis upon ridesharing and transit use but loses the effects of bicycling, walking and telework. An example as illustrated by Burch (1994) is the widespread use of average vehicle ridership (AVR), which is a measure of the number of persons per vehicle used to commute to a work site. The preferred goal is to reduce vehicle trips rather than increasing passengers per vehicle. Therefore, vehicle trips are the variable that should be represented as the numerator in a ratio of vehicles to persons. As a vehicle employee ratio (VER), this encompasses all modes of transportation, including the contribution of bicycling and walking. (34)

While some local government comprehensive plans attempt to include provisions for multimodal transportation and transportation demand management, often other provisions of the plans maintain the status quo by protecting the roadway system from encroachment. For example, the City of Tampa Transportation Element of its Comprehensive Plan includes Objective 2.1 to implement programs to protect existing and future rights of way from building encroachment. The City requires, through its development review process, that development follow special street setback requirements as established in Chapter 27-99 Zoning, of the Code of Ordinance.

Small Area Plans (SAP) Although local government comprehensive plans provide guidance for entire jurisdictions, local governments are increasingly developing sub-area, small area, sector, or selected area plans to respond to individual land use, transportation, and economic needs as well as resident desires in specific areas. They are generally developed with oversight of an advisory group that represents area stakeholders, and may focus on a particular neighborhood, commercial district, or high growth area. A multimodal transportation district is one type of small area plan. Each of these plans also may address TDM for the specific area. The following examples illustrate how transportation demand management can be addressed in a small area plan.

City of Orlando. The overall vision for Southeast Orlando, a future mixed-use community that at buildout could have as many as 50,000 residents, is outlined in the Southeast Orlando Sector Plan (35). The transportation section of this document describes a plan designed around transit use, bicycle use and pedestrians, with "cars . . . kept in perspective." This will be accomplished via land use patterns, densities and street layout. The Growth Management Policy Framework makes one specific reference to TDM: 
In order to develop public transit systems and services that encourage public transit ridership, increase personal mobility, conserve energy resources, preserve air quality, and foster economic growth within the Southeast Orlando Sector Plan area, projects that will include a concentration of more than 500 employees shall coordinate with METROPLAN ORLANDO and the Central Florida Regional Transportation Authority to implement Transportation Demand Management programs.

Northeast Polk County's Ronald Reagan Parkway Selected Area Plan includes a specific TDM strategy in its vision for the area:

Live-Work Residential. It is anticipated that the percentage of commuter residents in this area will increase. The proliferation of long-term residents is vital to the sustainability and stability of the area, specifically the economy and property values. Therefore, it is imperative that greater accommodation be made for residents who choose to conduct business at their residence to reduce their amount of commuting as well as bring more commerce to Polk County. It is envisioned that residential developments will designate more areas and design more residences to enable this land use activity. In addition, greater latitude should be given to isolated properties along collector roads to develop live-work units through minimized or expedited permitting (36).

\section{Multimodal Transportation District}

A multimodal transportation district is one type of small area plan that can be a useful tool for incorporating TDM strategies in the long range planning process. In 1999, the Florida legislature amended Chapter 163, Florida Statutes authorizing local governments to establish multimodal transportation districts. The purpose of the legislation was to provide a planning tool that Florida communities could use to systematically reinforce across a defined area, those community design elements that support walking, bicycling and transit use. It also enabled Florida communities to advance transportation concurrency-a policy requirement that transportation facilities be available concurrent with the impacts of development-through development of a high quality multimodal environment, rather than the typical approach involving road widening for automobile capacity.

A multimodal transportation district is an area where primary priority is placed on "assuring a safe, comfortable, and attractive pedestrian environment, with convenient interconnection to transit" (Chapter 163.3180(15)(a)F.S.). Communities must incorporate community design features that reduce vehicular usage while supporting an integrated multimodal transportation system. Common elements include the presence of mixed-use activity centers, connectivity of streets and land uses, transit-friendly design features, and accessibility to alternative modes of transportation.

Multimodal transportation districts (MMTDs) are to be carried out through local comprehensive plans, land development regulations, and capital improvements programs. The National Center for Transit Research (NCTR) at the Center for Urban Transportation Research (CUTR) prepared a report entitled, Model Regulations and Plan Amendments for Multimodal Transportation Districts that contains model land development regulations and comprehensive plan amendments that local governments in Florida can use and adapt to promote multimodal transportation systems and development patterns. The report begins with an overview of the purpose and statutory requirements for multimodal transportation districts in Florida, and continues with model comprehensive plan amendments and land development regulations to assist local governments in implementing MMTDs. 
MMTD designation is accomplished by amending a local government comprehensive plan and accompanying future land use map, as provided in Chapter 163.3184, F.S. A proposed multimodal transportation district must be reviewed and approved by both the Department of Community Affairs (DCA) and the Florida Department of Transportation (FDOT). Local governments must demonstrate that an area qualifies as an MMTD based upon the following existing or planned future design elements defined in Chapter 163.3180(15)(b), F.S.:

- A complementary mix and range of land uses;

- An interconnected network of streets to encourage walking and bicycling, with traffic calming where desirable;

- Appropriate densities and intensities of use within walking distance of transit stops;

- Daily activities within walking distance of residences, allowing independence to persons who do not drive;

- Public uses, streets, and squares that are safe, comfortable, and attractive for the pedestrian, with adjoining buildings open to the street and with parking not interfering with pedestrian, transit, automobile, and truck travel modes.

Local governments may be interested in establishing a MMTD because transportation concurrency is not primarily based upon motor vehicle level of service but by demonstrating an adequate level of mobility based upon professionally accepted multimodal LOS methodologies. Within a MMTD, local governments may also choose to reduce impact fees or local access fees imposed on land development based upon the reduction of vehicle trips or vehicle miles traveled expected based upon the development pattern planned for the district. 


\section{Land Development Regulations}

Many local governments are doing just that. Florida law requires each local government to develop land development regulations that facilitate their individual long range comprehensive plans. Land development regulations include a wide range of regulations including adequate public facilities or concurrency ordinances, impact fee ordinances, zoning and subdivision regulations and other requirements for the development of land within the governing jurisdiction.

\author{
"What is being built today is \\ very much the product of the \\ limits and instructions \\ written into codes. If we \\ don't like what is happening, \\ we need to adjust the \\ regulations" Jonathan \\ Barnett (37).
}

Impact Fee Ordinances. An impact fee ordinance provides another opportunity in the land development process to encourage developers to incorporate transportation demand management strategies. Impact fees have been defined as "a monetary charge imposed by local government on new development to recoup or offset a proportionate share of public capital costs required to accommodate such development with necessary public facilities” (38). Florida state law explicitly encourages local governments to enact land development regulations, including impact fees, to manage growth. Impact fee programs may be either demand driven (most prevalent), facility driven (less prevalent), or a combination of the two approaches (least prevalent) (39). Demand-driven approaches translate new auto trips into cost-per-trip based on the cost to improve a mile of roadway. Facility-based approaches arrive at a fee by taking the road improvement budget in the capital improvements program and dividing it by the trip generation rate for a proposed land use.

Most jurisdictions provide some form of credit, also known as an "offset," for developer-initiated improvements or in-kind contributions. The Model Impact Fee Authorization Statute defines offsets as "the amount by which impact fees should be reduced to fairly reflect the value of land dedications or other physical improvements provided by a developer pursuant to any local requirements. Such offsets shall apply only to external or off-site improvements or dedications" (40). These offsets, known as impact fee waivers, reductions or exemptions, provide for a full or partial exemption from impact fees to accomplish specific planning objectives. A certain percentage discount is sometimes offered as part of the impact fee formula or in the impact fee ordinance, reducing the amount of the assessment by a given percentage. Because many TDM strategies are programmatic and on-site in nature, impact fees and the use of offsets have had limited application. However, several municipalities have applied them toward physical improvements to encourage alternative transportation and traditional neighborhood development as described in the examples below.

Orlando, Florida. The City of Orlando adopted an impact fee formula in the late 1990s that includes a schedule based on vehicle miles of travel (VMT) indicators (for various development units) (41). Rates vary according to geographic location and nature of development (e.g. lower or higher trip intensity patterns). For example, downtown and traditional city rates are comparatively lower than those in the "other city" area, because of the intensive land use mix and higher use of alternative modes in those areas.

The VMT indicator is used to adjust impact fee rates for compact developments that have lesser impacts on the road network. If the VMT indicator calculated for a specific traffic zone or zones is lower than the previously determined regional VMT indicator, the impact fees are adjusted accordingly. Under this approach, residential developments in the downtown area could receive as much as a $38 \%$ discount in road impact fees when compared to the previous formula. 
Following the adoption of the new impact fee schedule, the City of Orlando Transportation Planning Bureau engaged in a special study to determine the transportation benefits of the traditional neighborhood development (TND) for walking and bicycling. The purpose of the study was to determine whether and by how much to reduce the transportation impact fee for the Southeast Sector Plan, which also incorporated TND requirements and called for higher accessibility as measured by a connectivity index (42). The study involved a survey of bicycle-friendly cities including Portland, Seattle, Vancouver, Davis, and Boulder to identify their bicycle/pedestrian mode split by trip purpose. The survey results showed an average 30\% bicycle/pedestrian trip share for work, schools, shopping and recreational activities in these cities.

The report recommended a revision in the Trip Generation Factor (TGF) (which addresses mode split where vehicle lane miles of travel decrease and alternative mode trips increase) in the traffic impact fee (TIF) formula from 1 to 0.7 for TND development-a 30\% reduction. The report acknowledged that "due to insufficient evidence supporting whether connectivity will translate into increased mode splits across all land uses, the reduction is proposed to apply only to those uses most closely associated with opportunities for non-automotive trips." This included the land uses in the Southeast Sector Plan that comply with TND and network connectivity criteria.

Under the Southeast Sector Plan requirements, any applicant that adds links to the bicycle/pedestrian network from the development to the surrounding network, such that the connectivity index is 1.4 or greater, receives a 30\% reduction in impact fees. These connections can be in the form of bicycle/pedestrian paths, sidewalks and streets. Staff notes that larger developments are those that typically benefit from the reduction, although some smaller, stand-alone sites could benefit depending upon their contributions.

Estimating trip generation for proposed new development is a challenge in the design and application of impact fees or any other fee or regulation that relies upon trip generation. Actual trip generation can vary widely for similar land uses; however, due to lack of resources to conduct their own studies, local governments commonly rely upon the use of trip generation estimates from the Institute of Transportation Engineers. Shoup points out this precarious use of ITE trip rates for transportation planning and design purposes despite cautions provided by ITE for their appropriate application. For example, ITE describes the trip rates for land uses as estimated from observations generated at selected developments, primarily from suburban localities with little or no transit service, nearby pedestrian amenities, or travel demand management programs. There is strong evidence to suggest that most selected sites offer free parking. Half the rates are based on five or fewer studies per land use. At most sites, vehicle trips are observed during the course of one day only. Shoup also points out that many factors influence the number of vehicle trips generated at a site, and we should not expect floor area, acreage or any other single variable to accurately predict the number of vehicle trips at any site or land use. Transportation planning decisions have contributed to the design for a car-oriented system because of the systematic misapplication of ITE trip rates by local governments over the years. The ITE trip rates represent land development patterns that provide no other choice besides private automobile driving and therefore demonstrate no use of alternative transportation. The lack of use of transportation alternatives is misinterpreted as a lack of need for transportation alternatives. Reinforcing this outcome is also the misapplication of ITE parking generation rates that are likewise generated from locations that offer no transit service and which result in overestimates of needed parking (43).

Due to the above observations, it is evident that impact fees can be used to encourage the use of transportation demand management strategies, but planners must be aware of how the methodology for determining the fee may inadvertently reinforce an outcome that reflects the status quo rather than helping to shape a more balanced supply of physical transportation facilities and their use. 
City of Loveland, Colorado. The City of Loveland Colorado enacted a credit for mixed-use development in November 2001. The program offers a 25\% reduction in the road impact fee to encourage mixed-use development. The ordinance provides rationale and eligibility criteria for the reduction. However, city staff has not had much experience with administering the credit for the mixed-use development. To date, the credit has been provided at two locations-both relatively large developments (approximately 70 acres). Staff indicated that the mixed use credit program may be disbanded. One reason is that Loveland is currently a small town that is developing in a low-density suburban fashion and many developments are not designed in a pedestrian-oriented fashion. Another constraint is that the credit works for large developments, but is not applicable to small single-use developments under separate ownership that together achieve comparable results, such as where a multi-family development is built next to a commercial development with adequate connectivity. According to staff, this has raised fairness concerns.

Palo Alto, California. One example of the use of transportation impact fee credits to entice developers to incorporate TDM strategies in their developments is in Palo Alto, California. In an effort to reduce new vehicle trips, the City of Palo Alto is implementing a strategy to provide effective alternatives to automobile travel. The transportation impact fee (TIF) expenditure plan includes citywide transportation demand management, expanded shuttle service, bicycle facilities, and computerized traffic management (44). Using an improvements-driven approach, the recommended transportation impact fee is "based on charging new development for $7.6 \%$ of the cost of the expenditure plan (which) represents the proportion of 2025 vehicle trips that is expected to be generated by development subject to the TIF."

The impact fees are based on p.m. peak hour trip generation (ITE or Santa Clara County Valley Transportation Authority (VTA) sources). Credits are not given for transportation improvements required before the imposition of the fee (such as for intersections). Trip reduction credits are allowed for mixed-use development, locations close to transit, and effective TDM programs. The following table indicates the maximum potential trip reductions generally allowed for by VTA. 
Table 3: Maximum Trip Reduction Credits

\begin{tabular}{|l|c|}
\multicolumn{1}{|c|}{ Trip Reduction Strategy } & $\begin{array}{c}\text { Maximum Trip } \\
\text { Reduction }\end{array}$ \\
\hline Mixed-Use Development Project & $13 \%$ \\
\hline With housing and retail components & $10 \%$ \\
\hline With hotel and retail components & $3 \%$ \\
\hline With housing and employment & $3 \%$ \\
\hline With employment and employee-serving retail & \\
\hline Location Within 2,000-Foot Walk of Transit Facility & $9 \%$ \\
\hline Housing near LRT or Caltrain Station & $2 \%$ \\
\hline Housing near a Major Bus Stop ${ }^{2}$ & $3 \%$ \\
\hline Employment Near LRT or Caltrain Station & $2 \%$ \\
\hline Employment near a Major Bus Stop & \\
\hline Effective TDM Program & $5 \%$ \\
\hline Financial Incentives & \\
\hline Shuttle Program ${ }^{3}$ & \\
\hline -Project-funded dedicated shuttle & $3 \%$ \\
\hline -Partially-funded multi-site shuttle & $2 \%$ \\
\hline
\end{tabular}

${ }^{1}$ For mixed-use projects, the percentage is off of the smaller trip-generator with the same number of trips reduced for the smaller generator applied to the larger generator.

${ }^{2}$ Major bus stop defined as a stop at which six or more buses per hour from the same or different routes stop during the peak period.

If the shuttle trip reduction is being combined with the 'Employment near LRT or Caltrain Station' reduction, the maximum shuttle trip reduction that can be taken is $1.5 \%$

Clark County, Washington. Another effort to incorporate TDM in the land development process through impact fees is found in Clark County, Washington. Clark County adopted an ordinance that provided an impact fee reduction as an incentive to making specific improvements in order to achieve desired densities within transit supportive and mixed use development. However, discussions with Clark County staff reveal that this approach was never implemented (no developers attempted to use the provisions) and was later repealed due to problems with other areas of the ordinance. Initial actions eligible for credit included a $1 \%$ credit for "designation of ten percent of all non-residential parking as carpool/vanpool parking facilities if located in a manner maximizing accessibility subject to ADA requirements," a 3\% credit for "installation of parking spaces which will become paid parking (by resident or employee)," and a 1\% credit for "installation of preferential carpool/vanpool parking facilities.” The complete tables of incentives are provided in Appendix E.

A new credits table within a proposed mixed used zone is currently under review in support of a provision in the recently adopted comprehensive plan, zoning map and development regulations (see Table 4). The amount of credit available is simply to create a developer incentive rather than being the result of specific analysis. The Clark County model provides several specific actions, such as the installation of bus-stops or bike lockers, and the corresponding impact fee credits that could be incorporated into local impact fee ordinances. 
Table 4. Proposed Traffic Impact Fee (TIF) Credits for Mixed Use Zone

\begin{tabular}{ll}
\hline ACTION & $\begin{array}{c}\text { MAXIMUM TIF } \\
\text { CREDIT }\end{array}$ \\
\hline Installation of on-site sheltered bus-stop (with current or planned service) or bus stop & $1 \%$ credit to cover \\
within $1 / 4$ mile of site with adequate walkways of approved by C-TRAN & up to $80 \%$ of cost \\
Installation of bike lockers & up to $80 \%$ of cost \\
Connection to existing or future regional bike trail & $1 \%$ \\
Installation of paid parking (by resident or employee) & $3 \%$ credit to cover \\
& up to $80 \%$ of cost \\
Provision of Flex Car for project & $1 \%$ credit to cover \\
Total if all strategies were implemented & up to $80 \%$ of cost
\end{tabular}

Atlanta, Georgia. The City of Atlanta provides for a 50\% reduction in transportation impact fees for projects within $1000 \mathrm{ft}$. walking distance of a MARTA rail station or bus stop (measured by walking path or sidewalk). This amount is a partial exemption rather than a credit and was designed as an incentive rather than based on analysis. Full exemptions are provided for "Empowerment Zones" and "Linkage Communities"-federal designations for economic development of low-income areas-as well as for projects that provide affordable housing (50\% to $100 \%$ credit depending on whether it's ADA accessible). In addition, the City may designate a development that creates numerous jobs as an economic development project and provide a waiver for this as well, if it meets certain criteria regarding the number of employees hired from within the neighborhood or City.

These exemptions are subject to a requirement that the City make up the difference in lost transportation impact fees through the capital improvement program somewhere in the City (Note: they do not divide the City into zones for transportation impact fee administration; it is citywide). The exception to this requirement is the $50 \%$ credit for MARTA area development. Because the $50 \%$ credit for MARTA area development is an incentive for transit-oriented development (considered economic development) around transit areas, the City does not reimburse this credit through the CIP. The rationale, as explained by staff, is that the added development will increase property tax revenues for the City, offsetting the loss of impact fee revenues.

Concurrency Ordinances. Also known as adequate public facilities ordinances, these regulations require that public facilities be available to meet the needs of new development at the same time the development is occupied. Florida defines its own concurrency requirements in F.S. 163. 3180.

Rockville, Maryland. The City of Rockville, Maryland is moving away from mitigation measures related primarily to providing additional roadway capacity through physical improvements and is encouraging mitigation for alternative modes (e.g. ridesharing programs, shuttles to transit stations, installation of pedestrian and bicycle facilities, etc.). Rockville applicants for developments may be obligated to contribute toward the improvement of offsite transportation and safety facilities to help address identified safety hazards for all modes. As stated in the City Transportation Plan,

Providing safe, direct pedestrian routes between residential areas and activity centers can help reduce the number of day-to-day vehicle trips. These connections can be created or improved by installing sidewalks, adding paths to link cul-de-sacs and dead end streets, installing pedestrian signals and crosswalks, or by constructing pedestrian bridges over busy roadways. Treatments, such as lighting, landscaped buffer areas and other streetscape improvements, can heighten safety and make pedestrian facilities more attractive for users. 
The City enacted a Comprehensive Transportation Review Methodology (CTR) in September 2004 to evaluate the impacts of new development on the transportation system and to determine mitigation for alternative modes and assign corresponding "trip" credits. Because they are deemed to have a measurable traffic impact under the methodology, developments that generate 30 or more total peak hour site trips must conduct an off-site analysis for all transportation modes.

The off-site analysis includes an assessment of major intersections that are impacted by the development as well as non-auto facilities, including sidewalks, bikeways, and transit systems that lead to the development. The goal of the off-site analysis is to "ensure that the site can be accessed safely and efficiently through various modes and that adequate transportation facilities are in place to support the subject development without detriment to the overall transportation system." Upon completion of the required multimodal analysis, applicants must summarize all issues and impacts related to site access and circulation, automobile traffic, non-auto facilities and intersection safety as well as planned mitigating actions.

Applicants are encouraged to mitigate transportation impacts by providing non-auto improvements and modifications to the transportation system for which they receive trip credits. Applicants may receive a maximum 15\% trip credit for implementation of a TDM program and participation in the City’s TDM Program.

The CTR Methodology was developed as a precursor to adoption of a new adequate public facilities ordinance, which is expected in 2005. Staff indicated that the program is so new, there has not been experience with it for comment. The trip credit amounts were developed based on a review of what other communities were doing (e.g. Orlando, Portland, Montgomery County), as well as based on observations and experiences with multimodal development and mode split in the past. Staff plan to initiate a project this year to monitor outcomes through surveys and other methods, so they can determine how well the program is working and the appropriateness of the trip credits.

Although the program offers credits for participating in the City's TDM program, staff note that "it's tough to create a standard credit value for TDM because the developments are all so different and in different areas of the City." Therefore, the credits are highly subjective and determined on a case by case basis based on the feasibility of potential trip reduction in the given context. See Appendix F for a full discussion of Rockville’s CTR Methodology.

Transit Oriented Concurrency. In 2005, the county commission of Broward County, Florida, amended the county's land development code to provide for a transit-oriented concurrency system. These changes led to the creation of transit-oriented concurrency districts, defined as "compact geographical area[s] with an existing network of roads where multiple, viable alternative travel paths or modes are available for common trips." This contrasts with the county's standard concurrency districts, where roadway improvements are to remain the focal point of transportation enhancement efforts (45).

Because these definitions are open to interpretation, the county commission included specific locations for both types of concurrency districts within the text of the amendments.

The transit-oriented concurrency system begins with Transportation Concurrency Satisfaction Certificates (TCSC), which are required for issuance of a building permit from any local government within the county (with exceptions for types of development that will not generate any additional transportation impacts). For most areas of the county, including standard concurrency districts, the process of earning a TCSC is straightforward enough-usually a simple determination of adequacy, as defined by the land development code (45). 
Within transit-oriented concurrency districts, however, Broward County has outlined specific circumstances under which a TCSC will be issued. They include (but are not limited to):

- Projects located on land platted between March 1979 and the effective date of the ordinance, provided the planned development is consistent with current zoning approvals;

- Projects located on property where the county has made a vested rights finding with regard to transportation concurrency, provided the planned development is consistent with current zoning approvals;

- Projects taking place as the result of an approved DRI or FQD development order issued prior to the adoption of the Broward County Comprehensive Plan in 1989;

- Projects that will not increase the number of dwelling units, the type of unit, or will not cause an increase in the number of peak trips generated; and

- Developments that will promote public transportation.

However, if a proposed development within a transit-oriented concurrency district does not meet any of these criteria for obtaining a TCSC, the developer can simply pay to the county a Transit Concurrency Assessment (45).

Property owners wishing to develop land within transit-oriented concurrency districts can earn credits for transit-oriented development: “A property owner may apply for credit against the County's Transit Concurrency Assessment by demonstrating that a proposed development satisfies all the criteria for a specific level of credit.” Credit level definitions and the degree of credit earned for each level are described in exhibits within the text of Broward County Resolution 2005-291, included as an attachment to this document. The amount of credit potentially available to the developer increases with each level, as do the layers of approval required (46).

Level 1 credit applications can be determined during the Development Management Division's building permit review, and require no additional application forms. Level 2 credit also requires a review of a current approved site plan, and levels 3 and 4 require not only a site plan review but an agreement between the county, municipality and developer. This agreement is intended to "ensure the implementation of all required criteria, to provide for enforcement mechanisms . . . to specify the degree of credit granted, and to specify the property which would benefit by the grant of the credit" (46).

Additionally, under certain circumstances, a developer may opt not to pay some or all of the Transit Concurrency Assessment, and may instead implement or participate in the implementation of an alternative transit improvement. This alternative improvement must be intended to enhance transit ridership, and cannot focus predominantly on the occupants or users of the applicant's property. The alternative improvement must be determined to be beneficial to the regional transportation system within the relevant district (45). This approach would appear to resolve some of the site impact analysis methodology issues arising from Developments of Regional Impact, described in Appendix B.

Trip Reduction Ordinances. Trip reduction ordinances (TRO) are regulations enacted by local governments usually for the purpose of reducing the number of trips generated during the peak periods of traffic congestion. They are most commonly used in areas with severe air quality problems in an effort to reduce emissions. TROs usually target work sites employing over 100 employees and require the following: 
- work sites must conduct a yearly survey of trip making by employees during the a.m. peak period,

- employers must provide some combination of trip reduction incentives,

- employers must demonstrate a good faith effort to reduce trip making to the work site, and

- employees must reduce trip making by some percent over a designated period of time.

TROs often are considered by business groups to be draconian in nature; however, there are ways to formulate them for effectiveness and acceptance by those expected to implement them. There are over forty municipalities in the United States that have TROs. They are more often used on the West Coast in such places as Los Angeles and Irvine, California, the Puget Sound region of Washington State, and Tucson and Phoenix, Arizona, but can also be found in Alexandria, Virginia and Cambridge, Massachusetts.

TROs are the regulatory mechanism most adapted for use in the final stage of land development, in which property managers/owners and property tenants are required to carry out a specific plan developed for each work site as approved by the host local government. TROs are most often tied to a property manager and tenants because the relevant TDM measures are usually programmatic in nature rather than physical. A typical work site trip reduction program includes an employee transportation coordinator who is an employee assigned to promote the use of commute alternatives, administer trip making surveys, provide alternative transportation information, and serve as liaison between the work site and the host local government. Typical services offered by a participating work site include preferred parking for carpools and vanpools, free emergency guaranteed rides home, telework options, flex time or compressed work week schedules and subsidized bus passes.

The Parking and Transportation Demand Ordinance of Cambridge, Massachusetts is included as a case study in this report. Unlike other TROs, it is an example of the use of physical parking availability as a means to control traffic demand. In this way, the implementation stage is during the physical redevelopment of a site. Cambridge is also an example of a municipality that is essentially built out, but where redevelopment pressure is strong. As such, this example may be useful to Florida municipalities, such as Pinellas County, that are largely urbanized.

To date, the City of Boca Raton is the only Florida municipality that has passed a TRO, in response to conditions placed upon a citywide DRI. Detailed guidance was provided to the City by CUTR for the development of the ordinance. The conceptual framework for the development of an effective TRO centered upon 9 principles (47):

1. Take a long-term outlook

2. Foster public-private partnerships

3. Build in flexibility and choices

4. Allow voluntary participation

5. Seek continual improvement

6. Establish tiered levels of participation

7. Select performance measures carefully

8. Make it easy to administer

9. Coordinate with existing programs and services

To gauge effectiveness, it is important to implement a process for documenting baseline trip making conditions before the implementation of the TRO, and survey the results of program efforts after implementation. 


\section{Land Developer Engagement Through TMA Participation}

In cases where the land development process has been engaged to incorporate TDM strategies, a commonly employed condition that is sometimes required in trip reduction ordinances has been funding the start-up of a transportation management association (TMA) or requiring land developers or property managers to purchase memberships in an existing TMA. In some cases, this strategy has been misapplied where public-private interest in a TMA is weak; however, approximately 140 TMAs are currently in existence nationwide and many have land developer participation. TMAs have shown potential as a TDM strategy to organize business and community efforts toward common localized transportation goals. Based upon data collected by the 2003 Transportation Management Association Survey, TMAs nationally have provided a wealth of services to TMA members, to nonmembers and to the general public (48). Such services have included:

Employee Transportation Coordinator training

Rideshare matching

Telecommuting program assistance

Subsidized transit passes

Direct rideshare incentives

Shuttle/Local transit provision

Direct shuttle service operation

Guaranteed Ride Home

Vanpool subsidy program

Regional/Local advocacy

Site design assistance

Multilingual translated information

Active living program

Promotional events

Trip reduction plan preparation
Parking service provision

Parking pricing and/or management

Promotional materials/newsletters

Tax benefit program assistance

Carshare program

Bicycle program

Cycling Safety workshops

Walking program

Pedestrian amenity review

Visitor servicesRelocation assistance

Electric vehicle promotion

Construction/traffic advisories

Government reporting/compliance

Alternative fuel infrastructure development 


\section{Individual Site Plan Evaluation}

A review of sixteen municipalities in Florida indicates varying degrees of integration of TDM into long range comprehensive planning, municipal land development regulations, and in the development agreement process itself. For example, in Jacksonville, Florida, the commuter assistance program does not currently work directly with City staff in reviewing development proposals for potential use of TDM strategies. Some limited involvement in the process does occur through the MPO staff and the MPO Transportation Coordinating Committee (TCC) where the Metropolitan Commuter Assistance Program (MCAP) is a voting member. In the past, the commuter assistance program was part of Jacksonville's Transportation Division, and, therefore, was more directly involved. Now organizationally apart from it, efforts are underway to reestablish a coordinative process between the commuter assistance program and the Transportation Division.

Below is a summary of the major steps of the land development process. The City of Tampa, located in Hillsborough County, is used as a specific example throughout the discussion. All municipalities create their own processes; therefore, the details may be different from one locality to another, but most municipalities share the many issues raised and follow this general process. Suggestions for how TDM professionals can get involved in the process are interspersed in the process description.

\section{Where Municipal Plans, Policies, and Regulations Coincide with an Individual Development Proposal}

To understand the process of an individual land development proposal and opportunities presented by it, it is necessary to step back and briefly review the policy and regulatory context. The City of Tampa's major concerns for its transportation system include achieving and maintaining LOS standards, rights-of-way preservation, and access control on state-maintained roadways. These emphasis areas are explicitly stated as well as run as major themes throughout the policy language of the City's Comprehensive Plan and the Land Development Code. It is suggested that as TDM professionals consider how to engage in the land development process, a first step is to become thoroughly familiar with their local government's Comprehensive Plan and the land development regulations that are required to implement the Comprehensive Plan. The familiarization process results in an understanding of the major themes, concerns and goals for land development in the municipality and how transportation planning is intended to advance those goals.

This familiarization process will also demonstrate that while the Comprehensive Plan is the overriding document, it is frequently written in a style that leaves the Plan intent dependent on the interpretation of staff that administer the land development regulations. It is also possible and likely that, in a review of such Plan policies and the regulations that advance them, areas of inconsistency may be found. It may be found that regulations do not implement policies well or that no implementation mechanisms exist for advancing Plan policies. As with any kind of law, there is usually something lost in the translation between the spirit and intent of a policy and the regulations.

To be enforceable, adherence to regulations must be measurable and are often written in 'black and white” terms, such as quantitative standards, numerical thresholds and minimums, or as specific actions that must be taken. With that understanding, municipal land development codes are required to be reviewed by the zoning administrator on a periodic basis, and comprehensive plans undergo a continual process of evaluation and revision. TDM professionals should seek ways to get involved in these review processes because the plans, policies, and regulations are the litmus test against which every development proposal is reviewed. For example, because roadway LOS standards are the gatekeepers of transportation approvals for development, TDM professionals should become more active in the discussion about the application of multimodal LOS standards as part of the transportation approval process. Ideally, TDM professionals should generate support for the future 
development and application of a method to make tradeoffs across modes. Ultimately, this would change the definition of transportation LOS standards in the comprehensive plan to enable land development to proceed at the appropriate densities and qualities that support high quality transit service.

A concurrency management system is the set of procedures and processes that a local government uses to assure that development orders and permits are not issued unless the necessary facilities and services are available concurrent with the impacts of development. For the purpose of issuing development orders or permits, the City Land Development Coordination Division allows no less than a peak hour roadway Level of Service Standard D, as set forth in Chapter 17.5 of the City of Tampa Code, except for those road segments classified as backlogged, constrained or within a Transportation Concurrency Exception Area (TCEA). For any development proposal, TDM professionals should check to see if its location lies within a TCEA or some other district requiring special considerations.

Level of service of a roadway segment is initially measured by its volume to capacity (v/c) ratio. If a road segment volume exceeds the adopted v/c ratio, further study is done based upon specific roadway characteristics in addition to travel speed. If further studies indicate that the adopted standard is not being met, then regulatory actions are required before the issuance of development orders and permits. The interpretation and application of transportation concurrency requirements of land development are the foundation for what is considered and approved thereafter. The outcome of the analysis relies heavily upon the initial methodology and underlying assumptions agreed upon by the developer's consultant and the local government as well as the professional judgment of the consultant. The transportation analysis happens early in the process, as discussed further below.

The entirety of Tampa is within a designated Transportation Concurrency Exception Area (TCEA), except for the northeast portion of the city known as New Tampa. As such, these portions of the City contain not more than 10 percent vacant developable land. TCEAs are designated locations where roadway LOS standards are not being achieved, and where, due to redevelopment, urban infill or revitalization goals, the area is exempted from roadway LOS standards. Within Tampa's TCEA, alternative forms of mobility may have to be made available by the land developer's proposal. For example, Policy 2.7.2 of the City of Tampa Transportation Element specifies various activities that may be used to decrease automobile travel on or encourage the efficient use of the Florida Intrastate Highway System and other identified roadways within the TCEA. The one specified activity that relates to land development is the potential requirement that transit, bicycle, and pedestrian design considerations are included in the design of all redevelopment and new development. TDM professionals have an opportunity to use the intent of TCEAs as a means to promote TDM strategies for consideration as congestion mitigation and mobility enhancement. This is because local governments with TCEAs must adopt, as part of their comprehensive plans, guidelines and policies that specify programs to address transportation needs in such areas. These may include timing and staging plans, parking control and pricing strategies, the availability of public transportation, other transportation demand management programs, transportation system management programs, and the use of creative financing tools for the provision of transportation services and facilities.

For example, in 1998, the City of Tampa completed a Congestion Management System, which gives higher priority to corridors serving the TCEA and recommends improvements for congested corridors within the TCEA as priorities to be included in the MPO's Transportation Improvement Program. Concerning the use of City funds, the City will likewise prioritize congested corridors in the TCEA. The Congestion Management System establishes measures and standards to assess mobility patterns and the performance of roadways and transit. It identifies congested corridors and areas, identifies short and long range transportation strategies, and establishes a monitoring process to assess the 
effectiveness of congestion management strategies. While the Congestion Management System emphasizes physical improvements to the roadway system, these can go hand in hand with demandside strategies offered by TDM.

\section{Reliance Upon External Agencies}

The City of Tampa's Comprehensive Plan is the responsibility of the City to implement; however, many policies in the Transportation and Land Use Elements call for actions by various external agencies. In order to work successfully in the land development process, TDM professionals should establish working relationships with key technical people within the following agencies:

- FDOT oversees the Florida Intrastate Highway System (FIHS) and assesses the use of high occupancy vehicle (HOV) lanes on the Intrastate System;

- MPO responsibilities include the Long Range Transportation Plan, the Transportation Improvement Plan and the Congestion Management System. Policy guidance directs the MPO to consider the needs of projects identified to support infill development when it prioritizes highway system needs and improvements in developing the Long Range Transportation Plan.

- The Hillsborough County City-County Planning Commission administers the Future Land Use Map and Designations and the Plan Amendment Review Process.

- HARTline develops the Transit Development Plan (TDP). The 2004-2013 TDP lists bus rapid transit (BRT) projects and "transit emphasis corridors."

Transit emphasis corridors are identified bus routes targeted for physical improvements. Improvements may include traffic signal priority systems, slip lanes, "super stops" with passenger amenities, and intelligent transportation systems applications. Using Tampa's Transit Development Plan (TDP) as an example, four transit emphasis corridors have been identified. The goal is to locate "super-stops" where the corridors intersect and to have high frequency at the stops. If this proves successful, BRT may be used along other corridors. Two "super express corridors" were also identified, in which improvements are planned to increase the speed of the service and make it more attractive to passengers. Funding has been earmarked for these improvements. Where special emphasis is placed upon enhanced transit service development, TDM professionals should advocate for special incentives to attract land development projects along these corridors. Incentives should particularly reward land developer efforts that arrange transit-oriented development at major transit node locations and bus stops.

\section{Rezoning: Where a Land Development Proposal Usually Begins}

Zoning is a police power of the local government to regulate the subdividing of land and to specify allowable uses, lot size, building height, dimensions and placement, population density, parking, and other standards to protect public safety, welfare, and property value. In Tampa, the zoning ordinance is consistent with and implements the objectives of the City's Long Range Comprehensive Plan, as required by State law. Often, property owners and land developers seek rezoning. This can be accomplished if it is found that a rezoning results in land usage that remains consistent with the Comprehensive Plan. The City Council can initiate a rezoning for reasons of broad scale future land use planning. More often, rezoning occurs one parcel at a time. Land development often begins with a petition from the property owner/land developer for a rezoning, either of an individual parcel or of some larger area. 
A pre-application conference with the city traffic engineer must be held prior to the submittal of the rezoning petition in order to determine what traffic information is required in the application. The land developer must explain in the rezoning application why the change is necessary to promote public safety and welfare and how it conforms to the objectives of the Tampa Comprehensive Plan. A transportation analysis, prepared by a professional traffic engineer or approved by the city traffic engineer, must be submitted with all rezoning applications. The analysis must include the total trips generated by the rezoning and the distribution of the trips onto adjacent streets. Institute of Traffic Engineers (ITE) trip generation rates or other approved source must be used as the basis for trip generation calculations.

As also discussed in the above section on impact fee ordinances, ITE trip generation and parking generation rates must be used with caution. Most local governments nationwide use ITE Trip generation and parking generation rates. Shoup demonstrates how improperly used ITE rates may lead to an overestimation of the need for private motor vehicle level of service and a conclusion that transportation alternatives are neither needed nor desired. For example, ITE describes the trip rates for land uses as estimated from observations generated at selected developments, primarily from suburban localities with little or no transit service, nearby pedestrian amenities, or travel demand management programs. There is strong evidence to suggest that most selected sites offer free parking. Half the rates are based on five or fewer studies per land use. At most sites, vehicle trips are observed during the course of one day only. Shoup also points out that many factors influence the number of vehicle trips generated at a site, and that floor area, acreage or any other single variable does not accurately predict the number of vehicle trips at any site or land use (43). It is recommended that TDM professionals should raise questions about the application of the ITE trip rates and suggest that the rates be supplemented with traffic counts. Based upon the magnitude of the proposed development, TDM professionals can suggest to the local government to consider requiring supplemental traffic counts if similar developments can confidently be found for comparison purposes. Additional analysis should be conducted with the intent to estimate the nature and magnitude of transportation demand under conditions where transit service approaches a level of quality described in long range transportation planning documents and after a program of parking management. Based upon the area vision for the development site, other conditions may include where transit oriented development phasing has reached completion, where a high quality pedestrian environment has been achieved and where TDM programs have been established.

The Tampa City Code requires that no zoning change be permitted if it reduces roadway level of service standards as specified in the Comprehensive Plan. However, the Comprehensive Plan also specifies that, as early as the rezoning process, the City can require a developer to provide on-site transit amenities "where appropriate" and "adequate." While it is not practical for TDM professionals to attend all meetings relating to a rezoning, it is recommended that TDM professionals should meet in advance with the municipal traffic engineer to review the methodology used to determine what information is needed for a rezoning application and provide general suggestions to the traffic engineer regarding how the assessment of a rezoning application can be made to incorporate TDM considerations.

The zoning administrator must distribute copies of the application to the appropriate agencies and one copy of the application to the City Clerk for presentation to the City Council to set the public hearing. Any department or agency has the right to enter written or oral testimony into the record at the public hearing. Written testimony is submitted to the zoning administrator for consolidation into a single document. At this stage, TDM professionals should request a copy of the application and provide written and oral testimony suggesting how the proposal could incorporate TDM strategies to enhance transportation level of service and reduce congestion. 
A rezoning application is essentially a reactive process in which an application is submitted describing what the developer wants to do. Reviewing parties then approve it contingent upon changes or conditions, or disapprove it based upon whether the application meets minimum requirements. To save the developer and all other stakeholders time, preferred development types and characteristics should be explicitly communicated via a neighborhood plan or at least during the pre-application conference. This includes a discussion of building height, square footage and dimensions, parking configuration, occupancy classification, and minimum building setbacks. Ideally, TDM professionals should be involved in the development of prior neighborhood, area, or district plans and have garnered interest and support to apply TDM principles, such as transit oriented development, into future land development. These are items commonly reserved for later review in the building plan approval process; however, waiting that long to discuss them, the developer already has a detailed plan for what he wants to do. Disapproving detailed plans and asking for another concept at this point only wastes time, costs money, and frustrates land development efforts.

\section{Subdivision Review}

The City of Tampa's subdivision ordinance (Ch. 23) is distinct from the zoning code (Ch. 27) but these are both part of the City's Land Development Code. Both processes are followed concurrently in the development process. While zoning concerns the compatibility of land uses and defines densities, building types, surface paving and other development attributes, the subdivision process addresses the manner in which land is divided to provide mechanisms for bonding and construction of public improvements, ensure safe and convenient access and traffic control, and to provide authority requiring timely installation by the developer of adequate and necessary physical improvements. Figure 4 shows the development review process for planned developments, which are specially defined in the zoning code, and which are eligible for increased densities given that they provide certain amenities or design features. Planned developments are generally large projects with lengthy build-out schedules that are designed to contain mixed uses. They must be designed in such a way that residential and non-residential uses are compatible. The special zoning classification for planned developments provides flexibility. 


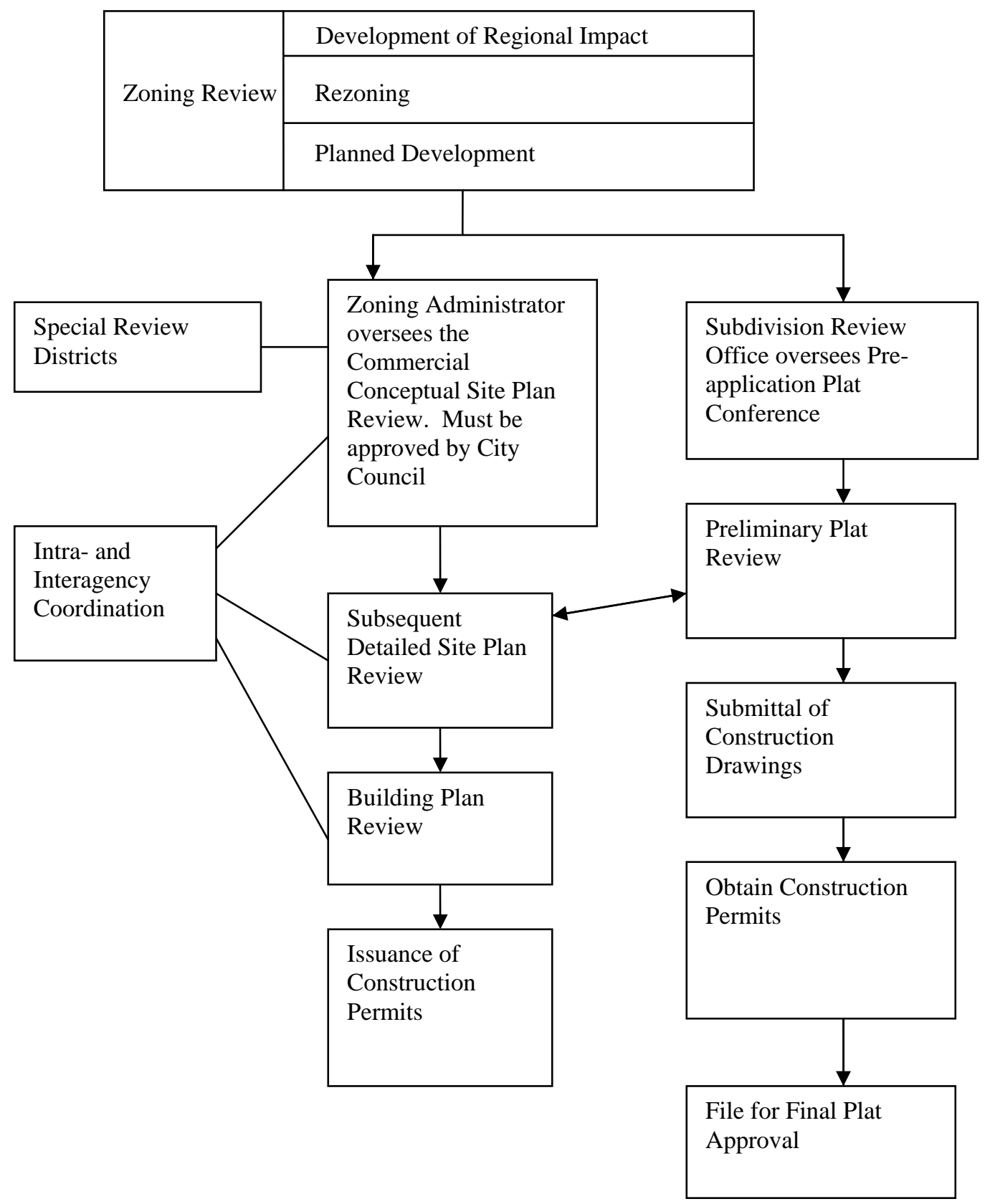

Figure 4. City of Tampa's Development Review Process for Planned Developments

Subdivision review occurs in stages. The first stage is the preliminary plat review. This review occurs usually in conjunction with the detailed site plan review in the same meeting. A plat is essentially a map that is a complete and exact representation of the subdivision of land. The purpose of the preliminary plat review is to ensure consistency with zoning and subdivision standards and the Comprehensive Plan. The preliminary plat for a phased development must show all construction phases and the proposed development schedule. Each development phase must be capable of operating independently and in conjunction with successive phases, with respect to vehicular 
circulation and access and other transportation facilities. The preliminary plat includes physical boundaries, existing site conditions, subdivision design, development schedule and a transportation analysis and concurrency review using ITE trip generation rates.

The Subdivision coordinator arranges for the preliminary plat review and the detailed site plan review to be discussed in the same meeting. The detailed site plan review includes lot layout, location of local streets, location of projected utility lines and improvements and location of drainage.

After preliminary plat approval, construction drawings are submitted that detail the installation of improvements to serve the subdivision. A temporary certificate of concurrency is issued at this stage. If public improvements are needed as a result of the development, the developer and the City enter into a subdivision agreement in which the developer agrees to post performance security prior to final plat approval for any public improvements not yet installed and accepted. The subdivision agreement also provides that the developer install all improvements in accordance with approved construction drawings. When the City approves the subdivision final plat, it accepts any dedicated improvements for maintenance by the City and a final certificate of concurrency is issued.

Process Timing. Not only do development review steps proceed in a particular order, but the timing of the review and revisions are important to the developer because lateness of plan revisions may subject the proposed development to any changes in the Code since initial approvals were granted. For example, after the rezoning, there is a conceptual site plan review. The zoning administrator provides recommendations to City Council. After a "reasonable period of time" following receipt of staff recommendations, City Council approves or disapproves the conceptual site plan. The applicant has three months to revise and resubmit the plan, after which the plan is subject to Code changes.

The detailed site plan review and the preliminary plat review can be conducted at the same meeting after City Council approves the conceptual site plan review. The applicant has 45 days to respond to comments on the detailed site plan and three months to respond to preliminary plat comments. After these deadlines, the plans are subject to Code changes. If the detailed site plan is disapproved, the applicant has 45 days to respond to comments, after which the applicant must pay a resubmittal fee. After the detailed site plan is approved, the building plan can be submitted for review. If it is disapproved, the applicant has another 45 days to revise and resubmit the building plan, after which the applicant must pay a resubmittal fee. After plan approval, the issuance of construction permits must happen within six months.

Upon approval of the preliminary plat, the applicant has six months to submit construction drawings after which time the preliminary plat approval expires. After construction drawings are approved, the applicant has six months to begin construction of required improvements. If the deadline passes, plans are subject to Code changes. After submittal of final plat review, the applicant has three months to revise and resubmit the plat, after which the plat is subject to Code changes.

\section{Site Plan Approval Process}

In Tampa, there are two review and permitting processes, one for projects that involve developing one's personal residence (one- and two-family dwellings) and another process for commercial projects, which include housing developments for profit. The Commercial Development Services office in the Business and Housing Development Department processes applications. The process consists of three phases: 1) review and approval of a site plan, 2) review and approval of a building plan, and 3) interagency coordination prior to issuance of construction permits. The City has a Construction Services Center, which functions as a one-stop shop where applications are submitted and where all communication is funneled. The purpose of the Construction Services Center is to 
streamline the application review and permitting process for the convenience of the customer, the land developer.

The Tampa Development Review Committee (DRC) reviews applications for land development. They provide technical assistance to land developers and City agencies. These applications include land rezoning applications, applications for approval of special use permits (described below), and planned developments. Planned developments become their own designated zoning classification. Members of the DRC include representatives of City agencies and others, such as the Department of Public Works, Department of Sanitary Sewers, Water Department, Legal Department, Sanitation Department, Police and Fire Departments, Department of Parks, Recreation and Cultural Services, State Department of Transportation, County School Board, County Health Department, designated land planning agency, Tampa Electric Company, the gas company, the Federal Housing Administration, HARTline, the Architectural Review Commission and the Barrio Latino Commission. The zoning administrator establishes meeting dates and these meetings are open to the public. A local TDM representative should request an appointment to serve on the Development Review Committee.

\section{Special Use Permits}

Special use permits are not rezonings but are applied for and granted for cases of land development that are unusual or complex in nature and the special use permitting process is intended to increase the efficiency in processing such applications. S-1 special use permits are for those that have impacts of a temporary nature or impacts that affect adjacent properties. These applications are decided by the zoning administrator. S-2 special use permits are those that may have potential impacts of areawide or citywide consequence and that may constitute a substantial deviation from the zoning code. In these cases, the zoning administrator ensures the land developer's application is complete, does an analysis, and files a recommendation to the City Council. A public hearing is required and the City Council decides on the application. After a special use permit is approved, any minor changes to the plans can be approved by the zoning administrator as long as the proposed changes are in harmony with the action of the City Council. If there is a substantial deviation requested, then it must be treated as a new application and the City Council must approve it. The special use must not set a precedent for encouraging more intensive uses. The Code provides specifications for many individual special uses.

\section{Internal and External Review}

Site plan review and approval can be done before or concurrently with the building plan approval process. Site plan review involves several City departments. These include those listed below. Transportation and land development coordination are just two of several reviews. This extended list illustrates the complexity of the land development process.

\section{City Departments}

- Land Development Coordination Division

o Zoning Office

o Subdivision Review Office

- Fire Marshal

- Historic Preservation Office

- Tree and landscaping

- Sanitation

- Wastewater Department 
- Stormwater Management Division

- Transportation Division

- Water Department

- Parks Department

- Other departments depending on the nature of the development project

The developer must also receive review and approval from outside agencies, including:

- Hillsborough County Environmental Protection Commission (EPC) and the Florida Department of Environmental Protection (FDEP)

o If the proposed project involves wetlands, SWFWMD, FDEP and EPC must issue approvals.

- Southwest Florida Water Management District (SWFWMD)

0 If the proposed project increases the amount of impervious surface or requires on-site stormwater management, SWFWMD must approve the project.

- $\quad$ Florida Department of Transportation (FDOT)

o If the proposed project is located along a State road, FDOT will review the application regarding traffic impact, driveway connection location and design, and drainage connection to the State Stormwater Management Facility.

If the construction is new, the developer applies for a unique address assignment from the Right-ofWay and Mapping Division, by submitting an application form. If the proposed development is in a designated Historic Special Review District, an additional application must be submitted to the Architectural Review Commission. If the proposed development is in another Special Review District, additional requirements apply, such as other design guidelines. Special Review Districts include:

- Central business district

- Channel district

- Commercial overlay districts

- Mixed use overlay districts

The Zoning Office determines if the proposed development is a Development of Regional Impact (DRI), based upon project location, size and scope. A DRI project must submit additional information to the Land Development Coordination Division. The Subdivision Review Office also reviews the project. A permit technician assigns a tracking control number to the application which the developer uses to follow his application through the review process and to post inquiries. The application is submitted with a plan review fee. The site plan application includes a Site Data Table of required information. This includes the amount of parking required for the site, with a breakout of parking calculations if it is a mixed use facility. In addition, the amount of parking included on the site plan must be stated with the number of compact parking spaces provided, if used. Of all features in the site plan and building plan, the availability and amount of parking is the cornerstone of shifting a balance toward the use of other modes, as well as other means to reduce the need to travel.

\section{City of Tampa Parking}

The City of Tampa sets forth the minimum required number of off-street parking spaces in its code of regulations, Article XVIII, Section 27-242. For redevelopment and development projects in the 
zoning categories of YC-1 and YC-3, an in-lieu parking fee ordinance exists that has traditionally waived all parking requirements for these areas.

Table 5. Minimum Number of Required Off-Street Parking Spaces Per Land Use Category*

Land Use Category

Grocery

Regional Mall

Strip Shopping Center

Business and Professional Office

Multiple-family dwelling

Single or two-family dwelling

*Rates excerpted from Table 10-1, Section 27-242, Tampa City Code

The challenge of parking is that satisfactory alternative transportation options must be in place as parking availability is decreased. Parking availability must be decreased and made more expensive in order to encourage the shift toward other modes once they are offered. Lastly, risk averse bankers are hesitant to offer financing to developers who propose site plans with reduced parking. TDM professionals should stimulate discussion through arranging forums among bankers, developers and local governments about this issue. TDM professionals should suggest a plan for staging the gradual reduction of parking availability in coordination with redevelopment. Valk recommends that such a plan would call for strategies working in tandem, including managing existing parking, expanding parking supply, reducing parking demand, protecting residential parking, creating a financing program and monitoring results to make changes as needed. Existing parking can be managed through enforcement of time limits and parking pricing. Parking supply should be expanded only after setting specific parking demand and access thresholds that when met, trigger parking construction. Parking demand can be reduced through offering a combination of incentives and services to use transportation alternatives as well as the adoption of regulatory measures. Residential parking can be protected through the use of residential parking permit programs, where needed. A financing program can use existing revenue to fund capital improvements, construction and operations. Additional revenue from increased parking fees and fines can support parking demand reduction efforts. The parking plan should include a schedule by which all elements of the program are implemented. The plan should contain specific parking demand and access thresholds to establish when more aggressive actions should be taken. Actual conditions should be recorded and used as the basis for refining actions taken (49).

\section{Building Plan Approval Process}

A site plan submittal package may be submitted before or concurrently with the submittal of a building plan application. The site plan and building plan must be approved before construction permits can be issued. City of Tampa offices that review the building plan application include the offices for architecture, plumbing, electrical, mechanical, and the Fire Marshal. It is the building plan application that includes a Building Data Table that includes, among many other things, the proposal for:

- Building square footage and dimensions

- Building height and number of floors

- Occupancy classification

- Minimum building setbacks and dimensions

The building plan application and approval process is probably too late for suggestions and negotiations regarding aspects of the building. Ideally, building design considerations should include 
a transit orientation and include sufficient densities to support transit service. Residential development should incorporate wiring to support telework and other telecommunications applications. These considerations should be discussed at the earliest stages of the land development planning process, such as during a rezoning application, as discussed above.

The building plan application is submitted with a review fee. After the site plan and the building plan are reviewed and approved, the developer must pay additional fees prior to receiving construction permits or prior to a final certificate of occupancy. These fees include:

- Hillsborough County School District

- Sewer

- Water

- Fire line impact fee

- Transportation impact fee

\section{Transportation Impact Fee}

Tampa's Transportation Impact Fee Ordinance includes a straightforward schedule of set fees based upon the type of land use and its size in terms of units, as identified in the Institute of Transportation Engineers' Trip Generation, An Information Report. Units include number of dwelling units, square footage, beds, parking spaces or number of students. Revenues are used to provide roadway improvements and related infrastructure necessitated by new development. In the spirit of promoting redevelopment, the City of Tampa has a waiver in place that exempts parts of the Ybor City Historic District from paying transportation impact fees, in addition to exemptions for the East Tampa and West Tampa districts. For example, an office under 100,000 square feet in size located in the Central Business District must pay \$6,056 per 1000 square feet. After the initial review of the site plan submittal package and the building plan application, the Permit Technician contacts the land developer with any questions or requested changes. The developer resubmits revised drawings, with an original for comparison purposes. If the developer already has three re-submittals for the same comment, the developer has to pay a re-submittal fee. If the developer does not respond in 45 days to plan examiner questions, the City will consider the project abandoned and will dispose of the application. For larger projects, phased permitting of construction allows for separate permits for foundations, building shell, and interior finish to help expedite construction scheduling. The submission requirements for these phases are identical to the site review and building plan review phases.

In many municipalities, an agreement can be reached in which the developer can receive an impact fee credit if there is indication that by implementing TDM the result will include reduced traffic. The challenge to this process is that the "default" transportation option is the already well-developed roadway system and the measure of transportation demand is not in units of person trips but in units of private auto trips. The burden of proof for trip reduction through TDM is on the developer. If the municipality has not already invested in a functioning TDM system, then there is no "TDM infrastructure" into which an individual site development can connect. The recent development of Broward County's transit oriented concurrency system is one example of how an impact fee system can be altered to finance a transportation system with more options. TDM professionals should keep abreast of ongoing evaluation and refinements to this approach and consider how the concept might be applicable in their own municipalities. 


\section{Development Phasing}

Policy 2.3.3 provides a means to achieve cost affordable level of service by using development phasing to assure consistency with the associated level of service standard required. Because land development is frequently built in phases, TDM professionals must be prepared for involvement in the development process as an ongoing effort that may require years for an individual development to reach completion.

A Land Development Case Study: Tampa General Hospital The above discussion provides a general overview of the land development process using the City of Tampa as an example. A Tampa land development case study is provided below to illustrate how the process unfolds in reality. Several observations emerge: the first two are procedural and other observations are idiosyncratic to the particular proposal, but may be a common scenario in other cases. All observations give TDM professionals information about how to be proactive in generating serious consideration to the use of TDM strategies as options for mitigating congestion and enhancing mobility.

Tampa General Hospital (TGH) is the region's only Level One trauma center and is located in the core of downtown Tampa on the north side of Davis Island. TGH is located within a TCEA. Davis Island extends to the south and is an affluent residential neighborhood. Access to the island is limited to a pair of bridges at the island's northernmost point, which is the same location as the hospital entrance. As a result, hospital-related traffic and island resident traffic affect each other.

To keep up with the needs of the region, TGH is in the process of expanding their facility by 280,000 square feet. In addition, TGH has requested permission from the city to rezone hospital property and lease 0.4 acre of a waterfront city park (Marjorie Park) for a 1,400 space parking garage, add an additional office building on the hospital campus and add a floor to an expansion already under construction. Both the earlier approved expansion and the new rezoning request combined would almost double the total size of the hospital to 2.2 million square feet. The rezoning request was necessary because the proposed expansion included building parking partly on hospital property that was previously zoned residential. In order to build the parking facility that traversed both hospital and City property, the zoning for the hospital land in question had to be changed to Planned Development, with a land use plan category of Public/Semi-Public.

The City Council initially attached nine conditions to TGH's rezoning application. One condition stated that prior to the issuance of a building permit, the hospital would have to prepare a parking management plan that would include a carpooling incentive program. The parking management plan was in response to the Davis Island citizens' concerns about traffic. This carpooling program would have permitted employees who carpool to park in the hospital's garage for free, while solo drivers must pay for their parking. Presently, the existing parking garage is owned and operated by the City of Tampa, not TGH. An hourly parking charge or an advance parking voucher can be purchased by visitors in a pack of three for $\$ 3.50$ per day. Employees currently park off-site. Nationally, there are difficulties recruiting and retaining nurses and other hospital staff. Transportation services such as transit subsidies, parking cash-out, guaranteed emergency ride home and company vanpools, have been offered by employers nationwide to recruit and retain employees. TDM strategies such as offering employee transportation services are not listed in the TGH menu of employee benefits.

The other rezoning conditions involved physical improvements to the transportation infrastructure in the immediate vicinity, or to new signage. All nine conditions were agreed upon by the hospital and the City's Transportation Department. However, ultimately the nine conditions attached to the rezoning application were eliminated by a final rezoning decision, which was intended specifically to provide for a parking facility that could more effectively meet the hospital's parking needs. 
There were a number of factors involved in the outcome of this development review. It was highly visible to the public; the Council's final vote was held at the Tampa Convention Center to handle the more than 500 people who turned out for the meeting. Almost 75 percent of the crowd was hospital supporters and employees. The local media had a hand in casting the issues, which were presented as pitting the desires of one affluent neighborhood, which already had more than their minimum required amount of city park land, against the medical care needs of the region. In the words of the St. Petersburg Times, "Council members ultimately agreed with [TGH] that the hospital's mission in providing health care to west central Florida and educating University of South Florida medical students outweighed the importance of saving a small, underused portion of the park.” (50).

Other concerns voiced by Davis Island residents included how a parking garage on a waterfront park would obscure the view. While these concerns were of importance to the Davis Island residents, they were trivial to the rest of the City and would not play well with the City Council. Instead of discussing how the hospital could expand, serve the needs of the region and USF, while at the same time mitigate impacts, it became a choice between hospital expansion or waterfront park preservation. In exchange for the loss of the 0.4 acre of Marjorie Park, the hospital agreed to build a 0.7 acre waterfront public walkway and give $\$ 1$ million for recreational improvements on Davis Island.

Overall issues of traffic congestion became invisible toward the end of the process. Typically, issues relating to parking management or other traffic mitigation plans are worked out prior to a City Council vote, but a parking garage became the main focus of the Council's vote. In this case, the Davis Island Civic Association initially commissioned its own transportation analysis. The hospital's consultants also conducted a traffic impact analysis. The Hospital examined several parking options. It is not known what the traffic analyses determined. After the final vote to approve the parking garage, one Council member commented that traffic snarls may increase with the hospital expansion, but, he continued, "that's part of living in a growing City." Shrugging off traffic congestion as part of urban life is unusual in a state where municipalities are obliged to maintain LOS standards. Even though the hospital is located within a TCEA, which gives it some flexibility from strict adherence to standards, there still must be some plan for improving mobility. Traffic impacts do not appear to have been a major discussion point in the public hearings. The public discussion overlooked how traffic snarls can affect the functioning of the hospital. TDM strategies could have been a condition to improve level of service on the bridges connecting Davis Island to downtown Tampa, achieving positive effects for the hospital and at the same time reducing traffic impacts to Davis Island residents. In addition, TDM might have provided opportunities to reduce the impact of the garage on the waterfront park (51).

Case Study Observations and Conclusions. Many, if not most, major projects within medium to large municipalities require a rezoning; conditions are often attached. In Florida, a rezoning cannot be allowed unless there is demonstration that the rezoning continues to preserve the intent of the Comprehensive Plan. A rezoning also cannot be allowed if it results in a violation of level of service standards. Rezonings occur well before the site plan review stage. A first question for TDM professionals to consider in evaluating a project is whether a rezoning request preserves the intent of the Comprehensive Plan, especially with respect to urban infill, revitalization, and urban redevelopment within a TCEA. It is recognized that transit usage, pedestrian trips, and the reduction of motor vehicle trips can be accomplished with transit oriented development (TOD). TOD requires compact, high density, mixed use development, which may require a rezoning or may show a high level of traffic generation. Neighborhood groups may express opposition to TOD. While TCEAs, by definition, do not have to adhere to LOS standards, they must demonstrate some plan for alternative mobility. Therein lies an opportunity for TDM strategies. 
Typically, issues relating to parking management or other traffic mitigation plans are worked out in the initial stages, often during the rezoning, and much prior to a City Council vote. The Council may have no questions or concerns about traffic, and the subject may never come up.

During debates over rezonings, the issue of traffic congestion might take a back seat to other issues. If traffic turns out to be key, it is often couched in terms of an "either/or" choice: "Either we allow the development to be built as proposed with abundant parking and increased roadway capacity or it cannot be done at all." TDM professionals have an important opportunity at these junctures to point out that the development can go on and there are other options to handling the transportation needs generated by the development.

It is essential for TDM professionals to seek out the news media covering the event, to frame the transportation issues from a standpoint of mobility management and see to it that this message does not get obscured. Just as important as a good working relationship with the Zoning Administrator and the Chief of Transportation in a municipality, TDM representatives should also develop a professional rapport with journalists. Typically, particular news reporters are assigned to consistently cover transportation, growth, and development in a specific area. The best outcome is that the news media refer to TDM professionals as sources of reliable and accurate information. Journalists know everyone has a bias. Ideally, journalists will come to know TDM advocates as professionals whose bias is the desire to identify all the possible transportation options, keep the public informed and involved in the process and seek out balanced solutions.

TDM professionals should attend high visibility public hearings and sign up to speak. TDM professionals should carefully prepare and rehearse their 3 minutes allotted time to speak. Understanding that the sound byte most often reported in the news is something sensationalist:

"Don't strangle [TGH's] growth because of parking and expansion problems. Let it flower and let Tampa be known for its educational and medical reputation, not lap dancing."

Les Valitutti, public hearing attendee (52)

TDM professionals should attempt to make their point succinctly, addressing emotional hot buttons with solutions backed up by reliable evidence.

Residential neighborhood input influences whether TDM provisions are included in rezoning requests on nearby land. Neighborhood input should focus on the traffic generation potential of the proposed land use and the cost/benefit to citywide concerns, and not just on the neighborhood impact of the type of proposed new use. TDM professionals should seek common ground with neighborhood groups and help them phrase their concerns as relevant to addressing citywide concerns.

It is common for proposals for new developments, redevelopments and expansions to be revised one or more times after agreements have been reached. TDM professionals should remain in the communication loop even after decisions and approvals have been issued, and expect proposed changes that will require new analyses and renegotiations. If TDM professionals want to get involved in the land development process, they must be prepared for a process that seems without end.

Even after a physical development is completed, promises, both verbal and written, about program implementation and what will or will not be permitted to take place in the future, are often forgotten or not enforced. If development pressure is there, no promise is secure. Agreements to engage in 
TDM are often not followed over time. Institutional memory and the capacity to monitor developer agreements are as tenuous as the rate of planning staff turnover. As a result, municipal agency procedures must be in place to enable a new staff member to take up where a former staff member left off, to continue tracking agreement implementation and documenting reasons for changes. Once tracking is achieved, instances will be found where provisions of agreements are not being implemented as originally drawn up. TDM professionals rarely hold positions in which they can enforce agreement provisions; however, they can bring forgotten provisions to the attention of those who do. Monitoring and enforcement is time consuming and expensive for municipalities. Nevertheless, TDM professionals can create a valuable partnership role for themselves as development monitors. Enforcement divisions of local government can choose to do nothing in response to violations, but it is important for TDM professionals working in a monitoring capacity to continue to track and document what is happening, because the working relationship between a local municipality and land developers is based on a foundation of professional trust and integrity of the development process. If it comes to light that more than a few developer agreements are not followed, then municipal leaders will eventually be forced to review and strengthen the process.

More often, agreements are renegotiated after the physical land development is complete. Here again, TDM professionals should be at the discussion table. Better yet, after an initial agreement is made, TDM professionals should help make the initial agreement stick by serving as technical support to assist the developer and property owner/manager with implementation. Furthermore, TDM professionals should serve as publicists to bring positive recognition of developers and property managers with good track records of implementation to the attention of municipal decision makers. 


\section{RECOMMENDATIONS FOR INCORPORATING TDM INTO THE LAND DEVELOPMENT PROCESS}

There are many opportunities to participate and provide valuable input for incorporating TDM into the land development process, from long range planning through land development and monitoring of completed developments. These recommendations provide basic guidance to that end. These recommendations are provided to municipal transportation planners, traffic engineers and land development proposal reviewers. Ideally, these professionals are in the best positions to use these recommendations to incorporate TDM into land development. However, because these professionals may be less familiar with TDM, it will be up to TDM professionals who work for commuter assistance programs, transportation management associations, or other allied organizations, to engage in most of these activities.

Recommendations for participation in the land development process are offered with the understanding that, for most organizations involved in TDM, implementation of the recommendations may constitute either a significant increase in workload or a significant shift in focus from existing activities. Adding to this condition, the land development application process is on a tight timetable. In order for TDM professionals to be useful participants, TDM involvement must be orchestrated so as not to slow the process down but to prove helpful in the transportation analysis aspects of the process as well as providing recommendations and ideas for alternative congestion reduction and mobility enhancement strategies.

Although individual TDM organizations may not be able to implement every one of the recommendations due to staffing constraints or other reasons, the best result will be realized by implementing as many as possible. If TDM professionals do not have the resources to review key development proposals and engage in the actions described below, TDM professionals should arrange to meet with local planners to provide training in TDM applications in advance of the review of specific proposals. This could include offering planners check lists of strategies or other prepared materials that outline key considerations.

To prepare to provide technical support to local planners, TDM professionals should seek professional training, such as the Florida Commuter Choice Program Certificate offered by the USF Center for Urban Transportation Research, or some other similar professional development opportunities. Alternatively, if local planners, traffic engineers and land development proposal reviewers have professional training opportunities, they can directly avail themselves of training in the application of TDM. However, it is anticipated that local governments will rely, at least initially, upon the assistance of commuter assistance programs and transportation management organizations to fill this need.

\section{Immediate Actions for Specific Proposals}

Consider staffing needs. A TDM agency that wants to get involved in the local government land development review process must commit a realistic amount of staff time and effort to participate because the process for each development application can take anywhere from several months to several years. In a large urban area this could easily occupy two full time positions. In a smaller but fast-growing county, this may also require two full-time staff positions with backgrounds in planning, land development, transportation, and public administration. Staff should not have to be at every meeting but there are key early meetings, when transportation analysis methodology is discussed and when various transportation alternatives are being identified. 
Choose proposals strategically. Based upon staffing and time constraints, TDM professionals will not be able to pursue all development proposals. A strategy should be devised for selecting which development projects should receive more attention. This can possibly be done by:

- Identifying which development proposals have the best chance at adopting TDM strategies, or

- Identifying which development proposals have the most potential for congestion reduction results where it is straightforward to measure the difference.

For example, TDM professionals may choose to focus their attention on land development applications where comprehensive plan policies provide direction for emphasis upon certain locations. These may be:

- Constrained corridors within the TCEA (where there can be no more road widening)

- Other roadway facilities violating the LOS standard within the TCEA (where there is a choice of roadway capacity improvements and/ transit)

- Transit emphasis corridors

- "Super express" service corridors

- Other areas within the TCEA that present development opportunities and through which some influence can be brought to bear upon the process due to membership contacts of a transportation management association or other allied organization

Through Comprehensive Plan Policy for the City of Tampa, for example, the roadways that receive the highest priority are those within the TCEA which are operating below the adopted LOS standard (Policy 2.7.5). This Policy calls for capacity improvements for both roadways and transit services within the TCEA. Every 5 years, the City Transportation Division must evaluate the effectiveness of the TCEA looking at several performance measures. It is important for TDM professionals to participate in the evaluation of the TCEA to identify other possible causes to the rise or fall of the five performance measures listed below. According to Policy 2.8.1, these include:

1. The amount of transportation impact fees set aside for transit or parallel roadway capacity.

2. Evaluate programs which promote pedestrian and non-automobile travel in the TCEA including improvements to the pedestrian and bicycle infrastructure.

With respect to urban infill, urban redevelopment and downtown revitalization areas:

3. The level of development or redevelopment activity

4. Improvements to mass transit infrastructure

5. Increase in mass transit ridership

The opportunity of a TCEA is that roadway concurrency requirements are suspended, providing an opportunity for alternative approaches. The TCEA concept was developed to enable urban infill, urban redevelopment and downtown revitalization. The performance evaluation, as outlined in the Policy above looks to see if development has increased and if overall mobility has increased. It is also recommended that TDM professionals prioritize the TCEAs in their urban areas for applying TDM strategies. While the status of development activity cannot solely be attributed to transportation conditions, a demonstration of mobility enhancement through TDM could encourage a review of the roadway LOS treadmill that many urban areas in Florida run upon without progress.

Get involved at the rezoning application stage. Vitally important to incorporating TDM effectively into land development proposals is involvement as early as the rezoning application stage. 
TDM professionals should request a copy of the application. A first question for TDM professionals to consider, in an evaluation of a project, is whether a rezoning request preserves the intent of the Comprehensive Plan, especially with respect to urban infill, revitalization, and urban redevelopment within a TCEA. TDM professionals should check to see if its location lies within a TCEA or some other district requiring special considerations. TDM professionals have an opportunity to use the TCEAs or other special district designation as a means to promote TDM strategies for consideration as congestion mitigation and mobility enhancement.

Challenge "either/or" thinking. TDM professionals should listen for discussion among other transportation professionals that begins to phrase the issues in "either/or" language that limits consideration of options ("Either more road capacity/parking is built or the project cannot proceed."). TDM professionals have an important opportunity at these junctures to point out that the development can go on and there are more options to handling the transportation needs generated by the development, as offered by TDM.

Participate early in development review. The site plan approval stage comes after a rezoning approval. It is recommended that a local TDM representative request an appointment to serve on the Development Review Committee that reviews the site plan applications. At the very least, establish a process by which local government staff communicates the existence, location, and status of development proposals. This possibly could be achieved through coordination with a "construction services center" or some other "one-stop" office set up to streamline the process. While some information is public record and there are scheduled public hearings advertised in newspapers, this point in the process is frequently too late to have an influence. Getting in early in the process of development review might be as simple as being copied on emails with attachments. Approval of this inclusion likely must come from top management offices and communicated by them to the appropriate Services Center staff and technicians.

Develop a check list. Develop a check list for transportation planners and land development proposal reviewers that describes non-capital intensive TDM strategies that can be implemented.

Transform parochial interests. TDM professionals should seek common ground with neighborhood groups and help them phrase issues such that their neighborhood concern has citywide transportation implications. For example, TDM professionals should guide neighborhood input to focus on the traffic generation potential of a proposed land use and the costs/benefits to the city, and not just on the neighborhood impact of the type of proposed new use.

Provide testimony. TDM professionals should provide written and oral testimony suggesting how the proposal could incorporate TDM strategies to enhance transportation level of service and reduce congestion.

Monitor developments over time. Because land development is frequently built in phases, TDM professionals should remain in the communication loop even after decisions and approvals have been issued, and expect proposed changes that will require new analyses and renegotiations. It is not uncommon for phased development to make revisions to development plans as market indicators suggest more profitable building scenarios. TDM professionals should help make TDM strategies successful by serving as technical support to assist the developer and property owner/manager with implementation. Staff turnover erases institutional memory of development proposal history. Municipal agency procedures must be in place to enable a new staff member to take up where a former staff member left off, to continue tracking agreement implementation and documenting reasons for changes. TDM professionals can bring forgotten provisions to the attention of those who can. TDM professionals can create a valuable partnership role for themselves as development 
monitors. Preparing "standard operating procedures" for development review and monitoring can ease the task of tracking a project as well as enable the project to be handed off to another staff member if necessary.

\section{Involvement in the MPO Planning Process}

Participate in MPO committees and other activities. Metropolitan planning organizations (MPOs) offer a number of opportunities for TDM professionals to be involved in the MPO transportation planning process. In addition to workshops, hearings, and other public involvement activities aimed at the general public, the MPO does the bulk of its work through established committees, with ultimate voting authority in the MPO Board. Occasionally, a transit authority may be included as either a voting or non-voting member on the MPO Board. At this level, a high-ranking representative should represent the transit authority. More often, a transit authority or TDM agency may have voting or non-voting membership on a Technical Advisory Committee. Even at this level, a representative with a leadership position, such as the executive director of the commuter assistance program, should be the one to attend meetings. Other committee involvement possibilities include the Citizen's Advisory Committee or other standing committees established by the MPO.

Attendance and participation at all committee or board meetings is essential to establishing both personal and professional credibility with other members of the committee and the MPO staff. Committee members are involved in every aspect of the MPO transportation planning process.

Influence MPO product content and advocate for funding of transit and TDM-related activities. As a committee member and regular participant in MPO activities, the TDM professional has the opportunity to influence MPO guiding policies which directly impact the content of the Long Range Transportation Plan as well as the Transportation Improvement Program (TIP) and subsequent project funding. The commuter assistance program (CAP) executive director should not only educate the MPO Board and committee members regarding the benefits of TDM strategies, but also offer specific ways for including them in the various MPO products. This report has included a number of useful policies for use in long range transportation plans. The CAP representative also should assist in developing alternative revenue sources and seek earmarks for TDM strategies. It is very important for this individual to understand and educate others regarding the trade-offs between accommodating travel demand and managing travel demand. The CAP representative should encourage planners to reconsider assumptions made in the analysis of transportation alternatives and be cognizant of the level of accuracy that analysis methods offer.

The CAP representative should work with MPO staff to consider more realistic time frames not only for implementation of TDM strategies but also for tracking and measuring program results. Match these with work programs and budgets that coordinate with those time frames.

Improve relations by involving MPO Board, staff, and committee members in transit or TDM agency activities. Raise the awareness of the MPO Board, staff, and committee members regarding various transit and TDM agency activities by inviting them to attend them or otherwise involving them in various transit or TDM agency activities.

\section{Involvement in Local Government Processes}

Study local planning documents. It is recommended that TDM professionals become thoroughly familiar with their locality's Comprehensive Plan, especially the Future Land Use Element and the Transportation Element. Some local governments have Congestion Management System Plans 
developed to address areas with low LOS. While the plans emphasize physical improvements to the roadway system, these can go hand in hand with demand-side strategies offered by TDM.

Articulate the trade-offs. In accommodating travel demand versus managing travel demand, this is an issue of making a different set of trade-offs at the policy level. The realm of TDM support at the level of long range planning includes such actions as "providing incentives", "continuing to support", "continuing to work with", "encouraging", and "coordinating". There is a great reliance upon city administrators to interpret what TDM actions conform to and advance the policies of the local government comprehensive plan. The policies, for example, may require developers to provide facilities and on-site amenities, "where appropriate"... "as needed" and "where feasible", which all rely on professional judgment. TDM professionals should listen to the ongoing discussions with regard to long range transportation planning because the stage is set here for land development. TDM professionals should prompt a revisiting of the difficult questions to encourage a more explicit articulation of what is being traded. Elected officials and decision makers must have the knowledge and understanding about the trade-offs in order to demonstrate leadership and the political will to make unpopular decisions that may upset the status quo of how benefits from the transportation structure are shared. Questions include:

1. How much right-of-way do we really need?

2. What level of service standard is acceptable?

3. For any course of action, what are the alternatives that we are foregoing?

4. What are the underlying assumptions?

5. Which groups are being served/not served? Which groups are most vocal and which are underrepresented? For example, is it the majority versus the low mobility groups? Is it the neighborhood versus the surrounding town?

Participate in planning document review. The “buck stops” where your municipality's land development code (LDC) of regulations places requirements, prohibitions, and quantitative standards. However, the LDC must be consistent with and implement the Comprehensive Plan. For example, review the applicability of sources that the municipality originally used as a basis for development and parking standards. If there are inconsistencies or opportunities to strengthen the means by which the LDC implements the comprehensive plan, then TDM professionals have the opportunity and responsibility to point these out in the comprehensive planning update process. Seek ways to get involved in the review processes for the comprehensive plan and the land development regulations because the plans, policies and regulations are the litmus test against which every development proposal is reviewed.

Adopt measurable objectives. It is recommended that TDM professionals encourage long range planners to replace vague language in plan policies, such as "continue to support", with clear unambiguous language about what is expected, based on measurable objectives. For example, "Reduce vehicle trips entering the business district during the a.m. peak period by 3 percent by the year 2010.”

Advocate for transit oriented development incentives. Consider policies that encourage land development proximity and connectivity, such as transit oriented development. In locations where special emphasis is placed upon enhanced transit service development, TDM professionals should advocate for special incentives to attract land development projects along these corridors. Incentives should particularly reward land developer efforts to arrange transit-oriented development at major transit node locations and bus stops. 
Stage gradual parking reductions. Limiting the availability of parking has a strong impact on the use of the transportation system but efforts can backfire if satisfactory alternative transportation is not concurrently in place. TDM professionals should advocate for a more complete multimodal system. As the level and quality of multimodal transportation service increases, parking limitations can gradually be established. TDM professionals should stimulate discussion through arranging forums among bankers, developers and local governments about the marketability of development with reduced parking. TDM professionals should suggest a plan for staging the gradual reduction of parking availability in coordination with redevelopment, which includes triggers or thresholds that precipitate the institution of parking reductions.

Review staff functions. Consider whether difficulties in coordinating land development planning, transportation planning and traffic engineering are in part due to the manner in which staffing tasks are compartmentalized within departmental functions.

Stay current on innovations in the field. Local governments often have found it helpful to borrow good ideas from other municipalities. This is a sound practice as long as borrowed ideas are tailored to the unique conditions of the locality. TDM professionals should keep abreast of ongoing evaluation and refinements to Broward County's transit oriented concurrency approach and consider how the concept might be applicable in their own municipalities.

Recognize TDM credentials. In the long run, an important way to elevate the usage of TDM is through incorporating a balanced approach to transportation engineering and planning at the college undergraduate and graduate levels. Local TDM professionals can suggest hiring criteria for key local land development administrative positions. Such criteria could include strong preference for candidates who have studied TDM, determinants of travel behavior, multiple methodologies for assessing traffic impact, and other indicators of a broadened transportation education.

\section{Involvement in State Government Processes}

Update the Development of Regional Impact (DRI) analysis process. In the DRI process, there is an emphasis on the use of capital improvements to resolve capacity deficiencies. Operations and management programs generally have not been used to address regional impacts. It is difficult to develop an intermodal and multimodal local transportation system if the regional and interstate transportation systems rely primarily on one mode. This is because the local system is so closely intertwined with the regional and interstate systems. State planners should revisit the long term possibilities for multimodal regional and interstate transportation systems. Florida DOT site impact analysis procedures used to evaluate DRI impacts are used with the intent to preserve level of service (LOS) on the State Highway System (SHS) and the Florida Intrastate Highway System (FIHS). Analysis tools for determining LOS focus on highway capacity for automobiles and trucks. Trip generation is characterized as motor vehicle movements. Transit share is based on existing transit usage in areas where transit service often is underdeveloped. The DRI Application for Development Approval (ADA) questions should be reviewed and updated to place greater emphasis on transportation alternatives, transit oriented development and pedestrian-friendly development design. The site impact methodology should be updated to reflect an anticipated future multimodal system, otherwise site impact analysis will tend to mirror and reinforce the existing conditions of a private motor vehicle oriented system. Broward County's transit-oriented concurrency approach may offer concepts that could be borrowed by the DRI review process to widen the possible options for addressing regional transportation impacts with alternative modes.

Consider the impact of emergency evacuation on statewide transportation planning. It is recommended that TDM professionals suggest a reconsideration of statewide strategies for 
emergency evacuation and include TDM in evacuation strategies. Maintaining regional highway capacity for emergency evacuation attracts and disperses new land development where capacity exists, which limits mobility choices and thwarts application of many TDM strategies. It is recommended that while FIHS capacity is maintained for evacuation events, the bus fleets of urban areas should also be maintained to satisfactorily serve low-mobility populations during evacuation events. This increase in bus service capacity then can be made available daily, encouraging a trickledown effect upon land development location decisions and site design.

Funding allocations are influenced by the source of revenues. This is because it makes sense to tie the funding of services to those who use them, when possible. It is recommended that state and local policy makers reconsider sources of transportation revenue and TDM professionals should be participants in the dialogue. Alternatives could include raising motor vehicle fees, especially registration fees for new motor vehicles and parking pricing. The increased revenue should be earmarked to complete the road system for alternative users, including pedestrians, bicyclists, and high occupancy vehicle lanes and bus rapid transit. There should also be consideration of other transportation revenue sources to remove dependence for revenue generation from private automobile ownership and usage, such as fuel taxes.

\section{Seek refinement of methodology for determining transportation impact of land development.}

This review recognizes that the demand for transportation calls for a wider choice of mobility services (such as transit service, vanpools, guaranteed ride home), which would result in a transportation impact from land development that is characterized differently from a mere calculation of the number of additional vehicles generated by the development. This transportation demand for varied services will be suppressed if the basic system for providing such alternative transportation services is not yet in place. Once such a system is in place, transportation impact would have to be measured differently, such as the number of additional bus boardings, the number of pedestrian crossings at key intersections, and the numbers of additional vanpools and guaranteed ride home registrants. Differently measured impacts would call for an expanded menu of service improvements that could be contributed by the developer as part of the development agreements and development orders.

Select performance measures carefully. TDM professionals should encourage planners and engineers to weigh the limitations of using various TDM performance measures against the particular goals to be achieved. Examples include reducing single occupant vehicles (SOV), average vehicle occupancy (AVO), and average vehicle ridership (AVR), understanding that their use will limit the actions taken. Reducing SOV limits TDM strategies to mode shifting and does not recognize that SOV drivers can also participate in TDM. AVO does not incorporate the effects of bicycling, walking or telecommuting. AVR is a measure associated with work sites, limiting TDM application to commute travel. AVR also does not incorporate the effects of bicycling, walking and telecommuting. These are all useful measures but they should be applied only with the understanding of what they do not consider and should perhaps be used with other measures such as a vehicle employee ratio (VER), also known as vehicle trips reduced (VTR), which is the number of vehicles per 100 employees. Other measures might include reducing vehicle trips (VT) or reducing vehicle miles traveled (VMT).

Incorporate TDM as conditions for rezoning approvals. TDM professionals should meet with the municipal traffic engineer to review the methodology used to determine what information is needed for a rezoning application and provide general suggestions to the traffic engineer regarding how the assessment of a rezoning application can be made to incorporate TDM considerations. 
Reconsider trip and parking estimates. TDM professionals should meet with the municipal traffic engineer to discuss the use and limitations of the ITE trip generation and parking generation rates. Local government transportation planners should evaluate the extent to which their customary use could mislead to faulty conclusions regarding the magnitude and characteristics of travel demand. Ideally, to estimate for a land development proposal, trip and parking rates will be computed from counts from other local developments that closely match the proposal in terms of its physical features and function, development environment, and areawide development goals for the future.

Encourage the development of LOS evaluation that enables trade-offs among modes. Available transportation planning methods fall short of enabling an evaluation of a trade-off among modes. Research should continue to focus on this missing piece, starting with the SIS geodatabase. TDM professionals should become more active in the discussion about the application of multimodal LOS standards as part of the transportation approval process. Ideally, TDM professionals should generate support for the future development and application of a method to make tradeoffs across modes. Preserving roadway level of service standards for private motor vehicles as specified in the local Comprehensive Plan appears to drive the process thereafter. In the long range transportation planning process, TDM professionals should suggest exploring the use of alternative standards for combined people-moving capacity across modes along corridors carrying heavy directional traffic. In the case of Tampa, one way to do this is to implement Policy 4.2.3, which calls for the City to assist HARTline to increase the modal split for mass transit by providing the highest levels of transit service on transit emphasis corridors. This Policy specifically calls for providing dedicated travel lanes for exclusive transit or high occupancy vehicle use. Especially for constrained corridors in which additional lanes cannot be built, such strategies require making a trade-off for more transit usage and less private motor vehicle level of service.

\section{Develop professional relationships.}

Identify key people in the local development process. TDM professionals should establish working relationships with key technical people, including those representing the Florida Department of Transportation, the planning commission, the transit agency, and the MPO. Establish a working rapport with the zoning administrator and the municipal traffic engineer. Invite such key municipal development staff to participate in a meeting of your organization, to give them first hand knowledge about what services your agency provides, your mission and goals, and express a desire to participate in the land development process. Make the case how you can be helpful to the process. Demonstrate a knowledge of the complexities of land development, issues and trade-offs, and your flexibility of thinking and desire to help solve transportation problems through strategies tailored to help properly conceived land development succeed.

Involvement at the neighborhood level sets the stage for TDM implementation. TDM professionals should be active in the development of neighborhood, area, or district plans and work to establish community support for using TDM principles in future land development, such as transit oriented development. Such support would ease acceptance of alternative building square footage, building height and number of floors, occupancy classification, minimum building setbacks and dimensions that support transit and pedestrian use. These features are proposed in writing at the building plan approval stage but are conceptualized early.

Balance specificity with flexibility. Alternative transportation facilities and amenities must maintain the character of the surrounding neighborhood and be complementary to stable residential areas. Neighborhood groups may express opposition to TOD. This requires the exercise of interpretation and sensitivity to residents who do not want to see change in their neighborhoods. 
Where there is ordinance language that is more specific and less open to interpretation, such as numerical standards, this type of regulation has more enforcement power but a less flexible impact. In the development of regulation language that advances the application of TDM, the goal is to make ordinance language as specific as possible without losing the flexibility and leeway needed to be responsive to neighborhood concerns in individual cases of development.

Seek networking opportunities. TDM professionals should consider serving on citizen review boards as part of community service activities. This can provide valuable networking and partnership building opportunities. Participate on local boards and committees to develop an understanding of different aspects of the community as well as to provide information regarding the benefits of TDM to other participants. Most TDM professionals are becoming aware of the opportunities provided by participating in technical advisory committees of the MPO. In addition, there are appointed citizen review boards that are established to secure resident participation, promote good government and to promote the effective and efficient delivery of public services. While these review boards are for citizen residents of the municipality and not professional representatives of organizations like a commuter assistance program, clearly the persons who participate on these boards have related professional backgrounds. TDM professionals who have an interest in community service as well as individual members of the CAPs or TMAs could serve on these boards to provide a TDM perspective in the decision making process. These boards include variance review boards, architectural review commissions, neighborhood planning task forces, enterprise zone development agencies, and the municipal planning commission.

Establish partnering roles. TDM partnering agencies should make a decision whether/when participation in the development approval process for a particular application should be a coordinated team approach or whether one partnering agency should attempt to be the sole voice and conduit for involvement and recommendations. This decision could be decided in advance as a general coordinating policy or it could be decided on the basis of each individual application.

Agree upon an effective division of labor. Based upon staffing and time constraints, TDM professionals will not be able to pursue all development proposals. Consequently, they should form a strategy in advance for participating in the land development process that coordinates the agreed upon efforts of the regional commuter assistance program (CAP), the local transportation management associations, the local transit agency, the bicycle/pedestrian coordinator, the FDOT District public transit office and other key TDM agencies. For example, staff of the regional CAP might provide assistance to the TMAs in the form of information regarding rezoning applications and site plan applications submitted in the TMA service areas. The CAP might also serve on the MPO Technical Advisory Committee and provide updates to local TMAs regarding long range transportation planning initiatives.

Demonstrate a coordinated effort. It is important that in this coordination effort, there be communicated to the municipal offices overseeing the land development process, a unified voice among allied organizations with regard to TDM. It can only help to demonstrate a coordinated approach. The worst that can happen is for disagreement among allied organizations to become apparent, which will communicate disorder and a strong sense that including TDM in the discussion will complicate and slow the process down rather than be of assistance. It may help for TDM agencies to decide in advance what their respective roles will be through identifying what strengths each partner agency has and how best each agency can contribute. Deciding roles in advance may reduce or eliminate friction relating to "turf".

Be mindful of how one TDM strategy can impact others advocated by partners. In the development of combinations of TDM strategies, sometimes one strategy can offset the impact of 
another. For example, a dedicated bus lane may experience a lowered level of service if it is turned into a high occupancy vehicle lane shared by carpools and vanpools. In this case, coordination with and support of the local transit agency includes carefully weighing the impact of combined TDM strategies and open discussion about what will create the best overall outcome.

Reach out to economic development interests. TDM professionals should aim to apply TDM to residential and business location decision making because this sets the stage for using TDM strategies more effectively on a day-to-day level. Develop working relationships with realtor associations, economic development arms of local government and chambers of commerce.

Educate the media about the use of TDM as mobility management. It is essential for TDM professionals to seek out the news media covering the events relating to a development proposal, to frame the transportation issues from a standpoint of mobility management and see to it that this message does not get obscured. TDM representatives should develop a professional rapport with journalists. TDM representatives should attend high visibility public hearings and sign up to speak. TDM professionals should carefully prepare and rehearse their 3 minutes allotted time to speak, to succinctly address "hot button" concerns with factual evidence. While oral testimony at the public hearing stage is likely too late to influence transportation professionals, it can have an impact on how the issue is reported in the news media. This affects receptivity by the public and by elected officials who must vote on development matters.

Publicly praise land development that supports community transportation goals. TDM professionals should continue to serve as publicists to bring positive recognition to developers and property managers for good track records of implementation. 


\section{CASE STUDIES}

Two case examples were documented for this report as briefly described below:

- Commute Trip Reduction Program. Durham County, North Carolina. This ordinance requires major employers to provide employees with information on alternative transportation modes, to participate in a survey and reporting effort, and to prepare a plan to reduce commuterelated traffic generated by their employees.

- Parking and Transportation Demand Management Ordinance. Cambridge, Massachusetts. This ordinance is one of the measures the City uses to minimize the number of singleoccupancy vehicles operated within the City. Parking is strictly limited, and a variety of TDM measures are supported through negotiations with developers.

\section{Commute Trip Reduction Program}

\section{Durham County, North Carolina}

Sources: Interviews with Audra Foree, TDM Planner, Triangle Transportation Agency, Durham, NC and Charseem Anderson, Transportation Planner, City of Durham, NC; Durham County Code, Article V: Commute Trip Reduction Program.

Located in the Research Triangle of North Carolina, Durham County has an area of 290 square miles and is home to 236,781 people (2003 estimate). The American Community Survey estimates that, in the larger Raleigh-Durham-Chapel Hill metropolitan statistical area (of which Durham County is a part), $81 \%$ of working adults used single-occupancy vehicles as their primary means of transportation to work.

Durham County instituted a trip-reduction ordinance in 2000 for the main purpose of heading off imminent non-attainment status in local air quality. The ordinance takes an employer-based, rather than a development-based, approach to transportation demand management (TDM). Indeed, there is no land-use component to the ordinance at all.

The ordinance requires "major employers" (defined as organizations employing at least 100 people) to provide employees with information on alternative transportation modes, to participate in a survey and reporting effort, and to prepare a plan to reduce commute-related traffic generated by their employees. Technically, this plan must be approved by the county. The ordinance provides a mechanism for the county to object to any employer's traffic reduction plan, however, no plan has been rejected to date.

Durham County is intentionally taking a less confrontational and more conciliatory approach to TDM than are other municipalities. "Employers have lots of leeway regarding compliance," says Audra Foree, the TDM planner for Triangle Transit Authority (TTA), the lead transportation agency in Durham County. "The ordinance basically gives them suggestions; they can install bike racks, set aside designated parking spaces for carpoolers, or something else. The method they use to achieve traffic reduction is up to them."

Suggestions for employer's traffic reduction plans found in the ordinance include the following TDM strategies:

1. Commuter matching services to facilitate employee ridesharing for work trips;

2. Provision of vans for vanpooling; 
3. Subsidized carpooling or vanpooling which may include payment for fuel, insurance, or parking;

4. Use of company vehicles for carpooling;

5. $\quad$ Provision of preferential parking for carpool or vanpool users;

6. Reduction of on-site employee parking or re-designation of existing parking to pooling employee parking;

7. $\quad$ Subsidized bus fares;

8. Construction of special loading and unloading facilities for transit, carpool, and vanpool users;

9. Cooperation with the City or County of Durham in construction of sidewalks or bicycle routes for the work site;

10. Provision of bicycle racks, lockers, and showers;

11. Providing to employees information on alternate modes and other travel reduction measures;

12. Establishing a work-at-home program, including telecommuting;

13. Establishing a program of adjustable work hours which may include compressed work weeks and flexible starting and stopping hours;

14. Parking incentives and disincentives;

15. Implementing other measures designed to reduce commute trips, such as provision of day-care facilities, restaurant, or emergency ride home services.

The ordinance does set community-wide goals for traffic reduction, but does not hold employers to achieve any kind of citywide goal or standard, leaving them to their own devices to comply with the ordinance. As a result, the Triangle Transit Authority (TTA) acts as a consulting organization working with employers to identify the most successful (and cost-effective) methods of implementing TDM. According to Foree, the most important factor in creating an effective program is the person appointed by the employer to liaison with TTA. "An employer must designate an Employee Transportation Coordinator (ETC) at the worksite, and that person is the City's contact point within the company for the development of the program," she states. "We work with the ETC to implement the annual employee survey. The ETC is also in charge of keeping alternative transportation mode information at the worksite-things like bus schedules, brochures, etc."

Charseem Anderson, a transportation planner for the City of Durham, is in charge of administering the City's trip reduction plan with its goal "to reduce vehicle miles traveled for employees, and to encourage them to get out of the SOV (single-occupancy vehicle) mindset.” The City's plan encourages employees to participate in the program through incentives that are associated with each alternate transportation mode. For example, employees with valid City Employee IDs ride the transit system for free and are eligible to use the guaranteed emergency ride home. City employees are also allowed to adjust their arrival and departure times in accordance with the bus schedule.

One benefit of the flexible nature of the Durham County TRO is that it helps mitigate the resistance that is common to similar ordinances in other parts of the country. While development-based requirements can often breed contentious fights over TDM requirements (due at least in part to the amount of money involved in even a slight delay in construction), in Durham, the most significant variable is the attitude of the employee transportation coordinator (ETC). "It really depends on the person who's given the responsibility," says Foree. "If they're amenable to the idea of serving in that capacity, the process tends to work better. It helps if they are already of the mindset that [traffic reduction] is something that people should be doing." Prior to Durham County's adoption of the trip reduction ordinance, some corporations were already implementing traffic reduction plans, for example, GlaxoSmithKline. Some corporations are much less interested in coordinating trip reduction through the TTA, especially if the designated ETC is not interested in serving in that role. 
"We've been achieving our [traffic reduction] goals within the city, but one of the biggest hurdles we face is getting the supervisors to let their employees participate,” says Anderson. For example, although many employees would like to participate in the compressed work week and telecommuting options, they are not appropriate for everyone. Oftentimes, some managers are skeptical of "the idea that their employees can still be productive if they are not under direct and constant supervision."

Judging the success of any TDM initiative requires measurement and evaluation of the specific techniques implemented. Like most municipalities, Durham County takes a low-cost, low-tech approach to questions of verification and measurement. "We require major employers to conduct annual surveys among employees and to prepare an annual report to TTA," says Foree. The TTA then examines those documents "to determine if the plans are compliant with the ordinance." TTA uses an evaluation form for this purpose. Information provided on the form includes: the date on which the plan was first received; whether the employer has submitted all necessary fees; whether the employer has designated an ETC, and the identity of that person; a description of how TDM information is distributed to employees; descriptions of both current and planned trip reduction measures, to include specific goals for the following year; and the response rate of the survey. The City also tracks employee compliance through an annual survey. Typical topics covered include: basic travel habits; the type of vehicle used for travel (especially model, make, and fuel type); miles traveled; and the specific reasons the individual made the choices he or she did.

There are, however, some measurement-related pitfalls to consider. In particular, establishing a baseline can be tricky, due mainly to difficulty in obtaining baseline data. "Between years 2000 and 2002, we attempted to gather baseline info through a 'suggested' survey,” says Foree. Only some of the companies distributed the survey. In addition, reporting methods were not standard and were, therefore, difficult to measure, resulting in a very weak baseline. According to Foree, "In 2003, we developed and used a standard [required] survey and report, and we are now gathering the first measurements based on this standard survey. We expect to have all the results sometime in the spring of 2005.”

The ordinance does include a $\$ 1,000$ one-time penalty for noncompliance. Despite the seemingly small size of the fine for most companies that would be categorized as major employers, only one fine has been assessed since the program began in 2000, indicating compliance with the ordinance.

Some employers might be put off by the possibility of high costs for program implementation, but the flexibility of Durham County's ordinance can help mitigate those fears. In fact, the City of Durham hasn't yet incurred any specified costs, although that may be in large part due to the unique situation of City government. For example, the City subsidizes its own transit system on which employees ride for free. Further, Anderson says, "the emergency ride home service is set up in such a way that, if they need to pay a cab fare, employees are reimbursed directly by an individual department's travel budget, instead of by the Transportation Department's funds.”

As a result of the flexibility and leeway inherent in Durham County's ordinance, there is very little actual negotiation involved in the implementation of the trip reduction ordinance. The main advantage of this ordinance is ease of employer participation. Because compliance with the ordinance is determined by the number of full-time employees, it is easy for employers to determine whether or not they are subject to the ordinance. In addition, the requirements they must meet (as set forth in the ordinance) are not difficult. Thus, participation by employers is relatively simple to achieve. The disadvantage of this approach is that individual employers are not responsible for specific traffic reduction goals. Employers will almost always elect to implement the least rather than the most cost 
effective TDM strategies. As long as Durham County is able to meet its overall traffic reduction goals, this trip reduction ordinance can be deemed successful.

\section{Parking and Transportation Demand Ordinance}

\section{Cambridge, Massachusetts}

Sources: Interviews with Susanne Rasmussen (Director of the Environmental and Transportation Planning Division, Community Development Department, Cambridge, MA), Catherine Preston (PTDM Planning Officer, Cambridge, MA), and Jim Gascoigne (Executive Director, Charles River TMA); Cambridge City Code, Chapter 10.18

Resources: The following documents are available at www.cambridgema.gov :

- Parking and Transportation Demand Management (PTDM) Ordinance

- Interdepartmental Parking Facility Registration Form

- $\quad$ PTDM Employee Transportation Coordinator Designation Form

- $\quad$ PTDM Plan Property Transfer Form

- PTDM Small Project Plan

- Zoning Ordinance

This case study involves Cambridge, Massachusetts, a city of over 100,000 residents covering an area of 6.5 square miles. Located just across the Charles River from Boston, Cambridge is home to Harvard University, the Massachusetts Institute of Technology, and a strong high-tech business sector. The Parking and Transportation Demand Management Ordinance discussed here is but one part of the City's TDM program, designed "to improve mobility and access, reduce congestion and air pollution, and increase safety. These programs work to reduce the level of drive-alone travel by promoting walking, bicycling, carpooling, vanpooling, public transportation, and other sustainable modes. The City works cooperatively with citizens, businesses, and institutions in Cambridge and the Boston area to implement TDM measures” (53).

Another codified example of Cambridge's TDM program is Article 19 of the Zoning Ordinance which addresses special permits required for "large projects" whose definition varies, depending on the specific type of development being proposed (54). Applicants for a large project special permit are required to conduct a traffic study, which should "identify parking and transportation demand management measures and other mitigation measures proposed to ameliorate any adverse traffic impacts identified in the study.” Traffic mitigation measures are outlined in Article 18 of the Zoning Ordinance. Additional citywide transportation demand management efforts include support of the EZRide Shuttle, GoGreen Month, Bike Week, and a pilot project for Enhanced Bus Stop Signage.

\section{Background}

The Parking and Transportation Demand Management (PTDM) Ordinance (Chapter 10.18) was passed in November 1998 to provide some "teeth" to a stagnant Vehicle Trip Reduction Ordinance (VTRO) and address concerns about increased traffic within the community itself. The VTRO, passed in 1992, was a response to concerns about air quality, and, more specifically, about transportation's contribution to declines in air quality and the resulting parking freeze imposed by the Massachusetts Department of Environmental in the early 1970s. A broader goal of the VTRO was regulating improvements to air quality and reductions in vehicle trips via a new approach to transportation. It is interesting to note that the parking freeze was actually requested by the Cambridge City Council as a tool to guard against the growth of new parking spaces that would meet increased demand from the neighboring city of Boston. The freeze applies only to the construction of 
new, fee-based parking facilities, either surface or structures, and does not apply to on-street parking or accessory parking.

Another significant factor for passing the PTDM Ordinance was a general fear of traffic that might be brought about by the rapid growth of the biotech and dot-com industries within the city during the late 1990s; however, the very biotech firms seen by many Cambridge residents as being a major source of their city's traffic problems were, in reality, some of the city's earliest practitioners of TDM, developing in-house programs for their employees. Traffic fears were enhanced with the end of Cambridge's rent control program in 1996, when the resulting change in the city's demographics led many Cambridge residents to perceive the presence of a higher number of cars per household than in previous years.

\section{Parking and Transportation Demand Management Ordinance (PTDM)}

The Parking and Transportation Demand Management Ordinance, Chapter 10.18 of Cambridge's City Code, states its purpose: "to regulate and control atmospheric pollution from motor vehicles by formalizing parking and transportation demand management planning, programs, and coordination which have been ongoing for a number of years. This Chapter will reduce vehicle trips and traffic congestion within the city, thereby promoting public health, safety, and welfare and protecting the environment." The ordinance requires parking and transportation demand management plans for commercial parking facilities and other types of non-residential parking facilities, provided they meet certain size requirements. Elements of this ordinance include:

- Establishment of purpose, definitions, and designation of a PTDM Planning Officer;

- Registration of all parking spaces;

- Parking and Transportation Demand Management plans;

- Reduction in minimum parking requirements and maximum distance standards;

- Requirements applicable to small projects; and

- Enforcement, evaluation, and expiration.

Basically, the process involves registration of all parking spaces prior to the construction that creates the spaces. Building, expansion or operation of a parking facility requires a Parking and Transportation Demand Management Plan approved by the Planning Officer. The PTDM Plan may include requests for "fewer parking spaces that [sic] the minimum set forth by the Zoning Ordinance" or "utilizing off-site parking spaces that are further from the project site than the maximum distance requirements set forth in the Zoning Ordinance." Small projects (using 19 or fewer parking spaces) are required to implement a minimum of three PTDM measures. Enforcement of the ordinance includes a per parking space, per day monetary fine for violations. The ordinance, as originally written, had a three-year sunset clause; after re-approval in 2001, it contains a five-year sunset clause, set to expire in 2006.

The city's Traffic, Parking and Transportation department maintains an inventory of all off-street parking spaces located within the city. Anytime a developer or property owner attempts to increase the number of non-residential spaces beyond the number listed in the inventory for a particular piece of property, the PTDM ordinance is triggered. This is typically a result of other building activities, and therefore is flagged during the application process for special permits, building permits, open-air parking lot licenses, garage and gasoline storage licenses, or curb cuts, for example.

The annual cost of administering and enforcing PTDM in the City of Cambridge amounts to staffing one full-time professional planner. The city is able to achieve some economies of scale, because their 
Traffic and Parking Department (which maintains the inventory and is responsible for enforcement) is able to use existing staff to carry out inspections and enforcement actions.

\section{Negotiations between the City and the Developer}

Any developer or property owner who plans on increasing off-street non-residential parking must obtain an approved PTDM plan before a building permit, special permit, certificate of occupancy, license, or variance can be issued. This means that negotiations between the developer/property owner and the City do not include whether a TDM plan is required, but what specific form the plan will take.

The starting point for these negotiations is usually the identification of comparable plans that have already been implemented and have shown a reasonable amount of success. The ideal candidate for comparison would be a similar type of business, located in an area with a similar level of transit service, and one that has at least some monitoring to show successful achievement of the mode-split commitments. Once a starting point has been selected, the developer/property owner examines the plan and determines possible modifications to better fit their specific situation. Generally, plans that have elements supporting all modes of transportation and are sufficient to meet their mode-split targets stand the best chance of being approved. Developers typically do not propose radically different plans from those suggested by the PTDM manager. In general, negotiations revolve around the degree of support for various elements of the plan-how much subsidization of transit passes will be required, whether or not there is a need for a privately-run shuttle, or how many HOV spaces will be required, etc.

The draft process itself usually takes from 40 to 60 days. The process typically consists of the following elements:

- The developer/property owner writes and submits a draft plan;

- $\quad$ The PTDM Manager comments on the draft;

- The developer/property owner and the PTDM manager conduct a face-to-face meeting; and

- The developer/property owner writes and submits a final plan.

In some rare cases, there may be additional drafts and comments. If the process continues for more than the 60 days designated by the PTDM Ordinance, the parties have to agree to an extension of the deadline. Extensions are usually required because the developer has a large team that needs to be consulted on the plan. On the other hand, extensions required because of difficulty reaching an agreement between the developer/property owner and the City are relatively rare; to date, there has been only one plan rejected. Any plans not acted upon by the PTDM manager within 60 days of submittal are automatically approved.

Cambridge's experience with TDM negotiations suggests that developer resistance can vary significantly: "Sometimes, developers have been amenable to everything we suggest during permitting, and the ones we get resistance from are their eventual tenants," says Catherine Preston, Cambridge's PTDM manager. "Small property owners tend to be more resistant than larger property owners. At this point, we also encounter developers who have been through the process before on other projects and are somewhat accepting of it, but, based on their experience, have specific tweaks they look for." According to Preston, it is the tenants/employers occupying the buildings who tend to be most sensitive about PTDM. For this group, the strongest resistance comes from anything that affects the supply or cost of parking for their employees. Preston cites fairness and transparency within the negotiation process as a key element of success. It is critical not to give any developer or 
property owner the impression that they are being "singled out" or treated differently from others in comparable situations.

Sometimes, developers and property owners argue that there is a mistake in the inventory. In these instances, the developers and property owners may present to the City any available documentation that demonstrates the spaces in question existed prior to November 1998. However, the Traffic and Parking department makes the final determination of whether or not an increase has occurred. If one has, the project is referred to the PTDM manager, who then begins the negotiation process. There are some instances in which developers or property owners increase the number of spaces without City approval through re-striping of an existing lot or conversion of residential spaces to non-residential use. Typically, the City discovers these instances through word of mouth, whether from an annoyed neighbor, a city worker involved in a different project in the area, or a customer of the business. In these instances, Cambridge's inspectors then visit the site and verify the number of spaces in operation, as well as their purpose.

\section{Monitoring and verification}

All PTDM plans for projects of 20 or more parking spaces are required to submit annual monitoring reports to the City. These include annual mode-split surveys, and biannual driveway and parking utilization counts. Surveys must have a response rate of $60 \%$ to be considered reliable, and the City has the ability to audit the surveys and counts, should that prove necessary. Any discrepancies between the survey and the counts raise a "red flag" with the Parking and Transportation Department, which then works with the property owner to determine the cause of the discrepancy.

Cambridge does not measure the progress of PTDM by traffic counts on city streets, thereby leaving project monitoring reports as the primary source of data regarding the success of the program. There are two main reasons for this:

- PTDM only impacts new, non-residential development in the City (it is not retroactive to existing parking and does not affect new residential parking), and

- The City has very limited ability to influence regional traffic passing through Cambridge (i.e., trips without an origin or destination within the city); in fact, growth in traffic passing through Cambridge has been more significant than growth in traffic generated by projects within the city itself.

In determining the level of success, Cambridge's planning professionals look at how much traffic a new project has generated, and then attempt to estimate how much more traffic would have been generated without the PTDM ordinance: "We look at the 1990 census and determine the number of trips that would be generated with a project in that tract," says Susanne Rasmussen, Director of Cambridge's Environmental and Transportation Planning Division. "We then require limiting traffic increases to a maximum of that number, minus ten percent."

\section{Transportation Management Association role}

Cambridge's TDM efforts benefit from the presence of the Charles River Transportation Management Association (CRTMA), which assists regulated businesses in complying with their PTDM agreements. Boasting 20 members, CRTMA helps implement programs like shuttles, Emergency Ride Home, transportation fairs, information distribution and marketing, and car and vanpool ride-matching. This centralized implementation approach permits member businesses to achieve results in a cost-effective manner.

CRTMA Executive Director, Jim Gascoigne, describes how that process generally works: 
"We meet with each member to determine their interests and needs. We work with the members to develop a specific program, where necessary, or to implement existing programs. Programs that we implement for members are the standard tools of TDM. CRTMA provides an economy of scale; in many businesses, for a fraction of the cost and aggravation of implementing the programs in-house, CRTMA can perform the function.

Our biggest success in this regard is the EZride shuttle service. The five vehicles that comprise EZRide replace ten corporate shuttles, most of which were required by PTDM agreements. The result is a publicly accessible, privately funded service that offers greater frequency, greater comfort, and more destinations (including buses, three of Boston's subway lines, and the North Side Commuter Rail), all at a price significantly less than the cost of running an individual corporate shuttle. This service likely would not have been possible without shuttle requirements in PTDM agreements.

The PTDM got businesses into the shuttle business as a way to improve their mode-splits. CRTMA got the businesses to work together by saving them money.”

CRTMA's involvement in Cambridge's TDM plans actually began at a very early stage. CRTMA staffers pitched the concept of TDM to area businesses within the Chamber of Commerce, explaining why it made good business sense and, ultimately, ended up with their support. 


\section{REFERENCES}

1. TDM (Online) Encyclopedia. May 2005. Victoria Transport Policy Institute. http://www.vtpi.org/tdm/tdm12.htm

2. Kramer, Jeff and Edward A. Mierzejewski. 2002. The 2002 Review of Florida's Twenty-Five Long Range Transportation Plans. Center for Urban Transportation Research, University of South Florida, Tampa. August.

3. TEA-21 - Transportation Equity Act for the 21st Century, Moving Americans into the 21st Century, A Summary - An Overview. US Department of Transportation, 1998.

4. Federal Highway Administration. Federal Transit Administration. Metropolitan Capacity Building Program. The Metropolitan Transportation Planning Process: Key Issues. Online. US Department of Transportation. 6 June 2005.

5. Chapter 163.3161(3), F.S.

6. Chapter 163.3177(6)(J), F.S.

7. Chapter 163.3177(3)(a)1-4, F.S.

8. The complete language of the legislation can be found on Florida Sunshine Online at http://www.leg.state.fl.us/Welcome/index.cfm

9. Chapter 163.3180(15)(a). FL, Florida Statutes.

10. Callies, David L., Daniel J. Curtin, Jr. and Julie A. Tappendorf. 2003. Bargaining for Development: A Handbook on Development Agreements, Land Development Conditions, Vested Rights, and the Provision of Public Facilities. Washington D.C.: Environmental Law Institute.

11. Sarasota County. Article VIII Development Agreements, Exhibit A., Sarasota County Code. Adopted October 12, 2004.

12. Sarasota County. Board of County Commissioners meeting minutes, October 12, 2004.

13. Chapters 380.06(15)(d) and (e) and 380.06(16), F.S.

14. Transportation Research Board Statewide Data and Information Systems Committee. 2005. Florida Department of Transportation, Major Transportation Data Activities.

15. Liu, R., S. Polzin, and R. Pendyala. 1998. "Simulation of the Effects of Intermodal Transfer Penalties on Transit Use”, Transportation Research Record 1623, Transportation Research Board, National Research Council, Washington, D.C., pp. 88-95.

16. Florida Department of Transportation. "2002 Quality/Level of Service Handbook", Introduction, Section 1.4 Multimodal Structure, Office of the State Transportation Planner, Systems Planning Office, Tallahassee, Florida, p. 14.

17. Hendricks, Sara. 2002. "Land Developer Participation in Providing for Bus Transit Facilities/Operations”. Funded by the National Center for Transit Research. Sponsored by the Florida Department of Transportation. Prepared by the Center for Urban Transportation Research, University of South Florida, Tampa, Florida. March.

18. Wolshon, B., E. Urbina, and M. Levitan. 2001. "National Review of Hurricane Evacuation Plans and Policies”. Louisiana State University Hurricane Center, Baton Rouge, LA.

19. U.S. Bureau of the Census. 2003. American Community Survey. Washington, D.C.

20. U.S. Bureau of the Census. 2000. Summary File 3, Table DP-2, Profile of Selected Social Characteristics. Washington, D.C. See also U.S. Bureau of the Census, 2000. Florida Quick Facts. Washington, D.C. See also U.S. Bureau of the Census, 1997. "Census and You: Monthly News from the Bureau of the Census”. Vol. 32, No. 11, p. 5. Washington, D.C.

21. U.S. Bureau of the Census. 2003. Historical Poverty. Table 19. Washington, D.C.

22. Parker, Gretchen, Baird Helgeson and Neil Johnson. "We're Not Ready", The Tampa Tribune, October 2, 2005, p. 13. Figures based upon U.S. Census, 2000; Agency for Health Care Administration; Florida Geographic Data Library, 2004; Pinellas and Hillsborough county property appraisal data, September 2005; Hillsborough County Emergency Management. 
23. Florida Department of Transportation Fact Book. 2003. Compiled by the Center for Urban Transportation Research, University of South Florida, with source data from the FDOT Transportation Statistics Office, Tallahassee, FL.

24. Hendricks, Sara. 2004. "Commuter Choice Program Case Study Development and Analysis". Funded by the National Center for Transit Research. Sponsored by the Florida Department of Transportation. Prepared by the Center for Urban Transportation Research, University of South Florida, Tampa, Florida. August.

25. National Household Travel Survey. 2001. U.S. Department of Transportation, Bureau of Transportation Statistics, Washington, D.C.

26. Mason, John. Understanding the Communications and Information Needs of Elected Officials for Transportation Planning and Operations. Federal Highway Administration. January, 2005.

27. Context Sensitive Design for Major Urban Thoroughfares: A Joint Project of the Institute of Transportation Engineers and the Congress for New Urbanism. Project Summary and Update. Congress for the New Urbanism. Institute of Transportation Engineers. November 2004.

28. Kramer, Jeff and Edward A. Mierzejewski. 2002. The 2002 Review of Florida's Twenty-Five Long Range Transportation Plans. Center for Urban Transportation Research, University of South Florida, Tampa. August.

29. Kramer, Jeff. 2005 "Review of MPO Long Range Transportation Plans and Regional MPO Planning Activities and Products: Research Support for the Florida Transportation Plan Update”. Center for Urban Transportation Research, University of South Florida, Tampa, August.

30a.Winters, Phil and Chris Hagelin. 2000. Hillsborough County Long Range TDM Plan. Prepared for Bay Area Sommuter Services by the Center for Urban Transportation Research, University of South Florida, Tampa.

30b.Winters, Phil and Chris Hagelin. 2000. Pinellas County Long Range TDM Plan. Prepared for Bay Area Sommuter Services by the Center for Urban Transportation Research, University of South Florida, Tampa.

31. Hendricks, Sara and Phil Winters. February 2002. "Telecommunications and Its Future Role in the Public Transportation Arena”. Sponsored by the National Center for Transit Research and the Florida Department of Transportation. Center for Urban Transportation Research. University of South Florida, Tampa.

32. Federal Highway Administration. 2004. "Mitigating Traffic Congestion-The Role of Demand-Side Strategies". Prepared by the Association for Commuter Transportation, UrbanTrans Consultants, Inc., Parsons Brinckerhoff Quade and Douglas, Inc., and ESTC, in partnership with the U.S. Department of Transportation, FHWA Office of Operations. Washington, D.C. October.

33. Pinellas County. 2025 Long Range Transportation Plan Update. Metropolitan Planning Organization, Pinellas County, FL, October 2004.

34. Burch, David. "Vehicle Employee Ratio-A Better Trip Reduction Performance Measure", TDM Review, Association for Commuter Transportation, Vol II, No. 1, January 1994. Mr. Burch was Senior Environmental Planner for the Bay Area Air Quality Management District in California at the time of this writing.

35. City of Orlando. Southeast Sector Plan. Retrieved September 2004. http://www.cityoforlando.net/planning/deptpage/sesp/sespvisi.htm

36. Polk County, Florida. Ronald Reagan Parkway Selected Area Plan Amendment Text. Retrieved May 25, 2005. http://www.polk-county.net/county_offices/planning/projects.aspx

37. Barnett, Jonathan. 2003. Redesigning Cities: Principles, Practice, Implementation. Planners Press, Washington, D.C.. 
38. Nicholas, James C. and Arthur Nelson. 1988. "Determining the Appropriate Development Impact Fee Using the Rational Nexus Test.” Journal of the American Planning Association. Chicago: Winter, Vol. 54, Issue 1, pp. 56-67.

39. Cooper, Connie. 2000. B. Transportation Impact Fees and Excise Taxes: A Survey of 16 Jurisdictions. PAS Report No. 493, American Planning Association, Chicago, IL.

40. Nelson, Arthur C., ed. 1988. Development Impact Fees: Policy Rationale, Practice, Theory, and Issues. Chapter 13, "A Model Impact Fee Authorization Statute”. Chicago: Planners Press.

41. City of Orlando. Road Impact Fee Ordinance, Chapter 56, City of Orlando Code. City of Orlando, FL, December 1994, as amended.

42. City of Orlando. Proposal: A Southeast Orlando Transportation Impact Fee for Traditional Neighborhood Developments, in conjunction with Southeast Orlando Sector Plan, Development Guidelines and Standards. Planning \& Development/Transportation Planning Bureau, City of Orlando, Florida, circa 1999.

43. Shoup, Donald. 2003. "Truth in Transportation Planning”. Journal of Transportation and Statistics. Vol. 6, No. 1. Author is a member of the faculty of the Department of Urban Planning, University of California, Los Angeles.

44. Nelson\Nygaard Consulting Associates. City of Palo Alto, Transportation Impact Fee Nexus Study, Revised Draft Final Report. Nelson\Nygaard Consulting Associates, April 2004.

45. Broward County Ordinance 2005-08, Amending Chapters 5 and 27 of the Broward County Code of Ordinances. 2005.

46. Broward County Resolution 2005-291. 2005.

47. Winters, Phil and Sara Hendricks. "Transportation Initiative for Mobility and Economic Development”. Prepared for the City of Boca Raton. Center for Urban Transportation Research. University of South Florida, Tampa, October, 2000.

48. Hendricks, S. 2004. "2003 Transportation Management Association Survey: Final Report of the National TDM and Telework Clearinghouse”. Funded by the National Center for Transit Research. Sponsored by the Florida Department of Transportation. Prepared by the Center for Urban Transportation Research, University of South Florida, in association with the Association for Commuter Transportation. Tampa, Florida. April.

49. Valk Peter. President, Transportation Management Services. Parking and Transportation Management Workshop. Florida Commuter Choice Certificate Program. August 3, 2004. Center for Urban Transportation Research, University of South Florida, Tampa.

50. Zink, Janet. May 19, 2005. "Hospital Wins Tussle Over Park Land” St. Petersburg Times.

51. Linda Walker, HARTline; Melanie Calloway, City of Tampa Transportation Department; Catherine Coyle, City of Tampa Land Development Coordination Office; City of Tampa Rezoning Request Z03-57; meeting minutes of the Tampa City Council from June 11, 2003; Letter from Robert A. Rutledge, Dyer Riddle Mills \& Precourt, to Stephen Stanley, Davis Islands Civic Association.

52. Zink, Janet. May 19, 2005. “Hospital Wins Tussle Over Park Land” St. Petersburg Times, Quoting Les Valitutti, public hearing attendee.

53. Parking and Transportation Demand Management. City of Cambridge. Online. October 2004.

54. Zoning Ordinance. City of Cambridge. Online. October 2004. 


\section{BIBLIOGRAPHY}

Alden, Beth. Transportation Planning and Programs Team Leader, Hillsborough Metropolitan Planning Organization. Florida. Email interview. January 2005.

Allen, Tim. Growth Management Department. City of Tallahassee, Florida. Personal interview. June 22, 2005

Anderson, Charseem. Transportation Planner, City of Durham, North Carolina. Personal interview. November 2004.

Baier, Ned. Manager, Transportation Division, Planning \& Growth Management, Hillsborough County, Florida. Email interview. November 2004.

Barnett, Jonathan. Redesigning Cities: Principles, Practice, Implementation. Washington, D.C.: Planners Press. 2003.

Bay Area Commuter Services. Organizational website. http://www.tampabayrideshare.org. Retrieved May 2005.

Bowers, Wiatt. Transportation Planner, Parsons Brinckerhoff. Personal and email interviews. December 2004, May 2005, June 2005.

Burch, David. "Vehicle Employee Ratio-A Better Trip Reduction Performance Measure”, TDM Review, Association for Commuter Transportation, Vol II, No. 1, January 1994. Mr. Burch was Senior Environmental Planner for the Bay Area Air Quality Management District in California at the time of this writing.

Callies, David L., Daniel J. Curtin, Jr. and Julie A. Tappendorf. Bargaining for Development: A handbook on Development Agreements, Land Development Conditions, Vested Rights, and the Provision of Public Facilities. Washington D.C.: Environmental Law Institute. 2003.

Carpoolworld.com. Organizational website. Retrieved June 23, 2005. www.carpoolworld.com

Chiaramonte, Ray. Hillsborough County City-County Planning Commission. Email interview. June 2005.

City of Boulder. Modal Shift in the Boulder Valley. March 2004

City of Boulder. Transportation Master Plan Update. September 2003

City of Boulder. Transportation Options Toolkit. Retrieved October 2004.

City of Boulder. Revised Code. Retrieved October 2004.

City of Cambridge. Parking and Transportation Demand Management Ordinance. Cambridge, Massachusetts. Retrieved 10/5/2004.

http://bpc.iserver.net/codes/cbridge/_DATA/Title_10/18/index.html 
City of Cambridge. Zoning Ordinance. Cambridge, Massachusetts. Retrieved 10/5/2004. http://www.cambridgema.gov/ CDD/cp/zng/zord/index.html

City of Cambridge. Zoning Ordinance, Article 19.000 Project Review. Cambridge, Massachusetts.

City of Cambridge. City Code, Chapter 10.18. Cambridge, Massachusetts.

City of Jacksonville. 2010 Comprehensive Plan Transportation Element.

http://www.coj.net/NR/rdonlyres/efuh3avjdmwi3vgxkbn7om7t6d7gdidizrxkcbkxldlcjuim3f7l43yo5xhp q2d2aeibub57ao3yr4za2cbgdjofdjd/COMP+PLAN-TRANS+Nov04+9+03+T2.pdf

City of Orlando. Growth Management Plan Transportation Element.

(http://www.cityoforlando.net/planning/cityplanning/Policy\%20Document/5c.\%20Transportation\%2 oElement.pdf)

City of Orlando. Proposal: A Southeast Orlando Transportation Impact Fee for Traditional Neighborhood Developments, in conjunction with Southeast Orlando Sector Plan, Development Guidelines and Standards. Orlando, FL: City of Orlando Planning \& Development/Transportation Planning Bureau, circa 1999.

City of Orlando. Road Impact Fee Ordinance, Chapter 56, City of Orlando Code. Orlando, FL: City of Orlando, December 1994.

City of Orlando. Southeast Sector Plan. Retrieved September 2004.

(http://www.cityoforlando.net/planning/deptpage/sesp/sespvisi.htm)

City of Rockville. Rockville Bikeway Master Plan Update. As adopted April 2004. Rockville Maryland. Retrieved 1/10/04. http://www.rockvillemd.gov/masterplan/bikeway/index.html.

City of Rockville. Comprehensive Transportation Review (CTR) Methodology. Rockville, MD. September 2004.

City of Sarasota. City Plan Transportation Element.

(http://www.sarasotagov.com/Planning/SarasotaCityPlan/Current\%20Transportation\%20Chapter.P $\underline{D F}$

City of Tallahassee. Code of Ordinances. Retrieved October 2004, June 2005.

City of Tallahassee. 2010 Long-Range Comprehensive Plan, Transportation and Future Land Use elements. Retrieved June 2005.

City of Tallahassee. City Website http://talgov.com/citytlh/growth/develop/ldindex.htm. Retrieved June 2005.

City of Tallahassee. SouthWood draft development order. April 1999.

City of Tallahassee. SouthWood Planned Unit Development application. December 2003.

City of Tampa. City Council Meeting Minutes. June 11, 2003.

City of Tampa. Code of Ordinances. Retrieved October 2004, June 2005. 
City of Tampa. "Comprehensive Plan Monitoring/Management Report" Preliminary Draft. Comprehensive Plan Policies and Implementation Mechanisms by Element, Volume 1. Strategic Planning and Technology Department. Tampa, Florida: May, 2004.

City of Tampa. Comprehensive Plan. Planning Commission. http://www.plancom.org

City of Tampa. “Off-Street Parking Standards.” Land Development Code, Article XVIII, Section 27242.

City of Tampa. “The Commercial Permitting Process.” Commercial Plan Review Handbook. Commercial Development Services Division, Department of Business \& Housing Development. Tampa, Florida: March, 2004.

City of Tampa. Rezoning Request Z03-57. June 2003.

City of Tampa. Rezoning Request Z04-123. June 2005.

Clark County. History of Clark County Code Regarding Incentives for TransitOriented/Transportation Demand Reducing Site Design Elements. Memorandum from Evan Dust, Program Manager II (Transportation). Clark County, Washington, December 2004.

Commuter Services of North Florida. Quarterly Executive Summary. Third quarter, 1999.

Congress for the New Urbanism, Institute of Transportation Engineers. Context Sensitive Design for Major Urban Thoroughfares: A Joint Project of the Institute of Transportation Engineers and the Congress for New Urbanism. Project Summary and Update. Washington, D.C.: November 2004.

Cooper, Connie B. Transportation Impact Fees and Excise Taxes: A Survey of 16 Jurisdictions. Planning Advisory Service Report (PAS) No. 493. Washington, DC: American Planning Association, July 2000.

Coyle, Catherine. Planning \& Development Coordinator, Land Development Coordination, City of Tampa. Email interviews. June 2005.

Durham County. County Code, Article V. “Commute Trip Reduction Program.” Durham County, North Carolina. Retrieved October 2004.

Durian, Steve. Transportation Engineer, Planning \& Development Services, City of Boulder, Colorado. Email interviews. October 2004, June 2005.

Federal Highway Administration. Metropolitan Capacity Building Program. The Metropolitan Transportation Planning Process: Key Issues. US Department of Transportation. June 6, 2005.

Federal Highway Administration. Mitigating Traffic Congestion-The Role of Demand-Side Strategies. Prepared by the Association for Commuter Transportation/UrbanTrans Consultants, Inc., Parsons, Brinckerhoff, Quade, and Douglas, Inc. and ESTC, in partnership with the U.S. Department of Transportation, FHWA, Office of Operations. Washington, D.C.: October, 2004. 
Florida Department of Transportation. Fact Book. Compiled by the Center for Urban Transportation Research, University of South Florida, with source data from the FDOT Transportation Statistics Office. Tallahassee, FL: 2003.

Florida Department of Transportation. Quality/Level of Service Handbook. Office of the State Transportation Planner, Systems Planning Office. Tallahassee, Florida: 2002.

Florida Department of Transportation, Major Transportation Data Activities. Transportation Research Board. Statewide Data and Information Systems Committee. Washington, DC: 2005.

Florida Statutes. 2005. http://www.leg.state.fl.us/Statutes/

Foree, Audra. TDM Planner for Triangle Transit Authority, Research Triangle Park, North Carolina. Personal interview. November 2004.

Gascoigne, Jim. Executive Director, Charles River Transportation Management Association. Massachusetts. Personal and Email Interviews. October 2004 \& June 2005.

Hendricks, Sara and Cecelia Dyhouse. Land Developer Participation in Providing for Bus Transit Facilities and Operations. National Center for Transit Research at the Center for Urban Transportation Research, University of South Florida. March 2002.

Hendricks, Sara. Commuter Choice Program Case Study Development and Analysis. National Center for Transit Research at the Center for Urban Transportation Research, University of South Florida. Tampa, Florida: August, 2004.

Hendricks, Sara. 2003 Transportation Management Association Survey: Final Report of the National TDM and Telework Clearinghouse. National Center for Transit Research at the Center for Urban Transportation Research, University of South Florida, in association with the Association for Commuter Transportation. Tampa, Florida: April, 2004.

Hillsborough County. Land Development Code. Hillsborough County, Florida. Retrieved May 2005.

Hillsborough County. Transportation Technical Manual. Tampa, Florida: October, 2003.

Hillsborough County. Understanding Transportation Concurrency. Planning and Growth Management Department, Transportation Division. Tampa, Florida: July, 2002.

Hillsborough County. Development Review Procedures Manual. Planning and Growth Management Department. Tampa, Florida: 2000.

Horton, Jeff. Executive Director, Commuter Services of North Florida. Email interviews. June 2005.

Improving Transit Involvement in Development Review: Year 2000 Baseline Measurements and Recommendations. The Marketing Institute, Florida State University College of Business. Tallahassee, Florida: July, 2002.

Kramer, Jeff and Edward A. Mierzejewski. The 2002 Review of Florida's Twenty-Five Long Range Transportation Plans. Center for Urban Transportation Research, University of South Florida. August 2002. 
Kress, Karen. Director of Transportation and Planning, Tampa Downtown Partnership. Email interviews. January 2005, June 2005.

Liu, R., S. Polzin, and R. Pendyala. "Simulation of the Effects of Intermodal Transfer Penalties on Transit Use,” Transportation Research Record 1623. Transportation Research Board, National Research Council. Washington, D.C.: 1998, pp. 88-95.

The Marketing Institute. 2002. "Improving Transit Involvement in Development Review: Year 2000 Baseline Measurements and Recommendations". Final Report. Prepared by the Florida State University College of Business. Prepared for the Florida Department of Transportation, Public Transit Office. Tallahassee, Florida. July.

Mason, John. Understanding the Communications and Information Needs of Elected Officials for Transportation Planning and Operations. Washington, D.C.: Federal Highway Administration, January 2005.

Morris, Marya, ed. Creating Transit-Supportive Land-Use Regulations. Planning Advisory Service Report (PAS) Number 468. Washington, D.C.: American Planning Association, 1996.

Nelson, Arthur C., ed. 1988. Development Impact Fees: Policy Rationale, Practice, Theory and Issues. Chapter 13, “A Model Impact Fee Authorization Statute”, Chicago: Planners Press.

Nelson\Nygaard Consulting Associates. City of Palo Alto, Transportation Impact Fee Nexus Study, Revised Draft Final Report. Nelson\Nygaard Consulting Associates, April 2004.

Nicholas, James C. and Arthur Nelson. "Determining the Appropriate Development Impact Fee Using the Rational Nexus Test.” Journal of the American Planning Association Vol. 54, Iss. 1 (Winter 1988): 56-67.

Organizational Review of the Capital Area MPO (CAMPO). Center for Urban Transportation Research. University of South Florida. June 2003.

Pinellas County. 2025 Long Range Transportation Plan Update. Pinellas County, FL: Metropolitan Planning Organization, October 2004.

Polk County, Florida. Ronald Reagan Parkway Selected Area Plan Amendment Text. Retrieved May 25, 2005. (http://www.polk-county.net/county offices/planning/projects.aspx)

Polk, Tom. Senior Planner, Sarasota County Public Works Transportation Planning Department. Personal interview. August 2005.

Preston, Catherine. PTDM Planning Officer, City of Cambridge, MAPersonal and Email Interviews. October 2004.

Rasmussen, Susan. Director, Environmental and Transportation Planning Division, Community Development Department, City of Cambridge, MA. Personal and Email Interviews. October 2004.

Rutledge, Robert A., Dyer, Riddle, Mills \& Precourt. Letter to Stephen Stanley, Davis Islands Civic Association, dated April 15, 2005.

Sarasota County. Board of County Commissioners meeting minutes, October 12, 2004. 
Sarasota County. Code of Ordinances, Article VIII, Development Agreements. Retrieved August 10, 2005.

Seggerman, Karen E. and Kristine M. Williams. Memo: Impact Fee Credits for Livable Community Improvements. Center for Urban Transportation Research, University of South Florida. January 2005.

Shoup, D. Truth in Transportation Planning. Journal of Transportation and Statistics. Vol. 6, No. 1, 2003. Author is a member of the faculty of the Department of Urban Planning, University of California, Los Angeles.

TDM Encyclopedia. Online. Victoria Transport Policy Institute. May 2005. http://www.vtpi.org/tdm/tdm12.htm

U.S. Census Bureau. American Community Survey. Washington, D.C.: 2003.

U.S. Census Bureau. Historical Poverty. Table 19. Washington, D.C.: 2003.

U.S. Census Bureau. Profile of Selected Social Characteristics. Summary File 3, Table DP-2. Washington, D.C.: 2000.

U.S. Census Bureau. Florida Quick Facts. Washington, D.C.: 2000.

U.S. Census Bureau. "Census and You: Monthly News from the Bureau of the Census.” Vol. 32, No. 11, p. 5. Washington, D.C.: 1997.

U.S. Department of Transportation. "TEA-21-Transportation Equity Act for the $21^{\text {st }}$ Century, Moving Americans into the $21^{\text {st }}$ Century. A Summary-An Overview.” Washington, D.C.: U.S. Department of Transportation, 1998.

Walker, Linda. Email interviews. June 2005.

Valk, Peter. President, Transportation Management Services. Parking and Transportation Management Workshop. Florida Commuter Choice Certificate Program. August 3, 2004. Center for Urban Transportation Research, University of South Florida, Tampa.

Winters, Philip L. and Francis Cleland. Worksite Trip Reduction Model and Manual. Tampa: National Center for Transit Research/Florida Department of Transportation, No. BC137, April 2004.

Winters, Philip L. and Sara J. Hendricks. Quantifying the Business Benefits of TDM. National Center for Transit Research at the Center for Urban Transportation Research, University of South Florida. June 2003.

Wolshon, B., E. Urbina, and M. Levitan. National Review of Hurricane Evacuation Plans and Policies. Louisiana State University Hurricane Center. Baton Rouge, LA: 2001. 


\section{Appendices}




\section{APPENDIX A: SARASOTA COUNTY DEVELOPMENT AGREEMENT}

The following is an excerpt from the Sarasota County Development Agreement, Section 94-261 of the Sarasota County Code. (Source: www.municode.com).

\section{ARTICLE VIII. DEVELOPMENT AGREEMENTS}

Sec. 94-261. Findings.

The Board of County Commissioners hereby makes the following findings:

(a) Pursuant to Article VIII, Section I(g) of the Constitution of the State of Florida, the Sarasota County Home Rule Charter, F.S. § 125.01, and the Local Government Comprehensive Planning and Land Development Regulation Act, (The "Act"), Chapter 163, Part II, Florida Statutes, as amended, Sarasota County is authorized and required to adopt a comprehensive plan.

(b) The Board of County Commissioners of Sarasota County adopted "Apoxsee, the Sarasota County Comprehensive Plan," in accordance with the provisions of the Act, including the adoption of acceptable levels of service for public facilities including transportation, potable water, sanitary sewer, parks, drainage and solid waste.

(c) The Board of County Commissioners of Sarasota County adopted Ordinance No. 89-103, as amended, the Sarasota County Concurrency Management System Regulations and codified as Chapter 94, Article VII, in order to insure that public facilities and services needed to support development will be available concurrent with the impact of such development.

(d) Pursuant to the Florida Local Government Development Agreement Act, F.S. §§ 163.3220-163.3243 (The "Development Agreement Act"), local governments are authorized to adopt by ordinance, procedures and requirements whereby a local government may consider and enter into a development agreement with any person having a legal or equitable interest in real property located within the local government's jurisdiction.

(e) The lack of certainty in the approval of development can result in a waste of economic and land resources; discourage sound capital improvement planning and financing; escalate the cost of housing and development; and discourage commitment to comprehensive planning.

(f) Development agreements entered into pursuant to the Local Government Development Agreement Act, strengthen the public planning process, encourage sound capital improvement, planning and financing; assist in assuring that there are adequate capital facilities to support development; encourage private participation in comprehensive planning; and reduce the economic cost of a development by providing assurances to a developer that, upon receipt of a development permit, the developer may proceed in accordance with existing laws and policies, subject to the conditions of a development agreement.

(g) The provisions of this ordinance, in their interpretation and application, are declared to be the minimum requirements necessary to accomplish the stated intent, purposes, and objectives of this ordinance. Nothing in this ordinance shall be interpreted as characterizing a development agreement as anything other than a discretionary, bilateral contract between the County and the owner with consideration given by both parties to the contract.

(h) The Board of County Commissioners of Sarasota County, has determined that it is in the best interest of achieving and maintaining the quality of life in Sarasota County to provide appropriate procedures and requirements for the adoption of development agreements through the provisions of Development Agreement Regulations.

(i) The Board of County Commissioners, sitting as the Sarasota County Land Development Regulation Commission has reviewed the proposed ordinance and has found that it is consistent with the Sarasota County Comprehensive Plan.

(Ord. No. 2004-086, § 1, 10-12-2004) 
Sec. 94-262. Adoption of the Sarasota County Development Agreement Regulations.

The Board of County Commissioners of Sarasota County hereby adopts the Sarasota County Development Agreement Regulations, attached to Ordinance No. 2004-086 as Exhibit "A" and made a part hereof by reference.

(Ord. No. 2004-086, § 2, 10-12-2004)

Editor's note: The Development Agreement Regulations are printed following this article.

Sec. 94-263. Applicability.

The Sarasota County Development Agreement Regulations shall be applicable throughout the unincorporated Sarasota County, Florida, and as otherwise provided by law.

(Ord. No. 2004-086, § 3, 10-12-2004)

Sec. 94-264. Effect on Other Ordinances and Regulations.

Nothing in this Ordinance shall be construed or applied to excuse or replace development approvals required under existing land development regulations, contained within Ordinance No. 97-051, the County's Land Development Regulations codified as Chapter 74 of the Sarasota County Code, nor to release any developer from its proportionate share of the cost of public facilities improvements otherwise required.

(Ord. No. 2004-086, § 4, 10-12-2004)

Sec. 94-265. Local Laws and Policies Governing Development Agreements.

Sarasota County's laws and policies set down in the development agreement as governing the development of the land at the time of the execution of the development agreement shall govern the development of the land for the duration of the development agreement, except that Sarasota County may apply subsequently adopted laws and policies to a development that is subject to a development agreement if the Board of County Commissioners holds a public hearing pursuant to the requirements of this article and determines any one of the following:

(a) The laws and policies are not in conflict with the laws and policies governing the development agreement and do not prevent development of the land uses, intensities or densities in the development agreement;

(b) The laws and policies are essential to the public health, safety, or welfare, and expressly state that they shall apply to a development that is subject to a development agreement;

(c) The laws and policies are specifically anticipated and provided for in the development.

(d) Sarasota County demonstrates that substantial changes have occurred in pertinent conditions existing at the time of approval of the development agreement; or

(e) It is demonstrated that the development agreement is based on substantially inaccurate information supplied by the developer.

(Ord. No. 2004-086, § 5, 10-12-2004)

Sec. 94-266. Forms.

Adoption of standard development agreement forms by resolution and certification of attorney.

(a) The Board of County Commissioners is hereby authorized to adopt by resolution standard forms for development agreements and security referenced in this ordinance.

(b) Development agreements submitted to the County for review shall be in the approved standard form and shall be accompanied by a certification from an attorney that the agreement is in the standard form, or that any changes, additions or deletions from the standard form are shaded or redlined in the proposed draft agreement. Additions shall be underlined; deletions shall be crosshatched or struck-through.

(Ord. No. 2004-086, § 6, 10-12-2004) 
Sec. 94-267. Enforcement.

(a) In accordance with F.S. $\S 163.3243$, as the same may be amended from time to time, any party to a development agreement, any aggrieved or adversely affected person as defined in F.S. § 163.3215(2) which will suffer an adverse effect to an interest protected or furthered by the Comprehensive Plan, or the state land planning agency may file an action for injunctive relief in the Circuit Court of Sarasota County to enforce the terms of a development agreement or to challenge compliance of the agreement with the provisions of the Development Agreement Act.

(b) In addition, any person who violates this article shall be subject to the enforcement provisions set out in Article VIII, Chapter 2, of the Sarasota County Code, as amended from time to time, and the penalties set forth therein.

(c) Nothing herein shall constitute an exclusive remedy, and the County reserves the right to pursue any and all legal and equitable remedies in order to abate a violation of this article.

(Ord. No. 2004-086, § 7, 10-12-2004)

Sec. 94-268. Legislative Act.

A development agreement is determined to be a legislative act of Sarasota County in the furtherance of its powers to plan and regulate by agreement and, as such, shall be superior to the rights of existing mortgagees, lien holders or other persons with a legal or equitable interest in the land subject to the development agreement, and the obligations and responsibilities arising thereunder on the property owner shall be superior to the rights of such mortgagees or lien holders and shall not be subject to foreclosure under the terms of mortgages or liens entered into or recorded prior to the execution and recordation of the development agreement.

(Ord. No. 2004-086, § 8, 10-12-2004)

\section{EXHIBIT A. SARASOTA COUNTY DEVELOPMENT AGREEMENT REGULATIONS}

\section{A. Intent and authority.}

The purpose of these regulations is to provide procedures and requirements whereby Sarasota County may consider and enter into a development agreement with any person having a legal or equitable interest in real property within the unincorporated Sarasota County, under the authority of The Florida Local Government Development Agreement Act, F.S. §§ 163.3220--163.3243.

The issuance of development agreements is intended to promote and facilitate orderly and planned growth and development by providing a degree of certainty in the development approval process. The certainty accorded developments under these regulations will: encourage greater participation in the comprehensive planning process; assure there are adequate public facilities for the development; and reduce the economic cost of development.

\section{B. Definitions.}

Apoxsee, the Sarasota County Comprehensive Plan, or Apoxsee means the document adopted by the Board of County Commissioners of Sarasota County and filed with the Clerk of said Board pursuant to Ordinance No. 89-18, as the same may be amended from time to time.

Applicant means any person or his duly authorized representative who submits a request for a development agreement for the purpose of obtaining approval thereof.

Board means the Board of County Commissioners of Sarasota County, Florida.

Comprehensive Plan means the document "Apoxsee, the Sarasota County Comprehensive Plan," ("Apoxsee"), adopted by the Board of County Commissioners of Sarasota County and filed with the 
Clerk of said Board pursuant to Ordinance No. 89-18, as the same may be amended from time to time.

Day means a working day, unless specifically referenced otherwise and shall exclude Saturdays, Sundays and legal holidays.

Density means the number of residential dwelling units permitted per gross acre of land as determined by the Sarasota County Zoning Regulations.

Developer means any person, including a governmental agency, undertaking any development.

Development, includes all other development customarily associated with a development permit unless otherwise specified. When appropriate to the context, "development" refers to the act of developing or to the result of development. Reference to any specific operation is not intended to mean that the operation or activity, when part of other operations or activities, is not development. Reference to particular operations is not intended to limit the generality of this subsection.

Development Agreement means an agreement entered into between Sarasota County and a person associated with the development of land pursuant to the terms of this Ordinance No. 2004-086.

Development Agreement Act shall mean F.S. §§ 163.3220--163.3243, as amended from time to time.

Development Order means any action granting, denying, or granting with conditions, an application for a development permit.

Development Permit means any preliminary subdivision plan, subdivision or other plat approval, site and development plan approval, rezoning, certification, special exception, variance, environmental permit or any other official action of Sarasota County or any other state or local government, commission, board, agency, department or official having the effect of permitting development of land located within the geographic area subject to the provisions of the Sarasota County Land Development Regulations.

Intensity means the degree to which an area is developed based on density, use, mass, size, impact, and traffic generations.

Land means the earth, water, and air above, below, or on the surface, and includes any improvements or structures customarily regarded as land.

Land Development Codes, Sarasota County means the code adopted by Resolution No. 89-384, pursuant to F.S. 163.3202, containing land development regulations that are consistent with and implement "Apoxsee, Sarasota County Comprehensive Plan".

Land Development Regulations (LDR), Sarasota County means the regulation of the development of land within the unincorporated area of Sarasota County, Florida as provided for in Sarasota County Ordinance No. 81-12, as amended and codified as Chapter 74 of the Sarasota County Code.

Laws for the purposes of these regulations means all ordinances, resolutions, comprehensive plans, land development regulations, and rules adopted by the Board of County Commissioners of Sarasota County affecting the development of land. 
Level of Service (LOS) means an indicator to the extent or degree of service provided by, or proposed to be provided by, a facility, based on and related to the operational characteristics of the facility.

Local Planning Agency means the Sarasota County Planning Commission.

Person means any individual, corporation, business or land trust, estate, trust, partnership, association, two or more persons having a joint or common interest, state agency, or any legal entity.

Public Facilities means major capital improvements, including but not limited to, transportation, sanitary sewer, solid waste, drainage, potable water, educational, parks and recreational, and health systems and facilities.

State Land Planning Agency means the Department of Community Affairs.

Third Party means a government, agency or other unit of local government which does not have regulatory authority over the use of land but provides services for which Sarasota County has adopted Level of Service standards.

C. General requirements.

1. Requirements of a Development Agreement. A development agreement shall include but not be limited to the following:

(a) A legal description of the land subject to the agreement and the names of its legal and equitable owners;

(b) The duration of the agreement;

(c) The development uses permitted on the land, including residential densities and building intensities, structure heights, maximum square footage of commercial buildings;

(d) A description of public facilities that will service the development, including who shall provide such facilities; the date any new facilities, if needed, will be constructed; a schedule to assure public facilities are available concurrent with the impacts of the development; and if necessary, any third party or other agreement assuring the provision of said public facilities;

(e) A description of any reservation or dedication of land for public purposes;

(f) A description of all local development permits approved or needed to be approved for the development of the land;

(g) A master conceptual development plan or an agreement to amend the development agreement within one year of the execution of said development agreement to include a conceptual development plan for the land subject to the development agreement containing the following unless the Board approves a modification to these requirements:

(1) The general layout of the proposed development by land use and identifying the acreage and density and/or intensity of each portion of the proposed development;

(2) Access points to the surrounding road system, internal and major road rights-of-way and road widths, any proposed pedestrian and bicycle facilities, and other easements;

(3) Common open space and native habitat preservation and mitigation areas, recreational areas and any public purpose lands;

(4) General stormwater retention areas; and

(5) The location of any on-site potable water supply (e.g., wells) or wastewater treatment facilities.

(h) A finding that the development permitted or proposed is consistent or will be consistent with the comprehensive plan and all applicable land development regulations;

(i) A description of any conditions, terms restrictions, or other requirements determined to be necessary by Sarasota County for the public health, safety and welfare of its citizens; 
(j) A statement indicating the failure of the agreement to address a particular permit, condition, term, or restriction shall not relieve the developer of the necessity of complying with the appropriate law governing said permitting requirements, conditions, terms or restrictions; and

(k) A description of the requirements for the filing of an annual report and a statement indicating who shall file an annual report and the required submission dates.

A development agreement may provide that the entire development or any phase thereof be commenced or completed within a specific period of time.

2. Duration of a Development Agreements and Relationship to the Comprehensive Plan. The duration of a development agreement shall not exceed ten (10) years. It may be extended by mutual consent of the Board, the developer, and any third party to the agreement, subject to a public hearing in accordance with the public hearing requirements contained in subsection C.6. of these regulations. No development agreement shall be effective or be implemented by Sarasota County unless the Sarasota County Comprehensive Plan and Plan Amendments implementing or related to the development agreement are found in compliance by the state land planning agency in accordance with F.S. 163.3184, 163.3187, or 163.3189.

3. Processing of Development Agreements With Other Applications for Development Approval. Where an application for a development agreement is filed in conjunction with other applications for development approval, the review periods for processing development agreement applications may be altered to accommodate the concurrent processing of the other applications.

4. Periodic Review of a Development Agreement. Within 12 months of the effective date of a development agreement, Sarasota County shall review the land subject to the development agreement to determine if there has been demonstrated good faith compliance with the terms of the development agreement. In addition to these requirements, any person with a legal or equitable interest in land for which a development agreement was entered into with Sarasota County, or their authorized representative shall submit an annual report to the Planning and Development Services Business Center on the date specified in the development agreement, pursuant to Section $\mathrm{G}$ of these Regulations.

5. Amendment or Cancellation of a Development Agreement. A development agreement may be canceled by the County or amended, subject to the procedural and public hearing requirements contained in these regulations, and under one or more of the following conditions:

(a) Where there is mutual consent of the parties to the agreement, or by their successors in interest.

(b) Where state or federal laws have been enacted which preclude one or more parties of the agreement from complying with the terms of the agreement.

(c) Where the Board has found, in the annual review of land subject to a development agreement, there is substantial noncompliance with the terms of the development agreement.

(d) Where, pursuant to Section 5.B. of Ordinance No. 2004-086 [section 94-265(b)], Sarasota County, may apply subsequently adopted local laws and policies to a development agreement.

6. Public Hearing. After the Planning and Development Services Business Center has made a recommendation on the application and the proposed development agreement, the application and proposed development agreement shall be considered at two public hearings.

If the proposed development agreement is being considered in conjunction with an application for a development permit which requires review by the Planning Commission, the first public hearing shall be held before the Planning Commission, who shall review the application, proposed development agreement, recommendation by the Planning and Development Services 
Business Center and public testimony and recommend its approval, approval with conditions or denial. The second public hearing shall be before the Board, who after review and consideration of the application, the proposed development agreement, the recommendations of the Planning and Development Services Business Center and the Planning Commission, and public testimony, shall approve, approve with conditions, or disapprove the development agreement. The second public hearing shall be a minimum of seven calendar days after the Planning Commission public hearing. The day, time, and place of the second public hearing shall be announced at the first public hearing.

In all other instances, both public hearings shall be held by the Board. The second public hearing shall be held a minimum of seven calendar days after the first public hearing. The day, time, and place of the second public hearing shall be announced at the first public hearing. At the conclusion of the second public hearing, the Board shall, after review and consideration of the application, the proposed development agreement, the recommendations of the Planning and Development Services Business Center and the Planning Commission, if applicable, and public testimony, approve, approve with conditions, or disapprove the development agreement.

The notice of public hearing shall state the intent of the Board to consider a development agreement and shall specify the location of the land subject to the development agreement, the development uses proposed on the property, the proposed residential densities, and the proposed building intensities and height and shall specify a place where a copy of the proposed development agreement can be obtained.

Notice of intent to consider a development agreement shall be advertised approximately 7 days before each public hearing in a newspaper of general circulation and readership in the county where the local government is located. Notice of time and place of the first public hearing shall be sent at least 7 days in advance of the hearing by mail, to the owner of the subject property or his designated agent or attorney, if any.

7. Recording of a Development Agreement.

(a) Within fourteen (14) calendar days after the Board has entered into a development agreement or the amendment to or cancellation of a development agreement, said agreement shall be recorded in the County public land records by the Clerk of the Circuit Court of Sarasota County. A copy of the recorded development agreement, or amendment or cancellation of a development agreement, shall be submitted to the state land planning agency within fourteen (14) calendar days after the agreement is recorded.

(b) A development agreement shall not be effective until it is properly recorded in the public records of the County and until 30 calendar days after having been received by the State Land Planning Agency pursuant to this section.

\section{Binding nature of the development agreement.}

The burdens of the development agreement shall be binding upon, and the benefits of the agreement shall inure to, all successors in interest to the parties of the agreement.

\section{E. Enforcement.}

Any party, any aggrieved or adversely affected person as defined in F.S. § 3.3215(2), or the state land planning agency may file an action for injunctive relief in the circuit court to enforce the terms of a development agreement or to challenge compliance of the agreement with the provisions of the Development Agreement Act.

The County shall withhold approval of developments or permits if provisions of the agreement are not met or fulfilled. 


\section{F. Development agreement procedures.}

1. Preapplication Conference. Preapplication conferences are required prior to the initiation of an application for a development agreement. Applicants shall submit a written request for a preapplication conference with the Executive Director of the Planning and Development Services Business Center. The pre application conference shall be held with the Executive Director of the Planning and Development Services Business Center or the Executive Director's designee. The purpose of the pre application conference is to assist in bringing the application as nearly as possible into conformity with these regulations or other regulations applying generally to the property involved and/or to define specifically other information essential to the review of the petition. In addition, the following information shall be discussed:

(a) Other applications for development approval to be filed in conjunction with the application for a development agreement. If appropriate, staff shall clarify the necessary requirements for the processing of the concurrent applications and any necessary revisions or exclusions to the review time limits;

(b) The appropriate composition of the review/negotiation team necessary to process the development agreement application;

(c) Other jurisdictional agencies that need to become a party to the development agreement;

(d) Any known Level of Service (LOS) or land use compatibility issues which need to be addressed; and

(e) Whether complexities inherent in the proposed development agreement warrant alterations to the required review times listed in Section F of these Regulations.

2. Filing an Application to enter into a Development Agreement with Sarasota County. Applications for a development agreement shall be filed with the Planning and Development Services Business Center.

(a) There shall be no deadline for filing an application for a development agreement.

(b) The filing fee shall be due upon submittal of the application for a development agreement.

(c) The submittal must contain all information required by the development agreement application form and these regulations.

(d) Fifteen (15) copies of the information required by the development agreement application form shall be submitted to the Planning and Development Services Business Center unless otherwise directed in writing by the Executive Director of the Planning and Development Services Business Center or the Executive Director's designee. However, when a property lies within 1/4 mile of the boundaries of the cities of Sarasota, North Port or Venice or the counties of Manatee, DeSoto or Charlotte, one (1) additional set of the required information shall be submitted.

3. Third Party Participation in a Development Agreement. If the participation of third parties is necessary or in the best interest of Sarasota County, the approval of a development agreement may be conditioned upon the participation of specified third parties in the processing of the development agreement application.

4. Sufficiency Review.

(a) Upon receipt of an application for a development agreement, or if appropriate, upon authorization by the Board of County Commissioners for third party participation in the processing of a development agreement, the Executive Director of the Planning and Development Services Business Center will forward copies of the completed application to the designated review/negotiation team for a determination as to whether the information submitted is sufficient to assess the application for a development agreement. Each agency on the review/negotiation team shall complete its sufficiency review and forward its comments to the Planning and Development Services Business Center within fifteen (15) 
days. All review/negotiation agencies must comment in writing on the sufficiency of the development agreement application.

(b) Upon receiving all review/negotiation agency comments, the Planning and Development Services Business Center shall notify the applicant, in writing, whether any additional information is needed.

(c) Should the applicant be notified of the need for additional information, the applicant may: supply the additional information requested; appeal in writing to the Planning and Development Services Business Center requesting a reconsideration of the need for additional information; or notify the Planning and Development Services Business Center in writing of the intent not to submit additional information.

(d) Should the Planning and Development Services Business Center receive a request for reconsideration of the need for additional information, Planning and Development Services Business Center shall, within ten (10) days, respond in writing to the applicant. The response shall state whether the Planning and Development Services Business Center is maintaining, withdrawing, or revising the request for additional information.

(e) The sufficiency review shall be complete upon the determination by the Planning and Development Services Business Center that all information needed to review the application has been submitted or upon the receipt from the applicant that no additional information will be forthcoming.

(f) Each member of the review/negotiation team shall be notified of the conclusion of the sufficiency review by the Planning and Development Services Business Center and sent copies of any additional information submitted by the applicant.

5. Formal Review and Negotiation of a Development Agreement. Unless otherwise altered, the following review time frames shall apply:

(a) Upon the conclusion of the sufficiency review, each agency on the review/negotiation team shall have ten (10) days to review the complete application and all supportive documentation. Each agency in the review/negotiation team shall then submit to the Planning and Development Services Business Center, their comments and recommendations regarding the disposition of the development agreement application.

(b) Upon receipt of all agency review reports, the Planning and Development Services Business Center shall have ten (10) days to compile a preliminary report. A copy of the preliminary report shall be sent to the applicant and all members of the review/negotiation team.

(c) The Planning and Development Services Business Center shall meet with the applicant and the review/negotiation team for the purpose of discussing the findings and recommendations contained within the preliminary report and to establish the basis for negotiating a mutually acceptable development agreement.

During the negotiations, or at any time prior to the issuance of a final report by the Planning and Development Services Business Center, the applicant may revise the submitted application for a development agreement. However, each additional submittal may initiate a new review period unless this requirement is waived by the Executive Director of the Planning and Development Services Business Center or the Executive Director's designee.

(d) At any time prior to or during the negotiation process, the applicant may be required by the review/negotiation team to prepare and submit a draft development agreement. The review/negotiation team may require inclusion of specific provisions necessary to protect the public interest which may be set forth in a standardized form provided by the County.

If the applicant submits a proposed development agreement, said proposal shall be considered part of the overall application for a development agreement. Therefore and unless otherwise notified, fifteen (15) copies of the proposed development agreement shall be 
submitted to the Planning and Development Services Business Center for distribution and review by the review/negotiation team. Each member of the review/negotiation team shall then submit to the Planning and Development Services Business Center comments and recommendations on the proposed development agreement.

(e) The applicant may, at any time prior to or during the negotiation process, elect not to negotiate further and have the application and any draft of a development agreement presented to the Planning Commission, if applicable, and to the Board.

(f) Upon completion of a negotiated development agreement or the review of the applicant's proposed development agreement and the election by the applicant pursuant to (c) above, the Planning and Development Services Business Center shall issue a final report on the application for a development agreement and set a date and time for the required public hearings. No amendments to the application shall be accepted from the applicant beyond this point in time.

6. Public Hearings. The Planning and Development Services Business Center report and recommendations regarding the proposed development agreement shall be presented to the Planning Commission, if applicable, and to the Board for consideration during a noticed public hearing(s). The applicant shall have the right, prior to the close of the public hearings, to respond to contentions advanced as part of any testimony or other evidence presented during the public hearing.

After the close of the public hearing, the Board, in the exercise of its legislative discretion, may approve the development agreement as proposed, approve the development agreement with amendments, or deny the development agreement.

In the event the petitioner has the proceedings before the Planning Commission or the Board taken down by a certified court reporter, pursuant to F.S. 286.0105, the County may require the filing of the transcript of such proceedings, and the decision of the Board shall be rendered within (30) calendar days of the filing of the transcript.

G. Annual review procedures.

1. Filing an Annual Monitoring Report. As required in a legally executed development agreement, any person with a legal or equitable interest in land for which said development agreement was entered into with Sarasota County, or their authorized representative shall submit ten (10) copies of an annual monitoring report to the Planning and Development Services Business Center for review. This report shall be submitted by the date specified in the adopted development agreement and each year thereof, until such times as the terms and conditions of the development agreement are satisfied. This report shall contain:

(a) Any changes in the plan of development, or in the representations contained in the development agreement, or in the phasing for the reporting year and for the next year;

(b) A summary comparison of development activity proposed and actually developed;

(c) The identification of undeveloped tracts of land, other than individual single family lots, that have been sold to a separate entity or developer;

(d) An assessment of the level of compliance with the conditions contained in the development agreement by the developer, the local government and if applicable, third party(s);

(e) Any indication of change in local jurisdiction by reason of annexation for any portion of the development in the reporting year or the following year;

(f) A list of local, state or federal permits which have been obtained or which are pending by agency, type of permit, permit number, and purpose of permit; and

(g) The identification of any changes in local, state or federal legislation substantially affecting compliance with the development agreement. 
Failure to submit an annual report or the deliberate misrepresentation or the use of gross inaccuracies in the report may be grounds for the initiation of proceedings to amend or cancel the development agreement.

2. Annual Development Agreement Review.

(a) Within five (5) days of receipt of the annual monitoring report, the Planning and Development Services Business Center shall send a copy of the submitted report to each of the review agencies for their review, analysis, and comments.

(b) Reviewing agencies, upon receipt of the submitted report, will have fifteen (15) days to evaluate the report and issue comments to Planning and Development Services Business Center. All review agencies must respond with a written report or comments. The review shall address the following:

(1) The completeness and accuracy of the information contained within the submitted document;

(2) The degree of compliance with the terms of the development agreement; and

(3) The identification of any substantial changes warranting an amendment or cancellation of the development agreements.

(c) Upon receipt of all review agency comments, the Planning and Development Services Business Center shall, within ten (10) days, issue a formal report on the findings of the annual review and issue a determination of compliance with the terms of the development agreement. This report shall be sent to the owner or authorized agent and shall be available for public inspection at the Planning and Development Services Business Center.

(d) The owner(s) or authorized representative of the land which submitted the monitoring report may request, in writing, a meeting with the Planning and Development Services Business Center to discuss the contents of the report.

3. Determination of Noncompliance. In the event that it is determined that there has been a failure to comply with the terms of the development agreement, the Planning and Development Services Business Center may find the use of the land is not in compliance with the development agreement. Should the Planning and Development Services Business Center issue a finding of noncompliance, the Planning and Development Services Business Center shall submit as an agenda item at a regularly scheduled meeting of the Board of County Commissioners a request to initiate proceedings to amend or cancel the development agreement.

\section{H. Procedures to amend or cancel development agreements.}

An application to amend or cancel an adopted development agreement may be initiated by the Planning and Development Services Business Center, the owner of real property for which a development agreement has been adopted or any third party to a development agreement. An amendment or cancellation of a development agreement may be initiated under the following conditions: following a proposed change by the owner; the adoption of state or federal laws preventing the carrying out of the development agreement; following the completion of an annual review; or a proposal to apply subsequently adopted local laws and policies to a development agreement pursuant to Section 5.B. of Ordinance No. 2004-086 [section 94-265(b)].

Applications to amend or cancel a development agreement shall conform to the general and procedural requirements for the processing of a development agreement. In addition, the following regulations shall apply:

1. Filing an Application to Amend or Cancel a Development Agreement with Sarasota County. Applications to amend a development agreement must contain all information required by the Development agreement application form relating to the requested amendment. Applications to 
cancel the development agreement must include sufficient justification warranting the cancellation of such agreement.

2. Formal Staff Review. Where the proposal is for a cancellation of an adopted development agreement, the allotted twenty (20) day staff review period may be reduced.

\section{Schedule of fees.}

The Board shall by resolution establish a schedule of fees for the filing, processing and reviewing of, or an amendment to or cancellation of a development agreement, or the annual review of a development agreement and related documents submitted to the County pursuant to the Development Agreement Act and these regulations. The fee as established shall be collected and administered in the manner prescribed by Sarasota County Ordinance No. 85-91 as amended, and Resolution No. 90212, as the same as may be amended from time to time.

(Ord. No. 2004-086, 10-12-2004) 


\section{APPENDIX B: DEVELOPMENTS OF REGIONAL IMPACT AND THE FDOT SITE IMPACT ANALYSIS METHODOLOGY}

Excerpted from "Land Developer Participation in Providing for Bus Transit Facilities/Operations". Funded by the National Center for Transit Research. Sponsored by the Florida Department of Transportation. Prepared by the Center for Urban Transportation Research, University of South Florida.

It is important to examine developments of regional impact (DRI) in this report because DRIs usually represent the largest developments and as such, have the greater potential impact on land development patterns and the opportunity to influence the development of the transportation system. The development of regional impact review process is concerned with identifying multi-jurisdictional impacts of development and establishing mitigative conditions under which building activity may be permitted to proceed. The structured DRI review process facilitates capital improvements planning.

A Florida Development of Regional Impact (DRI) is any development that, because of its character, magnitude, or location would have a substantial effect upon the health, safety, or welfare of citizens of more than one county [Chapter 380.06, F.S.]. There are different types of DRIs, including the following.

- Areawide DRIs, in which there are two or more development projects represented by separate property owners

- Downtown DRIs

- DRI Master Plan, in which construction is in phases over an extended period of time

DRIs are established by Chapter 380, F.S., which authorizes the Florida Department of Community Affairs to develop land and water management policies to guide local decisions relating to growth and development. DRIs are implemented by rules in the Florida Administrative Code, Chapter 9J-2.

The DRI designation of a land development proposal initiates a review process, in which the regional planning council, the state and other agencies have an opportunity to provide recommendations to the local government in the drafting of conditions attached to a local government development order for assuring that regional impacts have been properly addressed [A local government development order is any order granting, denying, or granting with conditions, an application for a development permit, whereas a development permit includes any building permit, zoning permit, plat approval, or rezoning, certification, variance, or other action having the effect of permitting development activity to proceed, as defined in Chapter 380, F.S.]. The regional impact review includes the documentation of impacts upon transportation as part of an Application for Development Approval (ADA), which must be approved by the Department of Community Affairs.

Transit service is addressed in the ADA question, "What provisions, including but not limited to sidewalks, bicycle paths, internal shuttles, ridesharing, and public transit, will be made for the movement of people by means other than private automobile? Refer to internal design, site planning, parking provisions, location, etc.”

The end result of the DRI process is a resolution passed by the host municipality, rendering a development order (DO) in response to an Application for Development Approval submitted for a project that has been determined to be a development of regional impact. The DO must be consistent with Chapter 380, F.S., Rule 9J-2 F.A.C., the local government comprehensive plan, the strategic regional policy plan, and the state comprehensive plan. 
Fourteen types of projects may be DRIs if they exceed specific size thresholds. These development types include airports, hospitals, and hotels, as well as industrial, office, retail, residential, and multiuse developments. Thresholds for determining DRI status include building square footage, acreage, and parking requirements.

If a project is determined to have a transportation impact, then a separate traffic methodology meeting must be held. This allows the regional planning council, the Florida Department of Transportation, the Florida Department of Community Affairs (DCA), the local government, and the applicant to decide on a mutually acceptable methodology for identifying a project's transportation impacts, thus saving time and simplifying the process.

Rule 9J-2.045(7)(a)1-5, Florida Administrative Code, lists the following measures that can be used to mitigate transportation impacts and which reasonably assure that public transportation facilities will be constructed and made available when needed to accommodate the impacts of the proposed development, consistent with Chapters 163 and 380, F.S.:

- scheduling of facility improvements

- alternative concurrency provisions

- proportionate share payments for roadway improvements based upon peak hour roadway trips generated.

- level of service monitoring with binding commitments for needed improvements

- a combination of the above mitigation measures, OR the provision for capital facilities for mass transit [e.g. buses for fixed route service, vehicles for vanpool or ride share programs]

Through the DRI process, RPCs in Florida have recommended to local governments a number of conditions as part of a DRI development order, that the developer:

- consult with the transit agency to determine the transit related needs to serve the project and coordinate with any plans to extend transit to the project;

- be financially responsible for any implementation of on-site amenities;

- establish a transportation systems management plan that includes use of bus transit as a means to reduce project-related p.m. peak hour automobile trips;

- coordinate with the city to promote transportation demand management strategies; and,

- when transit is already available to the site, build bus turnout bays and reasonably sized bus shelters along public roadways to serve the development, as required by the local government, or provide the transit agency with the funds to do it.

For approving a development order that requires developer exaction, the local government must comply with Paragraphs 380.06(15)(d), (e), and Subsection 380.06(16), Florida Statutes, which are similar to requirements for impact fees.

The Florida Statutes state that DRI developments must pay their proportionate share only if non-DRIs are required to pay also. The law further states that developers cannot be charged twice for the same impact. The key for a land developer to fund transit is to demonstrate that impacts would be mitigated by doing so. The existing DRI process instructs the developer to use professionally accepted methods for assessing level of service (LOS). The tools of analysis available for determining level of service are mode specific. Most commonly in use is the Highway Capacity Manual method for determining roadway level of service. Recommended development order conditions regarding bus transit generally assume that the local government or local transit provider will run a bus route past the development site, if they are not already doing so. 


\section{FDOT Procedures for Site Impact Analysis}

Proposed developments that do not meet the size thresholds constituting a DRI do not require site impact review by FDOT.

The FDOT procedure for site impact analysis is a process that is specifically geared toward determining a new development's roadway traffic impacts upon the State Highway System and the Florida Interstate Highway System. Most FDOT activities relating to site impact assessment originate from amendments to the future land use map (FLUM) of the comprehensive plan and amendments to the comprehensive plan due to a proposed development of regional impact (DRI).

The estimated traffic impact is the basis for determining the developer's fair share cost in contributing to roadway improvements that are necessary to maintaining roadway level of service. Considerations about transit usually only arise in relation to the ability of alternative modes to serve some of the new trips generated by the development, lessening the impact to roadway level of service.

According to FDOT's Standard Site Impact Procedures, there is a process composed of several steps, conducted in this order:

1. Methodology Development

2. Existing Conditions Analysis

3. Background Traffic

4. Trip Generation

5. Trip Distribution

6. Mode Split

7. Assignment

8. Future Conditions Analysis

9. Mitigation Analysis, if necessary

10. Site Access, Circulation and Parking

11. Review and Permitting

It is the applicant who proposes a methodology for reviewers' concurrence for determining site impact. The study area, also called the area of influence, is typically estimated using professional judgment and then refined during the study process. The DCA rule for DRIs requires that the study area include all facilities where traffic generated by the proposed development is equivalent to 5 percent of the maximum service volume at the LOS standard for the facility.

The methodology for determining the developer's fair share for funding of mitigation improvements is identified in the Methodology Development (Step 1) phase of the impact analysis. The fair share is determined in relationship to the number of trips generated by the development and the capacities on an affected roadway segment.

Step 2, the Existing Conditions Analysis, includes a review of existing transit service and transit ridership.

Step 4, Trip Generation, is a separate step conducted before the estimation of person trips. Trip generation characterizes person trips as motor vehicle movements and it is considered to be the most critical stage in the site impact analysis. The amount of travel that uses modes other than automobiles is estimated using regional and local guidelines based upon existing transit usage. As a result, 3 to 5 percent is considered a maximum realistic share of travel for modes other than automobiles. 
Step 6, mode split, is the analysis portion that estimates the amount of travel in person trips that will use the various modes available to the site.

References to transit appear again in Step 9, the mitigation analysis, in which the measures proposed must clearly demonstrate that they contribute to reducing traffic congestion along facilities where LOS has been made unacceptable upon the addition of the new development. The mitigation analysis includes a plan that details system improvements necessary with the phasing of the project and identifies the responsible party for implementing the improvements. Improvements typically include some combination of physical or operational changes to the roadway facilities, transportation demand management strategies, and fair share contributions by the developer.

Under Mitigation Analysis, various examples of mitigation measures are listed, including construction of new facilities and addition of general-use lanes. Where the construction of new facilities are considered, enhancements for the use of transit, such as geometric and operational improvements to accommodate bus travel are encouraged. Other encouraged mitigation measures include enhancements for the use of transit, such as the construction of park and ride lots, the construction of bus shelters and turn-out bays. The measures also include high occupancy vehicle (HOV) treatments such as the construction of HOV access ramps and the implementation of HOV priority lanes. Public transit operational improvements are other available mitigation measures. These improvements include new or modified service routes and employer subsidized transit. This measure can be used if it can be demonstrated that the necessary agreements are in place with the local transit agency and that the strategy can be demonstrated to cause a mode split shift toward transit. Transportation demand management techniques, such as providing transit subsidies, are recognized as having potential to reduce site traffic. A monitoring plan is usually put in place to measure effectiveness.

The mitigation analysis demonstrates that the proposed improvements will result in an acceptable operating condition along the roadway. The calculation of the proportionate share contribution is based upon a formula, as provided in the Florida Administrative Code. The final fee and mitigation fee considered is typically negotiated among the applicant, local governments, regional planning councils and FDOT if state highway improvements are involved.

\section{A Summary of Stipulated Conditions Relating to Bus Transit}

All RPCs in Florida were contacted with the request to provide best examples of RPC recommendations for the provision of bus service. The list below is a synthesis of conditions that RPCs in Florida have recommended to local governments as part of a DRI development order. These include recommendations that the developer do the following.

- Consult with the transit agency to determine the transit related needs to serve the project and coordinate with any plans to extend transit to the project.

- Be financially responsible for any implementation of on-site amenities.

- Establish a transportation systems management plan that includes use of bus transit as a means to reduce project-related p.m. peak hour automobile trips.

- Coordinate with the city to promote transportation demand management strategies.

- When transit is already available to the site, build bus turnout bays and reasonably-sized bus shelters along public roadways to serve the development, as required by the local government, or provide the transit agency with the funds to do so.

- $\quad$ Subsidize a bus route to a new mall and provide bus drop-off at the front entrance.

- Provide a parcel within the development for a transit stop that can accommodate multiple buses at one time. 
- In public gathering places, provide a place where transit information can be prominently displayed.

- Encourage tenants and owners within the employment centers to provide preferential parking for vanpools/carpools.

- Disseminate information to tenants and residents about local ridesharing programs.

- Some period of time after the issuance of the development order, propose transit-related actions, facilities, and sites to the municipality and transit agency.

- Consider paying the cost for an additional bus route to the DRI or increased frequency on existing routes during later phases of construction.

- Maximize access by interconnecting parcels within the development and providing road linkages to the local street system.

- Provide park and ride spaces proximate to a multi-bus transit stop, either in conjunction with commercial development or by purchase of property.

- Designate a part-time ride share coordinator to distribute transit information.

- Include transit-oriented design (TOD) features into the project design, as specified by a transit agency design manual, such as covered pedestrian walkways linking buildings to transit stops.

- Establish a transportation management association to implement trip reduction programs within the DRI.

- Provide sidewalk access between transit stops and nearby residential and commercial development.

The Development of Regional Impact (DRI) review process focuses upon identifying impacts to the existing roadway system. DRIs are often located on large tracts of undeveloped land to which transit service has not yet extended. Developers will seek less costly undeveloped land, on the suburban fringe, where there is usually little or no transit service but is attractive because of market accessibility by the existing road system. As the suburb-to-suburb home-to-work travel pattern expands with increasing suburbanization, some transit agencies are withdrawing poorly used bus service extensions from new developments to downtowns in favor of focusing on service enhancements to existing well-used bus routes serving neighborhoods closer to the urban core.

Under the current DRI review process, level of transportation service is measured in terms of roadway capacity. Alternative transportation, such as ridesharing and transit, are identified as part of Transportation Systems Management (TSM) strategies for the purpose of mitigating development impacts on roadways rather than as a mode of transportation with its own level of service (LOS) standards. This necessarily leads to a determination of improvements, to be accomplished by the developer, which are intended to restore roadway LOS rather than improving use of transit as a mobility solution to the new development.

For example, the DRI Application for Development Approval (ADA) emphasizes and provides detailed instructions on quantifying the impacts to roadways as part of Question 21-Transportation. At the end of Question 21, after parts A through $\mathrm{H}$ addressing quantifying roadway impacts have been addressed, there is the general question:

What provisions, including but not limited to sidewalks, bicycle paths, internal shuttles, ridesharing and public transit, will be made for the movement of people by means other than private automobile? Refer to internal design, site planning, parking provisions, location, etc. 
Alternative modes are a procedural afterthought and it is implied that not much attention is expected by the developer to seriously consider other modes of transportation. All other modes, each having very different characteristics, are combined into one "other than automobile..." category for purposes of review. The Application for Development Approval provides further instructions:

The applicant must clearly document any estimate of mode split to transit or non-motorized transportation. The proposed usage should also be supported through an agreement with the transit agency and an acceptable internal roadway design...Change in mode split must be supported by the developer based on data collected on projects of similar intensity and use.

The burden of proof is placed upon the underdeveloped alternative mode, to demonstrate a shift in mode split. The new project is not likely to be permitted to set a precedent, if projects of similar intensity and use that demonstrate a higher transit mode share cannot be found.

Despite the limitations of the current Application for Development Approval, the DRI process has the potential to be an opportunity to guide DRIs in a positive direction toward State Comprehensive Plan goals for a truly balanced transportation system.

Developers must submit annual reports regarding the phased development of DRIs, which must identify modifications that are consistent with the plans and policies of the local host municipality, the Florida Department of Transportation, and the metropolitan planning organization. This places the responsibility upon these state and local agencies to have plans and policies that set the tone for improving transit. One way to accomplish this is for the provisions of Florida Administrative Code 9J-2.045 and the instructions for determining impacts as part of the ADA to be updated to include new methods for measuring multi-modal level of service. The F.A.C. guidance and ADA instructions should be updated as these methods are refined in the future by the Florida Department of Transportation.

Other hurdles in elevating the use of public transit improvements to address the transportation impacts of DRIs are:

- providing public bus transit improvements that can be demonstrated to specifically benefit the particular DRI contributing funds, and

- demonstrating that those particular transit improvements cause a mode shift to transit.

Transportation improvements, as provided by developers, must meet certain tests as provided by state law. These tests are similar to those provided for impact fees, regardless of whether a local government has adopted an impact fee ordinance or not. These tests are that [Chapters 380.06(15)(d) and (e) and 380.06(16), F.S.]:

- The transportation need that must be mitigated must be attributable to the proposed development paying for the mitigation.

- The amount of the contribution must correspond to the amount needed to mitigate the impacts from the development.

- The funds must go toward improvements to serve that development.

- Developers of DRIs cannot be required to contribute funds for mitigation unless the host local government has an ordinance in place requiring non-DRIs to mitigate their impacts.

- Developers of DRIs cannot be charged twice to mitigate for the same impacts, as in the case that a local host government charges impact fees. 
These requirements pose special difficulties for developers to provide transit improvements as mitigation for the transportation impacts of a DRI. For example, if a high quality bus service, commensurate with highway level of service, is not in place, then it is not possible to reasonably estimate the need for transit service by a new development unless there is a way to measure latent demand for transit service. As a result, a very low number of bus trips is estimated. Consequently, a small amount of money or capital facilities is estimated to pay for bus mode share. Funds must be demonstrated to benefit the development. If there is an impact fee ordinance in place, then funds cannot go toward bus operations. This leaves capital facilities—bus shelters are the likely choice.

The Transit Capacity and Quality of Service Manual already assigns bus shelters as an amenity and not a necessary element of bus service availability. Bus shelters do not accomplish much if bus service is not available.

If funds can go toward operations, it is possible to quantify a cost of bus service to cover bus operations to serve those generated trips only; however, this still would not help if bus service does not yet extend out to the DRI. If effective bus transit service does not already exist in the area, then it is not possible to pay some incremental bus transit cost, commensurate with the number of new trips generated by a development, such that the new development benefits from the fees paid.

It is recommended that there to be some means to enable local governments to charge development for bus transit improvements that do not necessarily serve that development, but can be applied to bus routes that may be extended to serve the development in the future.

Whether the development is a DRI or not, the contribution should be consistent with the intent to provide transportation facilities concurrent with the impact of development and to maintain a transportation LOS, commensurate with the mobility demand generated by the development.

To reinforce the desired results of engaging land developers to pay for bus transit improvements as part of the DRI process, local governments should make full use of the planning and regulatory processes available to them to guide development toward locations where it is efficient to provide transit service.

These include:

- the long range transportation planning process and the transportation improvement plan of the MPO,

- the local government comprehensive planning process,

- urban development boundaries, and

- zoning and other tools within the land development code.

Additionally, local governments could provide disincentives for a development that is located outside the existing or planned service area of transit, while offering incentives that make it more desirable to build in areas within the existing and planned bus service area. 


\section{APPENDIX C: PINELLAS COUNTY LRTP TDM POLICIES}

From the Pinellas County 2025 Long Range Transportation Plan Update. Metropolitan Planning Organization, Pinellas County, FL, October 2004.

\section{Transportation Demand Management}

1.7. Objective: Reduce traffic congestion and positively impact air quality by decreasing the use of the single occupant vehicle (SOV) at peak hours.

1.7.1. Policy: The MPO shall work with local governments, transportation demand management (TDM) agencies and FDOT to develop vehicle trip (VT) reduction and vehicle miles of travel (VMT) reduction goals.

1.7.2. Policy: The MPO shall assist and support the efforts of Bay Area Commuter Services (BACS) to implement and achieve the goals of its Long Range Transportation Demand Management Plan and to carry out recommended actions derived from related studies.

1.7.3. Policy: The MPO shall assist and encourage the efforts of local TDM agencies by providing technical and funding support for promotion of alternatives to SOV travel, including carpool, vanpool, transit, walking, bicycling, telecommuting and variable work schedules.

1.7.4. Policy: The MPO shall continue to participate in events and other activities sponsored by local transportation-related agencies that support and facilitate the use of alternatives to driving alone by commuters and other travelers (e.g., Commuter Choices Week, B-BOPP, Tampa Bay Commuter, etc.).

1.7.5. Policy: The MPO shall work with transportation agencies and local governments to encourage non-work trips to be made at times other than peak to assist in the reduction of traffic congestion during those periods.

1.7.6. Policy The MPO shall work with transportation agencies and local governments to encourage those using non-work trips to use public transportation and/or other forms of ridesharing (i.e., carpool and vanpool) whenever possible.

1.7.7. Policy: The MPO shall encourage and participate in public-private partnerships and develop incentives to encourage employer, developer and other organizations' participation in meeting the mobility needs of County residents, visitors and businesses.

1.7.8. Policy: The MPO shall work with transportation-related agencies and local governments to encourage, promote and support employer participation in qualified transportation fringe benefit allowed under the federal IRS Code to provide tax-deductible public transportation benefits to their employees.

1.7.9. Policy: The MPO shall work with local governments, TDM agencies, employers and developers to encourage and implement effective parking management strategies, including preferential parking for carpools and vanpools, shared use parking and variable parking pricing.

1.7.10. Policy: The MPO shall provide policy direction and implementation support to city and county traffic departments, TDM agencies, FDOT and state/local emergency and police departments to maintain the flow of people and goods during major reconstruction of highway facilities. 
1.7.11. Policy: The MPO shall continue to work with the Pinellas County School Board, private schools and Bay Area Commuter Services to expand the school based carpool program and to encourage the use of non-motorized modes to reduce traffic congestion in and around schools and improve safety of our children.

1.7.12. Policy: The MPO shall encourage the development of a telecommunication infrastructure to provide universal service access to all citizens for expanding educational opportunities via distance learning, obtaining medical information via telemedicine, increasing commerce via the purchase of goods by online shopping, and creating job opportunities via telework. These elements will foster economic development by helping citizens and businesses move intellectual property, data and information electronically. This policy is intended to reduce or even eliminate the need to travel for these purposes.

1.7.13. Policy: The MPO shall encourage opportunities for advancement in telecommunications and other technologies and their impacts on travel behavior to identify other means for meeting some of the transportation needs of County residents and businesses.

1.7.14. Policy: The MPO shall encourage the business community to adopt telecommunication solutions such as web conferencing and telecommuting in order to substitute for some of their needs to travel by private vehicle and/or complement the transportation needs. 


\section{APPENDIX D: CITY OF SARASOTA TDM POLICIES}

From the Sarasota City Plan Transportation Chapter. City of Sarasota, Florida. November 1998. Only the objectives and policies directly referring to transportation demand management have been reproduced below.

\section{Objective 1 - Level-of-Service for Safe, Convenient and Efficient Transportation System}

To continue to provide a safe, convenient and efficient transportation system with a level-of-service that sustains the City's natural, aesthetic, social and economic resources.

1.4 Effect of Projected Deficiencies on Future Land Use: The City shall ensure that development which increases traffic on roads which are backlogged, constrained or projected to be at deficient levels of service by 2010 be required to provide:

- either conventional mitigation measures; and/or

- a Transportation Demand Management or Transportation Systems Management plan for approval by the City Engineer.

1.5 LOS Study for Below Standard Thoroughfares: The City, in cooperation with the Metropolitan Planning Organization's Congestion Management Task Force, will study and recommend specific roadway improvements, TSM and TDM measures, to alleviate congestion on thoroughfares whose LOS is, or is projected to be, below adopted standard.

1.23 Use of Transportation Systems Management (TSM) and Transportation Demand Management (TDM) to Remedy LOS Deficiencies: The City will pursue TSM and TDM measures, as appropriate, to remedy existing and projected Level-of-Service (LOS) deficiencies.

\section{Objective 2 - Alternative Modes of Transportation}

The City shall continue to provide for alternative modes of transportation, in coordination with other units of local government and the private sector, including handicapped-accessible mass transit to all existing and proposed major trip generators.

2.2 Transportation Demand Management Mitigation (TDM) Credits: The City will consider developing, in the Land Development Regulations, a mitigation bonus schedule for transit-oriented development, mixed use development, home-occupation-related development, and other commitments included in requests for development that reduce single-occupant motor vehicle trips.

2.6 Alternatives To Fixed-Route Services: The City, in conjunction with the Metropolitan Planning Organization, will examine Transportation Demand Management alternatives to supplement or complement certain Sarasota County Area Transit services. These include vanpooling for long-distance commuters, demand-responsive para-transit services to bus route outer termini, station cars, and privatization of services.

Objective 5 - A Transportation System to Enhance and Preserve City Neighborhoods

The City will continue to develop a transportation system which helps preserve and enhance the City's neighborhoods.

5.3 Transportation Demand Management Bonuses: The City should consider reducing parking requirements in the Land Development Regulations for development that: 
- commits to a trip reduction program through a Transportation Demand Management program approved by the City; and/or

- demonstrate that time-shared parking with other nearby land uses reduces the number of spaces required at any one time.

\section{Objective 8 - Transportation Concurrency Exception Area (TCEA)}

The City shall manage transportation concurrency within the City's Community Redevelopment Area (CRA), as defined in Illustration T-12A, through the use of a Transportation Concurrency Exception Area (TCEA). The purpose of the TCEA is to encourage the development of compact, dense and mixed uses in the CRA by replacing standard concurrency requirements with TCEA regulations.

The transportation and mobility needs within the TCEA shall be met through the following Action Strategies as an alternative to the statutory concurrency requirements.

8.1 Interim Standards: The City will apply the following interim transitional standards to development within the TCEA until the Sarasota City Plan is amended to provide permanent standards for concurrency requirements within the TCEA. The cumulative impact of any new development shall not:

- exceed $15 \%$ of the AADT on the effective date of the plan for roads which are operating at LOS "E" or "F;";

- degrade LOS below "E” for roads operating at LOS “D.”

LOS shall be calculated for the directional, peak hour LOS on any roadway impacted by the project seeking concurrency. An "impacted roadway" is defined as any roadway where traffic volume from the proposed development exceeds $4 \frac{1 / 2}{2} \%$ of that roadway's maximum service capacity at LOS " $\mathrm{D}$ ”. The calculations shall use the software and formulas derived from the latest edition of the Highway Capacity Manual, published by the Transportation Research Board:

- Transportation facilities needed to serve new development shall be in place or under actual construction no more than 5 years after issuance of a certificate of occupancy when the cost of such transportation facilities exceeds $\$ 400,000.00$.

- Transportation facilities needed to serve new development shall be in place or under actual construction no more than 3 years after issuance of a certificate of occupancy when the cost of such transportation facilities is $\$ 400,000.00$ or less.

- In lieu of traditional mitigation, (i.e. roadway improvements), developers may be allowed to mitigate up to $30 \%$ of new trips by using proven TDM programs with verifiable results. "Verifiable results" shall mean that it is possible to quantify the number of new trips which are eliminated by the use of TDM measures. The City shall have the discretion to determine the appropriate percentage of new trips to be mitigated in this manner up to the $30 \%$ maximum.

- Developers may be required to participate in a Transportation Management Organization (TMO) as a condition precedent to the issuance of a development permit; and,

- Developers shall prepare and submit traffic circulation plans including ingress and egress from and to adjacent roadways for automobiles, trucks and delivery vehicles, pedestrian, mass transit, and bicycles.

- Traffic circulation plans shall be reviewed and approved by the City Engineer.

- Development agreements which commit the developer to make specified transportation improvements may be required as a condition precedent to the issuance of a development permit. Development agreements may also require the developer to participate in TSM and TDM programs. 
- Non-de minimis developments will still be required to perform traffic studies to estimate their compliance with the LOS standards. If these studies estimate that a development traffic impact does not meet the new LOS standards, the City shall require enforceable development agreements which commit the developer to make certain improvements to meet those standards.

During this interim period, developments which cannot meet the above standards shall not be approved.

8.6 Transportation Demand Management (TDM) Developer Requirements: The City shall study the feasibility of amending the LDRs to require any development locating within the TCEA to implement and maintain a trip reduction program and/or to pay into a TDM trust fund if the impact of such development on any segment of roadway within the TCEA would exceed $4.5 \%$ of that roadway's two-way service volume at LOS “D.”

8.7 Transportation Management Organization: In cooperation with the Sarasota Downtown Association and residents within the TCEA, the City shall pursue establishing a Transportation Management Organization (TMO) to make recommendations to the City Commission concerning Transportation Systems Management and Transportation Demand Management strategies. Such recommendations may include both implementation of new strategies and modification of existing strategies. 


\section{APPENDIX E: TRAFFIC IMPACT FEE REDUCTION INCENTIVES, CLARK COUNTY, WASHINGTON}

(These incentives were never implemented and later repealed.)

Traffic Impact Fee (TIF) Reduction Incentives for Transit Supportive Zoning District ACTION TIF REDUCTION

Development within the Transit Supportive Zoning District* $2 \%$

Construction of on-site but off-road internal pedestrian/bicycle network $12 \%$

Construction of direct walkway connections to the nearest arterial for non-abutting developments

Commercial Development which would be occupied by an employer subject to, and complying with, section [

Direct pedestrian/bicycle connection to destination activity (such as a commercial/retail facility, park, or school) if residential development, or to origin activity (such as a residential area) if commercial/retail facility

Installation of on-site sheltered transit stop (with current or planned service or bus stop within $1 / 4$ mile of site with adequate walkways if approved by [local government transit agency])

Installation of one secure bike parking space per 10 vehicular parking stalls

Connection to existing or future regional shared use path (either $1 \%$ directly, or by existing, safe access)

Development of a trip reduction plan to be implemented by property management Designation of ten (10) percent of all non-residential parking as carpool/vanpool parking facilities if located in a manner maximizing accessibility subject to ADA requirements**

Total if all strategies were implemented

* Automatic reduction for developing within Transit Supportive Zoning District and compliance with the provisions of this Ordinance.

** Requires regular maintenance.

\section{Traffic Impact Fee (TIF) Reduction Incentives for Mixed Use Districts}

\begin{tabular}{lc}
\hline ACTION & TIF REDUCTION \\
\hline Construction of direct walkway connection to the nearest arterial & $1 \%$ \\
Installation of on-site sheltered bus-stop (with current or planned service) or bus stop & $1 \%$ \\
within $1 / 4$ mile of site with adequate walkways if approved by C-TRAN & $1 \%$ \\
Installation of bike lockers & $1 \%$ \\
Connection to existing or future regional bike trail & $1 \%$ (if existing) \\
$\begin{array}{l}\text { Direct walk/bikeway connection to destination activity (such as a commercial/retail } \\
\text { facility, park, or school) if residential development, or to origin activity (such as a } \\
\text { residential area) if commercial/retail facility }\end{array}$ & $2 \%$ (if constructed) \\
Installation of parking spaces which will become paid parking (by resident or employee) & $3 \%$ \\
Installation of preferential carpool/vanpool parking facilities ${ }^{1}$ & $1 \%$ \\
Total if all strategies were implemented & $10 \%$ \\
1 Automatic reduction for developing within the mixed use district &
\end{tabular}




\section{APPENDIX F: COMPREHENSIVE TRANSPORTATION REVIEW METHODOLOGY, CITY OF ROCKVILLE, MARYLAND}

- Comprehensive Transportation Review Methodology. City of Rockville, Maryland. This methodology is designed to evaluate the impacts of new development on the transportation system, to determine mitigation for alternative modes and to assign corresponding "trip" credits.

City of Rockville, Maryland

Source: City of Rockville. Comprehensive Transportation Review (CTR) Methodology. City of Rockville, Maryland, September 2004.

Contact: Katherine Kelly

Transportation Planner - Department of Public Works

240-314-8527

kkelly@rockvillemd.gov, www.rockvillemd.gov

The City of Rockville, Maryland is located in the Washington DC metropolitan area and is characterized by lower density suburban style development. Given the regional context, the City experiences a significant amount of through traffic on its major thoroughfares. The Transportation Plan describes the City as follows:

“The suburban nature of many areas in Rockville makes people dependent on the automobile. Residential neighborhoods are separated from commercial areas. Cul-de-sacs and dead end streets divide uses that are physically proximate. Some neighborhoods have no sidewalk or walkway system. There is competition between the automobile and pedestrians at intersections. All of these factors force many residents to disregard walking as a viable means of transportation.”

As a result, Rockville is moving away from mitigation measures related primarily to providing additional roadway capacity through physical improvements and is encouraging mitigation for alternative modes (e.g. ridesharing programs, shuttles to transit stations, installation of pedestrian and bicycle facilities, etc.). Rockville Applicants for developments may be obligated to contribute toward the improvement of offsite transportation and safety facilities to help address identified safety hazards for all modes. As stated in the City Transportation Plan,

"Providing safe, direct pedestrian routes between residential areas and activity centers can help reduce the number of day-to-day vehicle trips. These connections can be created or improved by installing sidewalks, adding paths to link cul-de-sacs and dead end streets, installing pedestrian signals and crosswalks, or by constructing pedestrian bridges over busy roadways. Treatments, such as lighting, landscaped buffer areas and other streetscape improvements, can heighten safety and make pedestrian facilities more attractive for users.”

The City enacted a Comprehensive Transportation Review (CTR) Methodology in September 2004 to evaluate the impacts of new development on the transportation system, to determine mitigation for alternative modes and to assign corresponding "trip" credits. Because they are deemed to have a measurable traffic impact under the methodology, developments that generate 30 or more total peak hour site trips must conduct an off-site analysis for all transportation modes (see Table F1). Smaller developments evaluate only on-site multimodal access and circulation needs. 
The off-site analysis includes an assessment of major intersections that are impacted by the development as well as non-auto facilities that lead to the development. The goal of the off-site analysis is: "to ensure that the site can be accessed safely and efficiently through various modes and that adequate transportation facilities are in place to support the subject development without detriment to the overall transportation system.”

Below is a summary of components of the CTR:

- Component A-Introduction and Existing Conditions: Project description.

- Component B-Site Access \& Circulation: Analysis of internal circulation, entrance configurations, vehicular access and other relevant access and on-site features; the Proposed Site Access and Circulation Transportation Statement; and the Proposed Conditions Site Plan.

- Component C-Automobile Traffic Analysis (Off-Site): Analysis of auto traffic using the technical guidelines for traffic analysis in the traffic study area.

- Component D-Non-Auto Off-Site Analysis: Analysis of access to the development from activity centers via alternative modes of transportation using the guidelines for creating an inventory of pedestrian, bicycle, and transit facilities in the non-auto study area and for analyzing intersection safety ratings for these modes of transportation.

- Component E-Summary, Mitigation, and Credits: Summary of the report findings and impacts; recommended mitigation plans.

Total Peak Hour Site Trips*

Less than 30

\section{Table F1: Completion of TR Components*}

Required TR Components

Component $A$ - Introduction

Component B - Site Access and Circulation

Component E - Summary, Mitigation and Credits

All Components Required

30 or more

* Peak hour site trips are calculated using the trip generation rates referenced in Section IIIC5.

* Note: Not all types of development applications are subject to CTR standards. Refer to Table 1 to determine types of development applications that must comply with CTR standards.

Non-Auto On-Site Analysis

The non-auto on-site analysis must address availability of sidewalks and bicycle facilities on the site frontage and in some cases through the site. Bicycle facilities are those identified in the Bicycle Master Plan. Transit facilities are based on projected daily ridership (existing ridership data plus additional ridership projected from the new development)

\section{Non-Auto Off-Site Analysis}

The non-auto off-site analysis must address access to the development from activity centers via alternative modes of transportation. Activity centers are defined as "areas with destinations such as schools, shopping, recreational facilities, and other points of attraction.” Under the guidelines, developers must conduct an inventory of pedestrian, bicycle, and transit facilities in the non-auto study area along routes to activity centers within a certain radii of the site, and evaluate intersection safety ratings for these modes of transportation.

Activity center routes to evaluate are determined in coordination with City staff based on "land uses surrounding the access route, volume of activity, and priority of the City to attract persons to the activity center(s).” The extent of the non-auto study area is based on trip generation and a radii based on City analysis of walk sheds to non-auto facilities and national studies of how far individuals will travel to use non-auto facilities (Table F2). The City also designated transit oriented areas (TOAs) where "viable non-auto options exist within 7/10ths of a mile accessible walking distance" from 
existing and programmed transit stations and major access routes to transit facilities. TOAs provide for lower LOS thresholds than non-TOAs given the viability of multi-modal options.

\begin{tabular}{|c|c|c|c|c|c|c|}
\hline \multicolumn{7}{|c|}{ Table F2: Non-Auto Study Areas } \\
\hline New & \multicolumn{2}{|c|}{$30-350$} & \multicolumn{2}{|c|}{$351-500$} & \multicolumn{2}{|c|}{$500+$} \\
\hline $\begin{array}{l}\text { Minimum Activity Center Routes } \\
\text { Evaluated }\end{array}$ & \multicolumn{2}{|c|}{1} & \multicolumn{2}{|c|}{2} & \multicolumn{2}{|c|}{3} \\
\hline Accessibility to Activity Centers & $\begin{array}{l}.25 \text { mile } \\
\text { radius }\end{array}$ & $\begin{array}{l}.35 \text { mile } \\
\text { radius }\end{array}$ & $\begin{array}{l}.35 \text { mile } \\
\text { radius }\end{array}$ & $\begin{array}{l}.45 \text { mile } \\
\text { radius }\end{array}$ & $\begin{array}{l}.45 \text { mile } \\
\text { radius }\end{array}$ & $\begin{array}{l}.50 \text { mile } \\
\text { radius }\end{array}$ \\
\hline TOA Designation & TOA & Non-TOA & TOA & Non-TOA & TOA & Non-TOA \\
\hline
\end{tabular}

Selected sidewalks and bicycle facilities within the non-auto study area must be evaluated for connectivity from the site to activity centers. The City of Rockville's Synthesis of Pedestrian Policies Manual is used to guide improvements to pedestrian facilities. Determinations of deficiency for bicycle facilities are based on bicycle level of service (BLOS) standards established by the City based on the "levels of comfort" that riders feel on designated facilities. BLOS is calculated based on volume of directional traffic, speed limit, lane width, pavement surface, percentage of heavy vehicles, and other roadway and sidewalk characteristics and conditions.

The City's goal for the bikeway network is to maintain a Bicycle LOS (BLOS) of "C." This is accomplished primarily by providing facilities that connect and are accessible. Routes are determined by staff, based on the City's Bicycle Master Plan [see City of Rockville Bikeway Master Plan Update as adopted April 2004 at http://www.rockvillemd.gov/masterplan/bikeway/index.html]. All bicycle facilities in the City's Bikeway Master Plan that lie within the non-auto study area, including shared roadways, signed-shared roadways, bike lanes, shared-use paths, or widened sidewalks, must be identified in the inventory.

The transit inventory along activity center routes must include the location of bus routes, frequency of service, hours of operation, existing daily ridership levels, and bus stops and amenities (concrete pad, bench, bus shelter and connectivity to the sidewalk network) at existing and programmed bus stops. The transit inventory must also include lighting features (overhead streetlights) at transit stops and nearby parking areas, as well as availability (posting) of schedules or real-time transit information.

Another interesting feature of the methodology is the requirement for each applicant to conduct an intersection safety analysis for all modes. The intersections to be rated for safety are determined in the scoping meeting, when the non-auto study area is being identified. Each intersection is evaluated and given a rating that ranges from poor to excellent, based on a table of safety rating indicators. Applicants must also determine if intersection crossing times are adequate based on City standards. For example, if the flashing walk time is less than the length of the lanes divided by four (4), then crossing time is deemed inadequate.

Summary of Development Application Issues and Impacts

Upon completion of the required multimodal analysis, applicants must summarize all issues and impacts related to site access and circulation, automobile traffic, non-auto facilities and intersection safety. All impacts must be noted in a chart listing impacts on the left and intended mitigating actions on the right. 


\section{Mitigation}

Trip credits for mitigation are applied against new peak hour site trips before any other trip credits or reductions (apart from pass-by reduction) are applied for the development application. No additional credit will be applied if modal split is used in traffic analyses. Mitigation plans must be approved by the Traffic \& Transportation Division and may consist of:

- Implementation of, or monetary contribution towards, proximate physical roadway modifications that increase auto capacity sufficiently to bring LOS to acceptable levels;

- Implementation of, or monetary contribution towards, physical non-auto improvements that appropriately address project-specific impacts through an alternative means, and

- Participation in the City's TDM Program or alternative TDM program.

Table F3 summarizes types of mitigation an applicant can consider and maximum credits.

\section{Table F3: Types of Mitigation and Credits*}

Mitigation $\quad$ Maximum Credits Allowed

Off-site mitigations to roadway network that a developer offers to implement. Goal Variable credit, depending is to lessen the impact from trips generated by the development.

Implementation of a Transportation Demand Management program. $\quad 15 \%$ of trips $10 \%$ of trips

* Note: On-site mitigations (per minimum standards) for access, circulation, pedestrian, bicycle and transit facilities are required and therefore are not eligible for mitigation credits.

The maximum total amount of trip reductions and credits per development application are outlined in Table F4. These are $30 \%$ of new peak hour site trips generated in a TOA and $20 \%$ of new peak hour site trips generated in a non-TOA, after pass-by trip reduction is applied and before any other trip reduction or credit is applied. Trips are credited against the total trip generation for the site and not at specific intersections and credits differ within and outside of the TOA. However, mitigation will be targeted toward intersections that are impacted by the new development. Drive-through facilities are not eligible for modal split reductions, mixed use reductions, or trip credits but may be eligible for other trip reductions.

\section{Table F4: Maximum Potential Trip Reductions and Credits}

Type of Trip Reduction or Credit

Modal split reduction

Mixed-use development reduction

Non-auto improvements credits

TDM credit

Combined trip reductions and credits ceiling

\begin{tabular}{cc}
\multicolumn{2}{c}{ Maximum Credits Allowed } \\
TOA & Non-TOA \\
$15 \%$ & N/A \\
$10 \%$ & $5 \%$ \\
$15 \%$ & $10 \%$ \\
$15 \%$ & $10 \%$ \\
$30 \%$ & $20 \%$
\end{tabular}

Applicants are encouraged to mitigate transportation impacts by providing non-auto improvements and modifications to the transportation system. Applicants may receive trip credits only for non-auto improvements approved by the Traffic \& Transportation Division that are beyond minimum requirements or that are not already required on site. Trip credits are applied as mitigation according to the rates outlined in Table F5 and may include a combination of facilities, given that certain facilities and programs are more effective in reducing trips than others. Mitigation involving transit facilities must be done in coordination with the Department of Public Works and the regional transit agency, taking into account the effects such facilities may have on operational costs and transit planning. 


\section{Table F5: Maximum Trip Credit Rates for Non-Auto Facilities}

New Peak Hour

Site Trips Generated

Facility $^{1}$

Shared bicycle/ped. Path at least 8' wide, 130' long

Sidewalk at least 4' wide, 130' 'long ${ }^{2}$

Bicycle lane at least 4'wide, 130' long 2,3,4

Indoor shower for bike commuters

Curb extension at intersection ${ }^{5}$

Bike locker (holds 2 bikes)

Bike rack ( $>5$ bike slots)

Concrete pad at bus stop 6

Bus bench ${ }^{6}$

Bus shelters ${ }^{6}$

Bus pull-off ${ }^{7}$

Multimodal Transit Center ${ }^{9}$

Enclosed (indoor)

Covered (outdoor)

Transit information kiosk $^{10}$

Transit information board ${ }^{11}$

Real-time

Static

"Per facility" refers to the number of credits granted per installation of on e facility of the indicated type. Credits

30-100

TOA Non- TOA Non- TOA Non-

$\begin{array}{llllll} & \text { TOA } & & \text { TOA } & & \text { TOA } \\ \text { Credit } & \text { Credit } & \text { Credit } & \text { Credit } & \text { Credit } & \text { Credit } \\ \text { per } & \text { per } & \text { per } & \text { per } & \text { per } & \text { per }\end{array}$

facility facility facility facility facility facility

$\begin{array}{llllll}4 & 3 & 5 & 4 & 6 & 5\end{array}$

$\begin{array}{llllll}4 & 3 & 5 & 4 & 6 & 5 \\ 3 & 2 & 4 & 3 & 5 & 4\end{array}$

$\begin{array}{llllll}3 & 2 & 4 & 3 & 5 & 4\end{array}$

$\begin{array}{llllll}3 & 2 & 4 & 3 & 5 & 4\end{array}$

$\begin{array}{llllll}1 & 1 & 1 & 1 & 1 & 1\end{array}$

$\begin{array}{llllll}2 & 1 & 3 & 2 & 3 & 2\end{array}$

$\begin{array}{llllll}2 & 1 & 3 & 2 & 3 & 2 \\ 2 & 1 & 3 & 2 & 3 & 2\end{array}$

$\begin{array}{llllll}2 & 1 & 2 & 1 & 2 & 1\end{array}$

$\begin{array}{llllll}2 & 1 & 3 & 2 & 4 & 3\end{array}$

$\begin{array}{llllll}5 & 3 & 6 & 4 & 7 & 5\end{array}$

$\begin{array}{llllll}2 & 1 & 3 & 2 & 3 & 2\end{array}$

$\begin{array}{llllll}\text { N/A } & \text { N/A } & 25 & 20 & 30 & 20\end{array}$

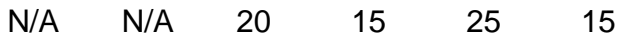

$\begin{array}{llllll}10 & 10 & 15 & 10 & 20 & 10\end{array}$

$\begin{array}{llllll}7 & 7 & 12 & 12 & 17 & 17\end{array}$

$\begin{array}{llllll}1 & 1 & 2 & 2 & 2 & 2\end{array}$
are applied above and beyond minimum N/A requirements for adequate public facilities or what is otherwise required on-site.

${ }^{2}$ When a sidewalk or bike facilities installed is not an exact multiple of 130' long, remaining fractions will be prorated.

${ }^{3}$ Facilities must link to existing or programmed portions of the bicycle network in the Bicycle Master Plan. Total width, length and location will be determined by the Traffic \& Transportation Division at time of development approval, based on development type and size.

4 Bicycle lanes that require street lane widening will be credited the same amount as shared bicycle/pedestrian paths.

${ }^{5}$ This facility must decrease the distance pedestrians must travel to cross a street.

6 Other than those required in the non-auto study area. Concrete pads must be installed before a bench or shelter is installed. Locations based on ridership numbers and by determination of the Traffic \& Transportation Division.

${ }^{7}$ Bus pull-offs are not desirable along roads classified as arterial due to speed and volume of traffic. Installation of pull-offs will be determined by the Traffic \& Transportation Division and in coordination with Montgomery County Department of Public Works \& Transportation.

8 Subsidization of a bus stop, portion of a bus route, or extension of service where service is scheduled to be eliminated by Montgomery County Department of Public Works \& Transportation due to low ridership or other factors.

9 A facility that is a dedicated space for transit information with a public waiting area. Commercial lobbies do not qualify. Must include no less than 1 seat for a transit resource person and no less than 5 seats in the public waiting area. Must be within .7 mile (3696 feet) of at least two bus stops and/or Metro stations.

${ }^{10}$ A facility with transit information and a resource person but no public waiting area.

${ }^{11}$ A facility that includes maps and schedules (when possible) of transit services.

The City also has a transportation demand management (TDM) program and TDM policy, which aim to reduce single-occupancy auto (SOV) trips and implement demand management throughout the City. In a TOA, a maximum of $15 \%$ trip credit may be applied for a developer's implementation of a TDM program (see CTR Appendix L for qualifying activities) and participation in the City's TDM program. Development in non-TOAs may be eligible for a maximum of 10\% TDM trip credit. TDM trip credit is summarized in Table F6. 
Table F6: TDM Trip Credit

TOA Designation Maximum Credit Amount*

TOA $15 \%$

Non-TOA $10 \%$

*Applied to new peak hour trips before any other trip credits or reductions, apart from pass-by reduction, are applied for the development application.

Note: When a development application is approved for trip reduction based on modal split, as described in Section III.C.5.b.ii, it is not eligible for TDM trip credit.

The City received a Transportation Community Services Program grant (TCSP) from the Federal Highway Administration to assess accessibility to the Town Center. The planning effort will evaluate the accessibility of the Town Center from all portions of Rockville, for existing conditions, the next five years, and through the Master Plan buildout of the area. The analysis will identify strengths and weaknesses in pedestrian, bicycle, transit, automobile, and truck access to the Town Center. Upon completion of the baseline analysis, the project will prioritize implementation of improvements using a Geographic Information Systems (GIS) model and a series of public participation and coordination activities. The findings will be fed into the master planning process.

The methodology was developed as a precursor to adoption of a new adequate public facilities ordinance, which is expected in 2005. Staff indicated that the program is so new, there has not been experience with it. The trip credit amounts were developed based on a review of what other communities are doing (e.g. Orlando, Portland, Montgomery County), as well as based on observations and experiences with multimodal development and mode split in the past. Staff plan to initiate a project this year to monitor outcomes through surveys and other methods so they can determine how well the program is working and the appropriateness of the trip credits.

Although the program offers credits for participating in the City's TDM program, staff note that "it's tough to create a standard credit value for TDM because the developments are all so different and in different areas of the City." Therefore, the credits are highly subjective and determined on a case by case basis based on the feasibility of the potential trip reduction in the given context.

Issues faced in program development include the need for proactive coordination with the County and adjacent jurisdictions. One issue that arose was how best to achieve a continuous multimodal network where an abutting jurisdiction does not have similar requirements. The challenge of developing a coherent multimodal network on a site-by site basis was another issue that arose. Staff indicated that there is some benefit to both a facility based as well as a policy based approach. The facility based approach is straightforward in that credits can be readily provided for developments that contribute toward development of the facility. The policy based approach, which is administered site-by-site, can then address the more micro issues of site network layout and continuity with adjacent sites. 